


\section{DISCLAIMER}

This report was prepared as an account of work sponsored by an agency of the United States Government. Neither the United States Government nor any agency Thereof, nor any of their employees, makes any warranty, express or implied, or assumes any legal liability or responsibility for the accuracy, completeness, or usefulness of any information, apparatus, product, or process disclosed, or represents that its use would not infringe privately owned rights. Reference herein to any specific commercial product, process, or service by trade name, trademark, manufacturer, or otherwise does not necessarily constitute or imply its endorsement, recommendation, or favoring by the United States Government or any agency thereof. The views and opinions of authors expressed herein do not necessarily state or reflect those of the United States Government or any agency thereof. 


\section{DISCLAIMER}

Portions of this document may be illegible in electronic image products. Images are produced from the best available original document. 
This work was supported by the US Nuclear Regulatory Commission, Office of Nuclear Regulatory Research, Division of Reactor Safety Research.

\author{
Printed in the United States of America. Available from \\ National Technical Information Service \\ U.S. Department of Commerce \\ 5285 Port Royal Road \\ Springfield, VA 22161 \\ Price: Printed Copy $\$ 5.00$ Microfiche $\$ 2.25$
}

NOTICE

This report was prepared as an account of work sponsored by the United States Government. Neither the United States nor the United States Nuclear Regulatory Commission, nor any of their employees, nor any of their contractors, subcontractors, or their employees, makes any warranty, express or implied, or assumes any legal liability or responsibility for the accuracy, completeness or usefulness of any information, apparatus, product or process disclosed, or represents that its use would not infringe privately owned rights. 


\title{
PHOEBUS/UHTREX: A Preliminary Study of a Low-Cost Facility for Transient Tests of LMFBR Fuel
}

\author{
Compiled by \\ William L. Kirk
}

Manuscript completed: August 1976 Issued: October 1976

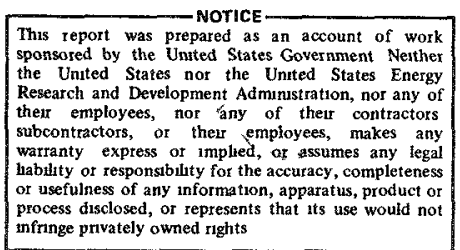


CONTENTS

ABSTRACT • . . . . . . . . . . . . . . . . . . . . . . . . . . . . 1

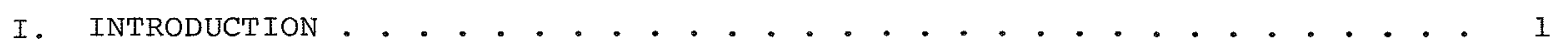

II. EXPERIMENTAL NEEDS - APPLICATION OF PHOEBUS/UHTREX . • . . . . . . . . . 3

A. Boilup . . . . . . . . . . . . . . . . . . . . . . . . 4 4

B. Material Freezing and Blockage Formation . . . . . . . . . . . . . . 4

C. Melting Attack... . . . . . . . . . . . . . . . . . . 4 4

D. Material Re-Entry . . . . . . . . . . . . . . . . . . . . . . 4

E. Threshold for Permanent Dispersal . . . . . . . . . . . . . . . . 4

F. Energy Exchange . . . . . . . . . . . . . . . . . . . . . . 4

III. REFERENCE DESIGN DESCRIPTION . . . . . . . . . . . . . . . . . . . . 5

A. Reference Experiment Description . . . . . . . . . . . . . . . 5

B. Reference Reactor Description and Performance . . . . . . . . . . . 10

C. Reference Design Diagnostic Instrumentation . . . . . . . . . . . . I4

D. Layout of Experimental Éacility . . . . . . . . . . . . . . . . 15

IV. SCHEDULE AND COSTS . . . . . . . . . . . . . . . • • . . . . . . 17

V. REACTOR STUDIES . . . . . . . . . . . . . . . . . . . . . . 17

A. General . . . . . . . . . . . . . . . . . . . . . 17

B. Neutronic Calculations . . . . . . . . . . . . . . . . . . 18

C. Thermal and Fluid flow Studies . . . . . . . . . . . . . . . 25

VI. DISCUSSION OF EXPERIMENT STUDIES . • . • . . . . . . . • • . . . . . . . 27

A. Loop Considerations . . . . . . . . . . . . . . . . . . . 27

B. Experiment Handing . . . . . . . . . . . . . . . . . . . 32

VII. CONTROL AND OPERATION . . . . . . . . . . . . . . . . . . . . . . 36

A. Introduction . . . . . . . . . . . . . . . . . . . . . . 36

B. Control Drum Characteristics . . . . . . . . . . . . . . . . 36

C. Prompt Burst Generation . . . . . . . . . . . . . . . . . . . 36

D. Constant Preheat Power Operation Followed by Short Burst . . . . . 39

E. Conclusions . . . . . . . . . . . . . . . . . . . . . 39

VIII. FUEL MOTION DIAGNOSTIC INSTRUMENTATION . . . • . . . • • . . . . . . . 39

A. General . . . . . . . . . . . . . . . . . . . . . . 39

B. Flash X-Ray Cinematography . . . . . . . . . . . . . . . . . . . 41

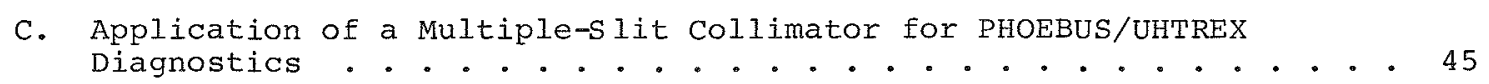

D. Backup Fuel Motion Monitoring Systems . . . . . . . . . . . . . . . 49

E. Fuel Motion Detection Outside the Driver Core . . . . . . . . . . 50

IX. DESCRIPTION OF THE UHTREX FACILITY . . . . . . . . . . . . . . . . . 51

A. Building Description . . . . . . . . . . . . . . . . . . . 51

B. Ventilation Systems . . . . . . . . . . . . . . . . . 57

C. Cooling Water Systems . . . . . . . . . . . . . . . . . 59

D. Electrical System . . . . . . . . . . . . . . . . . . . 60

E. Control Room . . . . . . . . . . . . . . . . . . . . . . 60

F. Contaminated Liquid Waste . . . . . . . . . . . . . . . . . 60 
G. Vacuum Cleaning System . . . . . . . . . . . . . . . . 60

H. Helium Blowers. . . . . . . . . . . . . . . . . . . . 60

I. MINOTAUR . . . . . . . . . . . . . . . . . . . . . 63

X. REMOVAL OF CONTAMINATED EQUIPMENT FROM UHTREX . . . . . . . . . . . . . 64

A. Burial . . . . . . . . . . . . . . . . . . . . . 64 64

B. Facility Preparation . . . . . . . . . . . . . . . . . . . 64

C. Gas Cleanup System . . . . . . . . . . . . . . . . . . . . 65

D. Reactor and Primary Loop . . . . . . . . . . . . . . . . 67

XI. DISCUSSION OF RADIOLOGICAL SAFETY . . . . . . . . . . . . . . . . . 70

A. Fission-product Inventory . . . . . . . . . . . . . . . . . . . 70

B. Radiation Fields Shortly after operation . . . . . . . . . . . . . . 71

C. Fission-Product Leakage from Core . . . . . . . . . . . . . . . . 72

D. Safety Instrumentation . . . . . . . . . . . . . . . . . . . . 72

E. Reactor Characteristics of Safety Significance . . . . . . . . . . 73

F. The Reference Accident . . . . . . . . . . . . . . . . . . 73

G. Interaction with Design . . . . . . . . . . . . . . . . . . 74

APPENDIX A: ROVER BACKGROUND . . . . . . . . . . . . . . . . . . 75

APPENDIX B: UHTREX BACKGROUND . . • . . . . . . . . • . . . . • . . . . 77

REFERENCES . . . . . . . . . . . . . . . . . . . . . . 74 
The work leading to this report was carried out by a task force operating for approximately two months early in 1976. The task force members were drawn from several LASL Divisions and represented a broad spectrum of scientific disciplines. The members were
J. D. Allen (Task Leader, Facilities)
R. J. Bard
E. W. Barts (Task Leader, Experiments)
G. A. Bennett
G. J. Berzins
J. E. Boudreau
G. E. Cort
K. V. Davidson
A. E. Evans, Jr.
K. S. Han
W. L. Kirk (Study Leader)
T. J. Merson
R. D. MCFarland
J. D. Orndoff (Task Leader, Instrumentation)

R. G. Palmer

H. C. Paxton (Task Leader, Radiation Safety)

L. J. Sapir

F. P. Schiling (Deputy Study Leader)

J.H. Scott

V. Starkovich

W. E. Stein

M. G. Stevenson

P. Wagner

T. C. Wallace

M. G. Wheeler

L. C. Wilkerson

T. F. Wimett (Task Leader, Controls)

W. T. Wood 


\section{PHOEBUS/UHTREX: A PRELIMINARY STUDY OF A LOW-COST FACILITY FOR}

TRANSIENT TESTS OF LMFBR FUEL

Compiled by

William L. Kirk

ABSTRACT

The results of a brief preliminary design study of a facility

for transient nuclear tests of fast breeder reactor fuel are described. The study is based on the use of a reactor building originally built for the UHTREX reactor, and the use of some reactor hardware and reactor design and fabrication technology remaining from the Phoebus-2 reactor of the Rover nuclear rocket propulsion program. The facility is therefore currently identified as the PHOEBUS/UHTREX facility. This facility is believed capable of providing early information regarding fast reactor core accident energetics issues which will be very valuable to the overall LMFBR safety program. Facility performance in conjunction with a reference 127-fuel pin experiment is described. Low cost and early availability of the facility were emphasized in the selection of design features and parameters.

\section{INTRODUCTION AND SUMMARY}

This report describes the results of an eight-week preliminary design study of a facility in which transient tests of fast breeder reactor fuel can be conducted. The study is based on the use of a reactor building, reactor hardware, and design and fabrication technology which are in existence at the Los Alamos Scientific Laboratory (LASL) as a result of LASL's participation in the UHTREX (high-temperature process heat) and Rover (nuclear rocket propulsion) programs. The initial premise and incentive for the study is that the existence of these items will substantially reduce both the time and the cost required to build the transient testing facility. Consistent with this theme, we have generally chosen design options and parameters that lead to minimum facility costs and short construction schedules. Thus, the reader is asked to remember that the facility described has not necessarily been optimized for cost effectiveness; we believe that a great variety of additional capabilities could be incorporated into the facility design, but these additions would be likely to require more money and could appreciably add to the construction time. The PHOEBUS/UHTREX facility would not only allow performance of a number of useful fast reactor fuel pin experiments pertaining to fuel pin failure and initial fuel-cladding motion, but would also be most valuable in providing information regarding gross fuel-steel motion useful in resolving accident energetics issues. In order to resolve these issues, a comprehensive program of ex-reactor experiments, in-reactor experiments and, perhaps, self-driven special purpose tests will be necessary. PHOEBUS/UHTREX could provide early information affecting the course of the total program, and in 
combination with tests in other facilities, lead to an early resolution of accident energetics issues.

A reference experiment and experiment configuration have been selected to aid in facility design and performance definition. The reference experiment configuration is a 127-pin array of fresh, enriched fuel $0.914 \mathrm{~m}$ in fueled length within an integral sodium loop. The in-pile section of the experiment is located in a $22.86-\mathrm{cm}(9-i n$.$) diam cylindrical$ test region in the center of the driver core that will accommodate in-core sections of currently available and proposed TREAT and ETR autoclaves and loops.

The reference experiment consists of a rapid start up of the driver reactor to a 15 -s power step that delivers an average power of $200 \mathrm{~W} / \mathrm{g}$ to the experiment, followed by a $<100$-ms pulse delivering $2000 \mathrm{~J} / \mathrm{g}$. Thus, the total average energy deposition in the experiment is $5000 \mathrm{~J} / \mathrm{g}$. These experiment parameters serve to define the design requirements for the facility with respect to driver reactor configuration, neutronic control system capability, heat energy storage and removal, and field-of-view and time and space resolution for the experimentviewing instrumentation.

The test facility would be located in the UHTREX building at Los Alamos, after appropriate cleanup and modification of that building. The major facility components are (a) the reference experiment described above with its support equipment, (b) the driver reactor with its reactivity controls, structure, and heat removal circuits, and (c) the experiment fuel-motion viewing instrumentation consisting in the reference case of a 30MeV flash $\mathrm{x}$-radiography unit.

The driver-reactor core and reflector configuration is based on the geometry of the Phoebus-2 reactor, the largest and most powerful reactor built and tested during the nuclear rocket propulsion program. Adopting this geometry allows direct reuse of existing Phoebus-2 beryllium reflector segments, control drums, and control drum actuators. In addition, refractory fuel, capable of withstanding the $1600 \mathrm{~K}$ core temperatures generated during operation, can be made to the Phoebus-2 fuel element external dimensions using the nuclear rocket technology still available at LASI.

In basic geometry, then, the driver core is a cylinder, $139.7 \mathrm{~cm}$ (55 in.) in diameter and $132.08 \mathrm{~cm}$ (52 in.) high, containing $\sim 4000$ hexagonal fuel elements, each $1.91 \mathrm{~cm}(0.753 \mathrm{in.})$ across flats and $132.08 \mathrm{~cm}$ (52 in.) long. The fuel elements are fabricated from 35 vol\% UC-ZrC in graphite with enriched uranium and each contains one $0.5-\mathrm{cm}$ axial hole. The total core uranium inventory is $332 \mathrm{~kg}$. Surrounding the core (radially) is a 5-cmthick region of carbon wool insulation. outside of that is the $20.32-\mathrm{cm}$ ( 8 -in.)thick beryllium reflector containing 16 control drums.

The basic cylindrical geometry of the core and reflector is modified in two ways. First, there is a $22.86-\mathrm{cm}$ (9-in.) cylindrical space at the center of the core to house the experiment. Secondly, a 12-cm-wide, full-length slot extends diametrically through the reflector and core as a viewing port for the diagnostic $x$ rays.

A stainless steel tube, cooled on its i.d. by high-pressure helium forms the inner radial boundary of the core. An aluminum barrel, located just outside the carbon wool insulation and cooled on its $0 . d$. by low-pressure air, forms the outer radial boundary of the core. The forced-air cooling may also be used to cool the control drum vanes and the additional aluminum structure outside the reflector. The core is isolated by these radial structures and inerted by lowpressure helium before and during test operation. 
The control drums are rotated outward to initiate the 15-s "Elattop" portion of the reference experiment, continue outward during the $15 \mathrm{~s}$ to compensate for the increasing core temperature, and move rapidly outward to produce the concluding power burst. They are then scrammed to help reduce the postburst power. During this entire sequence approximately $4000 \mathrm{MJ}$ of energy is generated in the driver core, which rises to an average radial temperature of $1600 \mathrm{~K}$ at the axial midplane including postburst heating. This heat is removed by radiation, conduction, and convection over a 50 - to 100 -h period.

The reference fuel motion monitoring technique is the use of flash $x$-ray cinematography, which is believed to be well suited for a wide range of experiments including the reference experiment. Diagnostic requirements established for the reference experiment include: a $95-\mathrm{mm}$ radial and 1.2-m axial field of view; 5-mm radial and $25-\mathrm{mm}$ axial spatial resolution; and 100 pictures/s repetition rate. Experiments conducted with the PHERMEX pulsed $x$-ray source at LASL indicate satisfactory radiographs at the desired repetition rate can be obtained using a state-of-the art linear accelerator based on the side-coupled, standingwave accelerator principles developed for the LAMPF proton accelerator at LASI. Tests with a single tank prototype of this design indicate that it will meet the PHOEBUS/UHTREX requirements.

It is planned to locate the accelerator and its power supply in an addition to the east of the present UHTREX building. The $30-\mathrm{MeV}$ electron beam would enter the reactor room through a small penetration in the containment, and interact with a tungsten target to produce bremsstrahlung $x$ rays that shine through the slot in the reactor to the imaging equipment. The $x$-ray target and the imaging plane are each located $3 \mathrm{~m}$ from the reactor centeriine.
Costs and schedules have been estimated for preparing the PHOEBUS/UHTREX facility assuming a project starting at the beginning of FY-1977. Two and threefourths years are required to make the facility ready for operation in July, 1979. Facility preparation costs are broken into: facilities, $\$ 875$ 000; equipment, $\$ 10690000$; and manpower, $\$ 3970000$ totaling $\$ 15535000$ in 1976 dollars. The cost for the facility operating staff is estimated to be $\$ 1000000$ per year. The annual cost of the experimental program itself (test vehicle manufacture, posttest examination, etc.) is not included. This depends upon the role that this facility plays in the total safety program and the number and type of tests required.

Examination of radiological safety questions does not reveal any substantial problem in operation of the PHOEBUS/ UHTREX facility. The technological base for this facility is much more complete than is possible in the usual proposal. A wealth of information from the Rover Program applies so directly to this system that behavior can be predicted reliably. As a result, we can be unusually confident of proper protection of the public, personnel, and property.

\section{EXPERIMENTAL NEEDS - APPLICATION OF PHOEBUS/UHTREX \\ Experimental needs for fast reactor} safety have been discussed in detail in a number of reports including the initial report ${ }^{1}$ from the Los Alamos Scientific Laboratory Safety Test Facility Study (STF report). In that report, needs related to core disruptive accident analysis were grouped into six major areas, that is,

1. fuel-pin failure and initial cladding and fuel motion,

2. gross fuel-steel motion within a subassembly,

3. gross material motion involving more than one subassembly, 
4. coupled hydrodynamics-neutronics,

5. postaccident heat removal, and

6. radioactive material transport.

Four facility types ( $A, B, C, D)$ were then defined that together spanned these needs. One of these, Facility $B$, was specifically intended to address the issues involved in area (2) above, that is, gross fuel-steel motion within a subassembly. This area is also integrally involved in the lines-of-assurance defined by ERDA, that is, in LOA2 (1imit core damage) and LOA3 (maintain primary system integrity). The coupled behavior of molten fuel and steel and, in some cases, sodium determines whether disruption is contained within subassemblies and also is a determining factor in the accident energetics, including questions of recriticality and fuel-coolant interactions.

The PHOEBUS/UHTREX facility discussed in this report can be described as a minimum Facility $B$, in the context defined in the STF report. It would allow performance of a number of useful experiments in the Facility $A$ area of fuel-pin failure and initial fuel and cladding motion, but would be most valuable in providing fuel-steel motion information useful in resolving accident energetics issued. In order to resolve these issues, a comprehensive program of ex-reactor experiments, analysis, in-reactor experiments, and, perhaps as a final proof, self-driven special purpose tests may be desired. A near-term PHOEBUS/UHTREX facility could be extremely valuable in providing early information impacting on the total program. Some of the specific questions which could be addressed by PHOEBUS/UHTREX are given below.

A. Boilup

Do core materials disperse monotonically after significant melting? How is dispersal affected by heat losses? Are heat transfer delays between fuel and steel significant in dispersal behavior? Does fresh fuel slump prior to dispersal?
B. Material Freezing and Blockage Formation

Does material (fuel, steel) tend to freeze and plug flow passages on its route outward? How strong are the plugs, and what is the response of the plugstructure? How extensive are the plugs? When is sodium re-entry possible? Is there an impact of these events upon boilup?

c. Melting Attack

What are the heat transfer rates between fuel-steel mixtures and subassembly cans, between fuel-steel mixtures and axial plugs? How do these depend on flow regimes and power densities? When and in what mode do subassembly cans fail under various combinations of thermal-mechanical loadings.

D. Material Re-Entry

Does plugged material tend to reenter the core region as it melts out? What are the controlling forces, such as vapor pressures and gravity? How much of the material re-enters?

E. Threshold for Permanent Dispersal

What thermophysical conditions allow for rapid and permanent dispersal of fuel out of the core region?

E. Energy Exchange

What are the controlling mechanisms involved in rapid heat exchange among fuel, steel, and liquid sodium? How do interactions change depending on initial configurations? Are there important rate effects?

Some typical experiments can be defined to address these questions in PHOEBUS/UHTREX. The initial experiments would be phenomenological (separate effects) in nature, since this provides optimal use of a near-term facility capable of relatively inexpensive subassemblyscale experiments. In general, we would expect several experiments to be performed in each set. Some phenomenological experiments would be performed in autoclaves, and later, more prototypic experiments 
would be performed in sodium loops. The most important advantages provided by the PHOEBUS/UHTREX system would be the experiment size (nominally 127 pins, possibly larger in autoclaves) and the advanced fuel motion-monitoring systems.

The experiments defined in Table I are, in our opinion, the most useful kinds of experiments that could be performed in PHEOBUS/UHTREX. Experiments such as these could greatly assist in an early resolution of accident energetics issues. Although it is recognized that the PHOEBUS/UHTREX facility could not alone provide the experimental data to close these issues, it can lead to an early resolution in combination with other facilities. For example, sodium Loop Safety Facility (SLSF) experiments could be used to determine whether builtin fission products caused significant differences in boilup and blockage dynamic behavior. PHOEBUS/UHTREX experiments could examine detailed fuel motion dynamics in subassembly-scale. These experiments could provide basic information and benchmark data for code validation and, in addition, serve as lead experiments for final proof-tests such as provided by Dispersal Mechanism Tests (DMT). An integrated program of this sort could lead to resolution and burial of accident energetics issues by perhaps 1983 .

\section{REFERENCE DESIGN DESCRIPTION}

The reference design fast reactor fuel safety test facility described in this section will provide a transient testing capability for up to 127 fuel pins. The facility includes (a) a reference experiment with its support equipment, (b) a reactor capable of pulsed mode operation, its reactivity controls, structure, and cooldown circuits, (c) fuel motion diagnostic instrumentation including a $30-\mathrm{MeV}$ flash $\mathrm{x}$-ray unit, and (d) appropriate instrumentation and controls, rooms, equipment, etc., housed in the existing UHTREX reactor building after suitable building cleanup and modification.

A. Reference Experiment Description overall system performance is described relative to the reference experiment, consisting of a 127-pin hexagonal array of fresh enriched fuel with a $0.914-\mathrm{m}$ fueled length. The reference experiment and support facilities are the largest and most complex expected in the facility. A $22.86-\mathrm{cm}(9-i n$.$) o.d. cylindrical test re-$ gion is provided in the center of the test reactor core to accommodate the in-core section of currently available and proposed TREAT and ETR autoclaves and loops.

The reference experimental capability is given in Table II. The values given in the table are determined by the ground rules of the present facility study; that is, to take the existing design to reasonable limits without making major modifications and improvements. The values given form a set of preliminary design requirements for the facility. Within the values given a wide range of experiments can be performed. For example experiments can contain from 1 to 127 fuel pins, have various energy depositions from a pure burst to a so-called "flattop" operation at a steady power, and have a variety of experimental geometries without grading test fuel enrichment.

The reference loop is an integral loop with a removable in-pile-tube with sodium experiment cooling provided by a oncethrough system. The experimental test train will be inside of and a part of the in-piletube.

The reference loop piping concept is shown in Fig. 1. In the concept chosen the sodium will flow from a pressurized inlet reservoir through a core inlet simulator to the inlet manifold in the in-pile-tube. Within the in-pile-tube the flow is through a concentric downcomer cooling a melt-through barrier and a melt-down cup. At the bottom of the in-pile-tube the flow reverses and 
TABLE I

POSSIBLE PHOEBUS/UHTREX EXPERIMENTS

Experiment Type

Boilup formation and meltout dynamics

(2) 127-pin (about 0.7-m long active fuel length) geometry in dry bundle. geometry in flowing sodium.

(1) Dispersed mixture of $(0.5 \mathrm{~m})$ of in lower portion plugged with steel at both ends of $0.8 \mathrm{~m}$ test section. Empty pins above plug to

(2) Same as (1), but with no upper axial plug.

(3) Full-length 127-pin no initial plugs).

(4) Full-length 127-pin geometry in flowing

(1) Full-length 127-pin (1) Full-length $127-$ pin
geometry in dry bundle.
(3) Full-length 127-pin

Vehicle

Desired Power History

Information Desired

Autoclave

Steady power at ful power $(200 \mathrm{~W} / \mathrm{g}$ peak or some fraction of full power for few tens of seconds.

\section{Autoclave}

Short partial burst

$(1300 \mathrm{~J} / \mathrm{g})$ to heat

fuel and melt clad-

ding followed by rapid

burst of $1800 \mathrm{~J} / \mathrm{g}$ and shutdown.

Short initial burst

$(1300 \mathrm{~J} / \mathrm{g})$ to heat fuel

and melt cladding fol-

lowed by rapid burst

(100 ms width) of 1800

$\mathrm{J} / \mathrm{g}$. Low power for $10 \mathrm{~s}$

following burst to allow

blockage meltout.

Short initial burst to heat fuel followed by steady power with loss of flow. Final burst of $2000 \mathrm{~J} / \mathrm{g}$.
Rate of initial boilup and subsequent motion ( $t$ ime-dependent density distributions). Rate of thermal attack on plugs and walls. Meltout or failure time of plug(s) and/or can. Pressure and temperature history in test section.
Initial fuel motion and blockage formation (if any). Motion after blockage meltout. Meltout or failure time of can. Pressure and temperature history in test section. 
TABLE I (cont)

Experiment

$$
\text { Type }
$$

Large-scale fuel-steelsodium

interactions

(1) 127 unclad solid fuel
pins ( $0.3 \mathrm{~m}$ long) in dry bundle. Bottom of pins at core midplane with solid steel plug below. Gas space $(0.1 \mathrm{~m})$ separating top of from steel diaphragm (or gate valve). Iiquid sodium near saturation phragm.

(2) same as (1), but with cladding on pins.

(3) Same as (2)

(4) Full-length 127-pin array in flowing sodium.

(1) Full-length 127-pin array in flowing sodium

SubassembI failure characteristics (dis-

assembly

conditions) loop. filling can above dia-

Vehicle

Desired Power History Long autoclave with sodium plenum and gas space at top.
Short period (100 ms width) burst of $2500 \mathrm{~J} / \mathrm{g}$.

Information Desired

Initial and extended fuel motion (time-dependent material density distributions). Sodium pressures and flow rates.

LOOP

Short initial burst to preheat fuel and melt cladding followed.

by high power to achieve pressurized boiled-up two-phase, two-component mixture.

Steady power to achieve prototypic temperature

distributions followed

by rapid burst of $2000 \mathrm{~J} / \mathrm{g}$

Loop

Short initial burst to preheat fuel, followed by steady power with loss of flow, followed

by rapid burst of $2000 \mathrm{~J} / \mathrm{g}$.
Subassembly can wall dynamic response. Radial fuel motion out of can. Axial fuel motion and formation of blockages (if any) . 
TABLE II

PHOEBUS/UHTREX

REFERENCE EXPERIMENTAL CAPABILITY

Number of FTR-Type Test Fuel Pins

Total Energy Deposition ${ }^{a}$

Burst Energy Deposition after Operation

at $200 \mathrm{~W} / \mathrm{g}$ for $15 \mathrm{~s}^{\mathrm{a}}$

Burst Width at Half Maximum

Test Enrichment

Total Radial Power Max/Min over Test

Fuel Pins

Axial power Profile

Visual Data

Field of View

Spatial Resolution

Time Resolution

Sensitivity
127

$5000 \mathrm{~J} / \mathrm{g}$

$2000 \mathrm{~J} / \mathrm{g}$

$100 \mathrm{~ms}$

Up to Full, No Enrichment Grading

1.30

$\pm 15 \%$ from Reference Profile

$10 \mathrm{~cm}$ Radial by $120 \mathrm{~cm}$ Axial

$5 \mathrm{~mm}$ Radial by $25 \mathrm{~mm}$ Axial

$10 \mathrm{~ms}$

15\% Change in Density

a Average, both radial and axial, energy or power in test fuel.

b Chopped cosine, Max/Avg. 1.24 over $91.44 \mathrm{~cm}$ length.

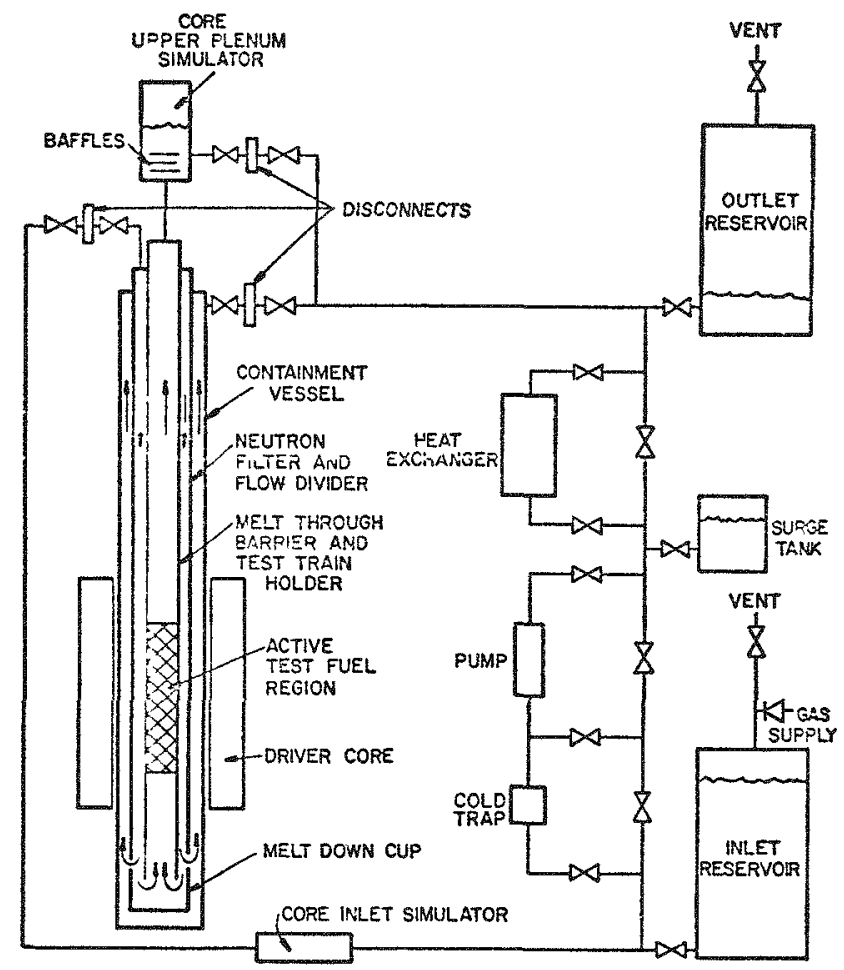

Fig. 1. Reference loop piping concept. divides to follow two paths. The concentric outer flow path cools the containment vessel and the neutron filter in the flow divider. The inner flow path is through the test section. Figure 2 is a cross section through the in-pile-tube at the test section. Both upflows meet in the baffled region of the core upper plenum simulator. The sodium then leaves the in-pile-tube through an outlet manifold and flows into the outlet reservoir. In addition to the inlet and outlet reservoirs, the out-of-pile system contains a sodium cleanup system, a small pump and, if necessary, a heat exchanger. The pump provides flow through the system to equalize temperature and to feed the sodium cleanup system prior to an experiment. The heat exchanger together with heaters provides initial loop temperature control and also could provide possible posttest cooling of the in-pile-tube. 


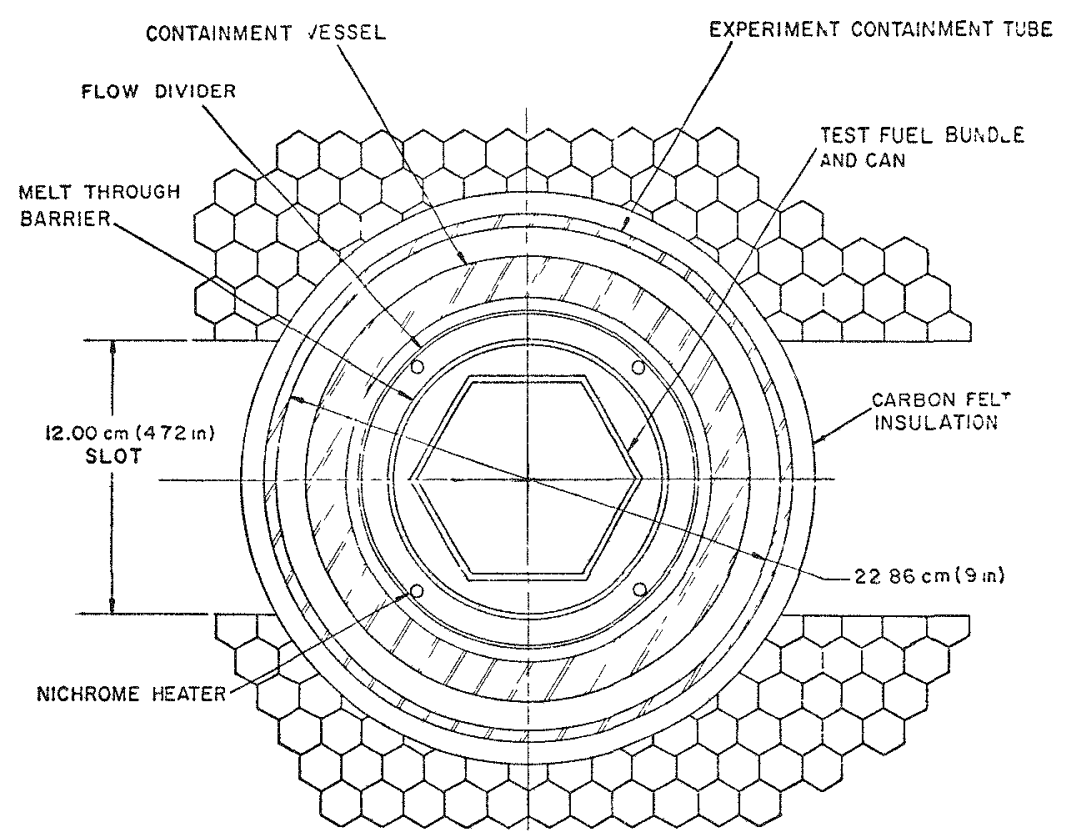

Fig. 2. Reference loop test section.

Other support facilities are as follows:

1. Assembly Area for pretest assembly of the test train and the in-pile-tube.

2. Test-Train-Transfer-Fixture for handling the test train in the assembly area or in the UHTREX building.

3. In-Pile-Tube Transfer Fixture for transferring the in-pile-tube from the assembly area to the UHTREX building and handling the in-pile-tube within the UHTREX building.

4. Sodium Fill Area for filling, remelting, and draining sodium from the inpile-tube.

5. Loop Connecting Fixture for use in connecting and disconnecting the inpile-tube with the out-of-pile system.

6. Storage Area for storage of inpile-tubes after an experiment.

7. Sectioning Area for cutting the test train into sections for final examination.
8. Casks for transportation of irradiated test-train sections from the UHTREX building to the final examination area.

9. Final Examination Area where a detailed posttest examination of the test train can be performed.

The listed support facilities would not be required for all experiments. The reference experimental loop concept would, of course, be limited to the use of fresh $\mathrm{UO}_{2}$ fuel in the test fuel pins. Depending upon the degree of retention of the test fuel and simulated fission products inside the inpile-tube during fresh $\mathrm{UO}_{2}$ fueled experiments, the use of preirradiated mixed oxides may be possible. of course, package loops or autoclaves can be used for experiments with preirradiated mixed oxide test fuels. The test thimble in the PHoEBus core and the support facilities, particularly those within the UHTREX building, have the capability of accepting modified versions of current and proposed TREAT and SLSF loops. 
B. Reference Reactor Description and Performance

1. General

The reference reactor utilizes

the basic fuel, core, and reflector geometry and some existing hardware from the Phoebus-2 nuclear rocket propulsion reactor. The existing hardware to be used includes the $20.32-\mathrm{cm}(8-1 \mathrm{n}$.$) -thick,$ 132.1-cm (52-ın.)-long radial beryllium reflector, the control drums located in the reflector, and the control drum drives. The external dimensions of the hexagonal composite fuel (UC-ZrC solid solution in a graphite matrix) will be the same as that of Phoebus-2. One $\sim 0.5-\mathrm{cm}$ axial hole in the center of each element will replace the 19 axial coolant holes $(0.25 \mathrm{~cm})$ used in the nuclear rocket reactor design. A cross-section sketch of the reactor is shown in Fig. 3. The reactor core is basically cylindrical except for the experiment region at the center and a $12-\mathrm{cm}$ wide diametrical slot provided for the $x$-ray viewing of the experiment. The experiment thimble at the i.d. of the core is formed by the $0.64-\mathrm{cm}$-thick stainless steel experiment containment tube that is cooled by high-pressure helium flowing in a gap between it and the experiment containment vessel. Outside the tube are a

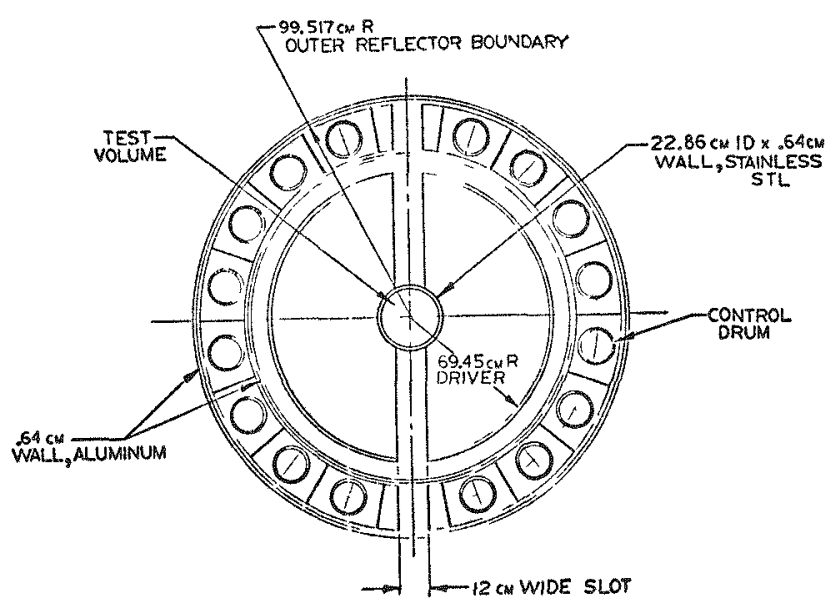

Fig. 3. Reactor cross section. thin $(\sim 0.25-\mathrm{cm})$ carbon felt insulation region and unloaded filler elements to make the transition between a cylindrical and hexagonal fuel array geometry. Approximately 4000 fuel elements are stacked together to form the core. Unloaded graphite filler elements are used at the outside of the core to fill out the cylindrical geometry. Approximately $5 \mathrm{~cm}$ of carbon felt insulation surrounds the core and separates it from the $0.64-\mathrm{cm}$-thick aluminum core containment vessel. A $0.64-\mathrm{cm}$ gap is provided between the aluminum vessel and the i.d. of the reflector for air cooling that keeps the aluminum at a safe temperature during the postburst cooldown.

The diametrical slot also extends through the reflector where the control drums and part of the berylitum are removed from 2 of the 18 reflector sectors to provide a $12-\mathrm{cm}$-wide slot. Another 0.64-cm-thick aluminum vessel surrounds and supports the beryllium reflector.

An axial view of the reactor assembly is shown in Fig. 4. Additional

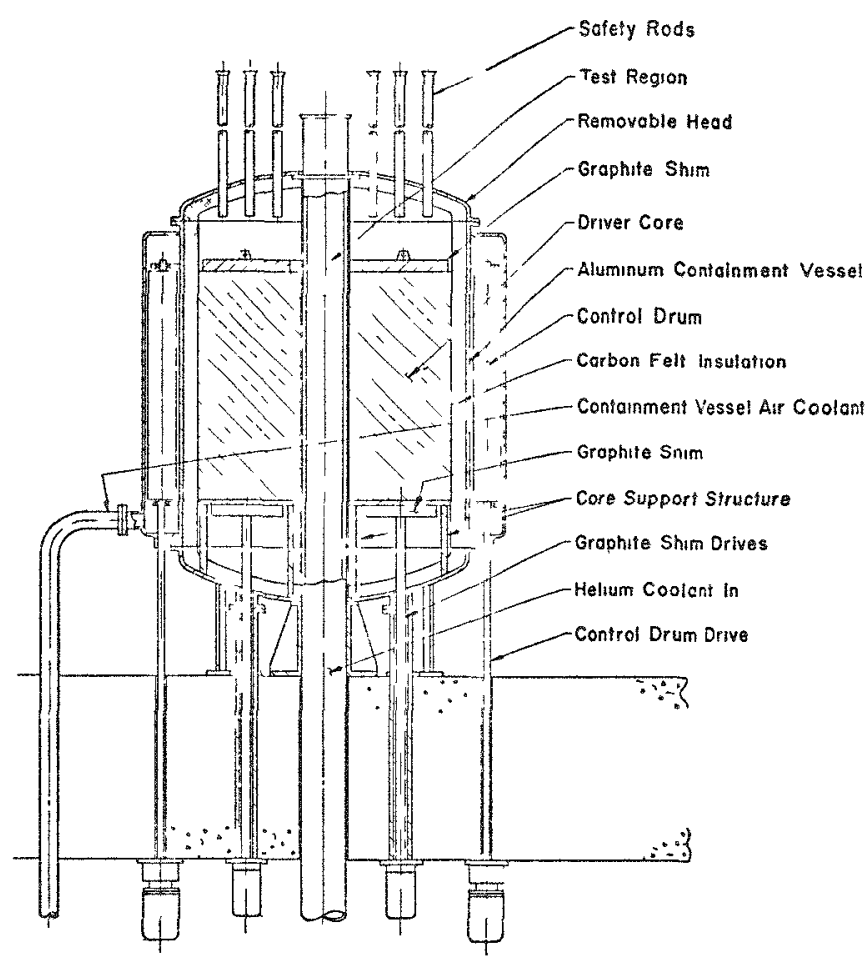

Fig. 4. Reactor elevation. 
design features shown in this view include six axial safety rods that enter the core slot region in case the reflector control drums do not operate properly; moveable graphite cylinders at core top and bottom which can be used to shim system reactivity to a desired value; top and bottom heads of the vessel that isolates the core region; core support structure; and inlet ducting for the helium and air coolants.

The helium core inerting system, helium experiment containment tube cooling systems, and air core containment vessel cooling systems components will be located in a room immediately beneath the reactor room. The core inerting system will provide a relatively low pressure, low flow of helium $\left(3.9 \times 10^{-4} \mathrm{~m}^{3} / \mathrm{s}\right.$ at $25-\mathrm{cm}$ water gauge) to the core containment vessel exhausting through an activated charcoal bed sized for suitable hold up and decay of fission products. Temperature, pressure, and purity will be monitored prior to discharge to the stack. The experiment containment tube recirculating cooling system will provide approximately $1.27 \mathrm{~kg} / \mathrm{s}$ of helium at $3.45 \times 10^{6} \mathrm{~Pa}$ utilizing an existing UHTREX helium circulator. The containment vessel air cooling system will provide approximately $1.13 \mathrm{~kg} / \mathrm{s}$ of ambient air at $13.8 \times 10^{3} \mathrm{~Pa}$ to the containment vessel walls.

\section{Reactor Neutronic Design and performance \\ The reference driver core has} been designed to maximize the Figure of Merit (FOM) * for a 127-pin test bundle while maintaining the radial maximum-tominimum fission ratio across the bundle at a value $\leq 1.3$. The survey calculations which led to the selection of the reference driver configuration are described in sec. V. The calculational model

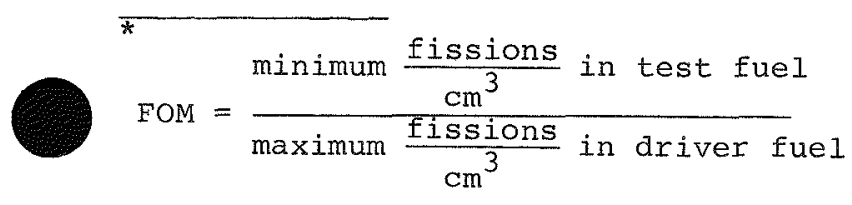

incorporated a 127-pin test bundle and the reference test vehicle described in sec. III.A and shown in Fig. 2 .

The weights and uniform reactivity coefficients of the core materials are shown in Table III. The core contains a total of $332 \mathrm{~kg}$ of highly enriched (93.2\%) uranium with an average $\mathrm{c} /{ }^{235} \mathrm{U}$ atom ratio of 142. The uranium loadings are varied in the driver to flatten the radial fission distribution. The resulting fission profile is shown in Fig. 5 along with the corresponding uranium loadings. The uranium loadings range from $60 \mathrm{mg} / \mathrm{cm}^{3}$ to $300 \mathrm{mg} / \mathrm{cm}^{3}$ and result in a max/avg radial fission density of $\sim 1.07$.

TABLE III

CORE WEIGHTS AND COEFFICIENTS

\begin{tabular}{lcc} 
Material & $\begin{array}{c}\text { Total weight } \\
(\mathrm{kg})\end{array}$ & $\begin{array}{c}\text { Reactivity } \\
\text { Coefficient } \\
(\$ / \mathrm{kg})\end{array}$ \\
\cline { 2 - 3 } Uranium & 332 & $\frac{0.05}{\text { Carbon }}$ \\
Zirconium & 2230 & 0.01 \\
& 3220 & 0.00
\end{tabular}

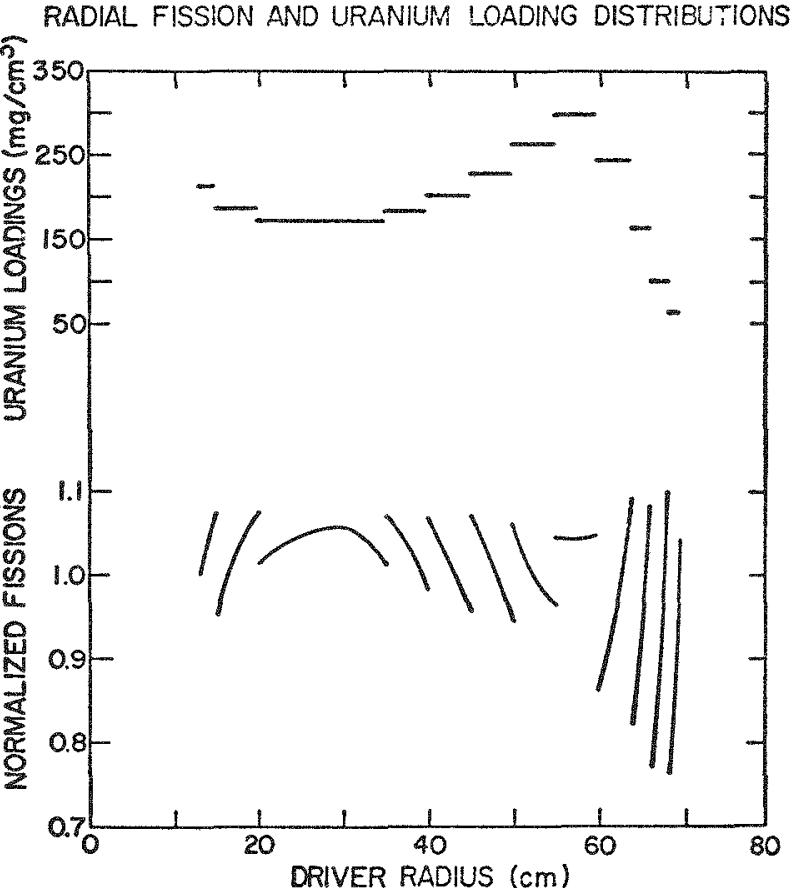

Fig. 5. Radial fission and uranium loading distributions. 
The neutronic characteristics of the reference reactor are summarized in Table IV. The calculated $k_{\text {eff }}$ of the onedimensional model with a boron sheath simulating the control drums in their outermost position was 1.16. Since the onedimensional model does not incorporate the 12-cm-wide diagnostic instrument slot, the calculated reactivity must allow for losses associated with this slot as well as for control and burst requirements. Monte Carlo calculations performed with the MCNK code $^{2}$ indicated that a 12-cm-wide slot through the core and reflector will reduce reactivity by $13.4 \% \Delta \mathrm{K}$. The calculated temperature coefficient indicates that reactivity will decrease < $0.5 \%$ in establishing a preburst flattop power, and kinetic calculations show that $2.0 \% \Delta \mathrm{K}$ will be sufficient to initiate the maximum desired burst. An excess reactivity of $16 \% \Delta \mathrm{K}$ is therefore sufficient for the one-dimensional ambient calculation. Neutron leakage from the relatively soft-spectrum core into the highly enriched test pins would produce an excessive fission spike at the test bundle boundary. The calculations therefore incorporated a boron filter in the flow divider of the test vehicle to preferentially absorb low energy neutrons. An equivalent natural boron thickness of $0.09 \mathrm{~cm}$ is required to reduce the maximumto-minimum fission ratio across the 127pin bundle to 1.3. The resulting FOM for this reference configuration is 11.9 .

The volume-averaged fission energy distribution in the 127-pin test bundle is shown in Fig. 6. The median fission energy in the test fuel is $45 \mathrm{keV}$. The volume-averaged neutron flux spectrum in the test fuel is compared with a typical LMFBR spectrum in Fig. 7. The neutron spectrum in the test fuel has a greater percentage of both high and low energy neutrons.

The calculated isothermal temperature reactivity changes shown in Table IV include the effects of uranium and zirconium Doppler and axial expansion. Because of the uncertainty of the behavior and reproducibility of radial expansion in the current design, its effect on reactivity was omitted. The thermal

TABLE IV

NEUTRONIC CHARACTERISTICS OF REFERENCE REACTOR

\begin{tabular}{|c|c|}
\hline$K_{\text {eff }}$ & 1.16 \\
\hline Median Fission Energy & \\
\hline Driver, ev & 92 \\
\hline Test, keV & 45 \\
\hline Max/Min across 127 pins & 1.30 \\
\hline FOM in $127-\mathrm{P}$ in Test & 11.9 \\
\hline Isothermal Temperature Reactivity Defects, $\frac{\Delta \mathrm{K}}{\mathrm{k}}$ & \\
\hline $300 \mathrm{~K}-600 \mathrm{~K}$ & 0.285 \\
\hline $600 \mathrm{~K}-1200 \mathrm{~K}$ & 0.395 \\
\hline $1200 \mathrm{~K}-1800 \mathrm{~K}$ & 0.285 \\
\hline Control Worth of 16 Drums, $\div \Delta \mathrm{K}$ & 4.4 \\
\hline Prompt Neutron Lifetime, us & 40.0 \\
\hline
\end{tabular}


FISS:ON ENERGY DISTRIBUTION IN DRNER AND TEST SECTION

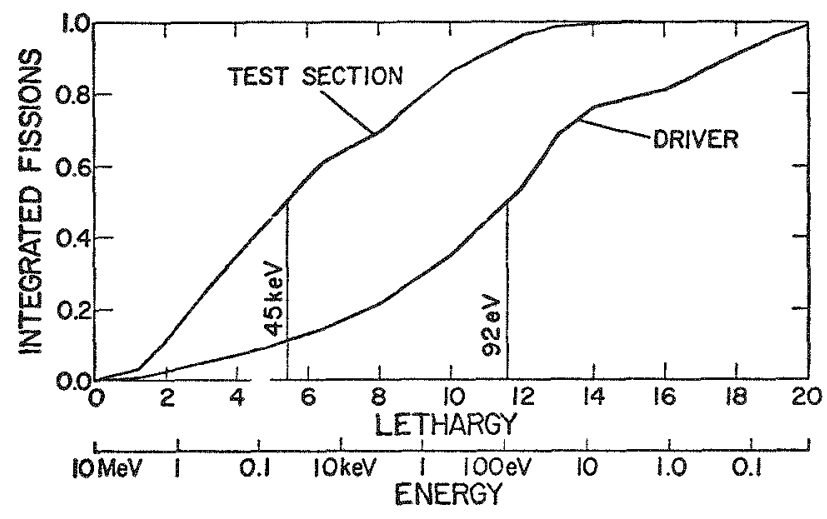

Fig. 6. Fission energy distribution in driver and test section.

neutron component in the driver is too small for there to be any significant temperature coefficient from thermal neutron leakage.

The reactivity worth of the reflector control drums were estimated by simulating the drums with a boron sheath and comparing the sheath worth with corresponding Phoebus-2 calculations. In the Phoebus-2 reactor model the reactivity change produced by moving a thin boron sheath from a radius of $84.1 \mathrm{~cm}$ to a radius of $96.6 \mathrm{~cm}$ very closely approximated the measured worth of $5.3 \% \Delta \mathrm{K}$. The reactivity change for the corresponding sheath calculations in the reference reactor was $7 \%$ less than that obtained in the Phoebus-2 calculations. Applying a 7\% reduction to the Phoebus-2 control drum worth and an additional factor of $16 / 18$ to account for the removal of two drums by the instrument slot yields an expected control worth of $4.4 \% \Delta \mathrm{K}$. The reactivity worth of the control system as a function of control drum position is shown in Fig. 21, Sec. VII. The figure uses the same shape as that measured in Phoebus-2.
FLUX SPECTRA-PHOEBUS / UHTREX AND FFTF

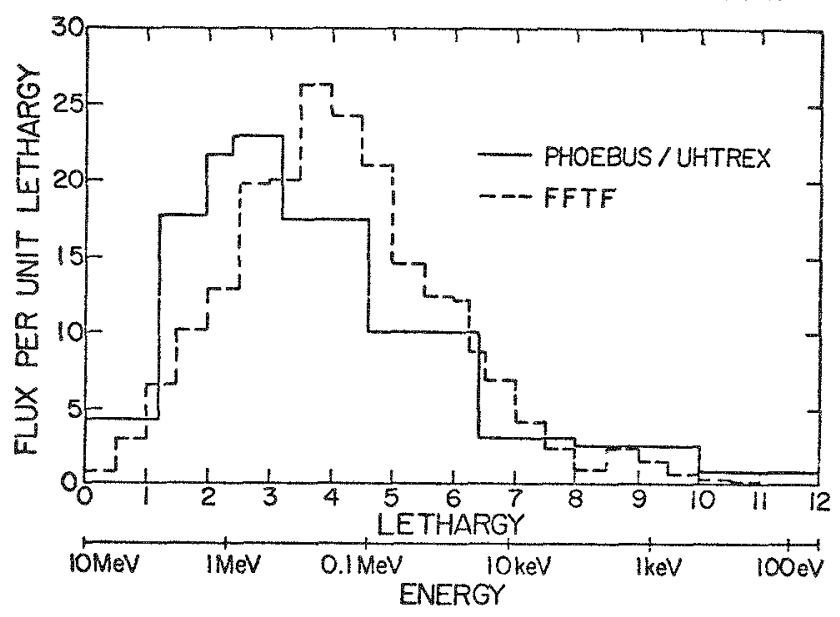

Fig. 7. Flux spectrum in LMFBR and test section.

The calculated prompt neutron lifetime of the reference reactor is $40 \mathrm{us}$. The measured lifetime for Phoebus-2 was 39 Hs.

3. Reactor Operations

This section provides a brief description of the sequence of reactor operations and events in carrying out the reference experiment. We first suppose that the reference 127-pin experiment is in place and has been preheated so that its sodium coolant is flowing. We also assume that the axial graphite shim reflectors have been positioned so that all reflector control drums will rotate to their maximum outward position during the burst. The core helium purge has been operated for a sufficient period to assure a benign atmosphere in the core. Air and helium coolant flow is established to the containment vessels and the viewing instruments are readied. The reactor is ramped quickly to a power level of $160 \mathrm{MW}$ for $15 \mathrm{~s}$, then pulsed with a total energy of $1500 \mathrm{MJ}$ and a pulse width at halfmaximum of $0.1 \mathrm{~s}$. During the 15-s hold, the axial maximum (radial average) core temperature rises to $1150 \mathrm{~K}$, then increases to $\sim 1500 \mathrm{~K}$ at the end of the 
pulse. The pulse is ended by rotating all the control rods to the full-in position. Residual power then adds another $100 \mathrm{~K}$ to the temperature. The core energy is dissipated by radiation and conduction from the ends of the core and by conduction through the insulation to the containment vessels and from them by convection to the air and helium coolants. Complete core cooling will require 50-100 h. Pulse cooling may be used late in the cooldown. C. Reference Design Diagnostic Instrumentation

Instrumentation is required to monitor fuel motion occurring in a wide range of possible PHOEBUS/UHTREX experiments. Satisfying the requirements for the reference experiment does not necessarily guarantee that the same instruments will satisfy requirements for all experiments of interest. However, fuel motion monitoring by flash $x$-ray cinematography, which we believe can meet our requirements for the reference experiment, is well suited for other experiments that may be conducted with the facility. This conclusion is based on the fact that $x$-ray interrogation is independent of the power level of the fuel pins other than for background concerns. In view of these considerations and because of its demonstrated capability for satisfying our space and time resolution requirements, we are proposing flash radiography as our major diagnostic technique. The major requirements and conditions of the reference experiment in regard to diagnostic instrumentation are listed in Table V.

Experimental studies conducted with the PHERMEX pulsed $x$-ray source indicate that satisfactory radiographs at the desired repetition rate can be obtained with a state-of-the-art linear accelerator (linac) for the $x$-ray source and an electrooptical imaging system. A $30-\mathrm{MeV}$ electron linac delivering $4 \mu \mathrm{C}$ of charge in $2 \mu \mathrm{s}$ appears to be adequate. A linac of a new design based on the side-coupled, standing-wave
TABLE V

DIAGNOSTIC INSTRUMENTATION REQUIREMENTS Field of View

Radial

$95 \mathrm{~mm}$

Axial

$1.2 \mathrm{~m}$

Spatial Resolution

Radial $5 \mathrm{~mm}$

Axial

$25 \mathrm{~mm}$

Time Resolution

$0.01 \mathrm{~s}$

Maximum Test Fuel

Power

$2 \times 10^{4} \mathrm{~W} / \mathrm{g}$

accelerator principles developed for the LAMPF proton accelerator has been developed at LASL. A single tank prototype of this design has been built and performance tests indicate that this type of accelerator can conservatively meet the requirements for PHOEBUS/UHTREX.

An accelerator building addition east and adjacent to the UHTREX reactor bay would assure that accelerator activities would incur little interaction with the rest of the facility. The electron beam would enter the reactor bay through a small penetration in the containment. A transverse slot through the Phoebus driver reactor will allow access to the test assembly for flash radiography, and adequate shielding between the reactor and the detector room will be essential. A distance of $3 \mathrm{~m}$ between the $\mathrm{x}$-ray target and the test fuel bundle, and between the test fuel and imaging plane has been assumed in the present concept.

We are considering a multiple-slit $x$-ray collimator detector system as an alternate to electro-optical imaging. This is simply a matrix of collimator slits aimed at the $x$-ray source position and including the fuel pin test section in its field of view. A sodium iodide crystal at the end of each slit would provide high $\mathrm{x}$-ray detection efficiency and the 
collimator would discriminate against gamma ray and scattered $x$-ray background. Conventional $x$-ray imaging will require more than a single camera to cover the entire 1.2-m field of view and low intensities will be a serious problem at the extremes. off-axis x-ray intensities may require a highly sensitive discriminating detector such as the proposed collimator system.

Another solution to the field-of-view problem is to deflect the electron beam to three vertically separated targets in order to provide three $x$-ray sources from one accelerator. The beam would then be cycled sequentially from one target to another at the appropriate rate and three detector systems would each view one of the images produced by the three $x-r a y$ source positions. We do not propose beam switching as an option for initial PHOEBUS/ UHTREX operations, but we will not exclude the capability for providing it as an addon feature.

In addition to the requirements of Table $V$, it is highly desirable to determine when and what quantity of fuel intrudes into areas of the test capsule outside the driver reactor. For this purpose we will monitor delayed neutron activity at selected stations using directional detectors.

We consider neutron hodoscope and coded aperture imaging as backup techniques. We expect to explore these in more detail and are prepared to revise our priorities as these other methods develop and warrant more attention.

D. Layout of Experimental Facility

The reactor, reactor support equipment, coolant system, diagnostic instrumentation, and posttest experiment handling equipment will be located inside the UHTREX secondary containment structure. The tests will be conducted from the central control room, viewed by closed circuit television. It is assumed that all personnel will be excluded from the secondary containment during a test, but that access will be acceptable in a very short time following a test (less than one hour) to retrieve diagnostic data, set up posttest instrumentation, etc. All radioactivity and contaminated equipment will be confined to a small, well-shielded area of the facility to which access will not be routinely required.

The flash $x$-ray accelerator and its power supply system will be on the east end of the facility as shown in Figs. 8 and 9. The roof of this facility is at the current grade level at the facility. Access at grade will be made to the east end of the accelerator building. A description of the accelerator is found in Sec. VIII.

Room 310, the reactor cell, will be divided as shown in Fig. 8 with a heavy shield wall. The east end will contain the $x$-ray target, reactor, and some of the sodium blowdown loop equipment. This is the only area of the facility which is expected to see any significant radiation - and this radiation level is very low in comparison with that found near reactors running continuously. The west half of Room 310 will be used for the $x$-ray diagnostic instrumentation. Further use may also be made of Rooms 309 and 217 for instrumentation in support of the diagnostics.

The reactor will be supported off the floor of Room 310 with penetrations through the floor to Room 402 for the control drum drive shafts, helium and air cooling ducts, and instrumentation cables. Room 401 will be utilized for reactor support equipment. The control drives, helium circulator, air blowers, and other miscellaneous equipment in Room 401 are well shielded from the reactor, will not become contaminated in normal operation, and can be maintained and inspected directly. 


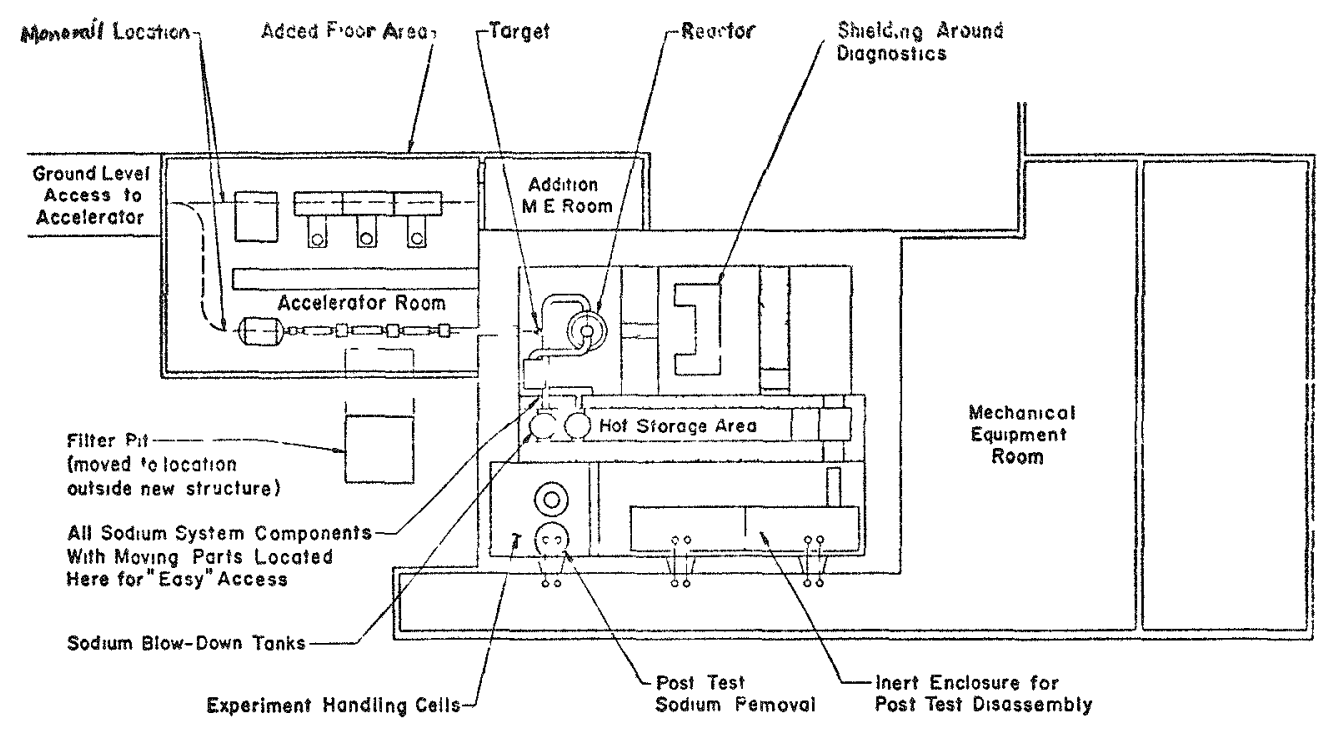

FIg. 8. UHTREX, section, plan.

The sodium handling equipment, valves, etc., will be placed along the wall of Room 310 where the equipment is accessible to Minotaur for maintenance and/or remote remova1. The large sodium blowdown tanks wlll be placed in Room 308 which is a wellshielded pit running the length of the facility. Room 308 is also available for other potentially contaminated equipment and for temporary storage of radioactive items prior to their removal for long term disposal.
The present gas storage area and Room 217 will be modified and equipped for posttest experiment handling. The gas storage area is an essentially square pit that extends all the way to the subbasement level of the facility. This area will be equipped for the initial functions of posttest handling that are most easily handled in a vertical position. Expected functions include a gamma scan, heating to melt and drain all sodium, and cutting off the top "fire plug" flange

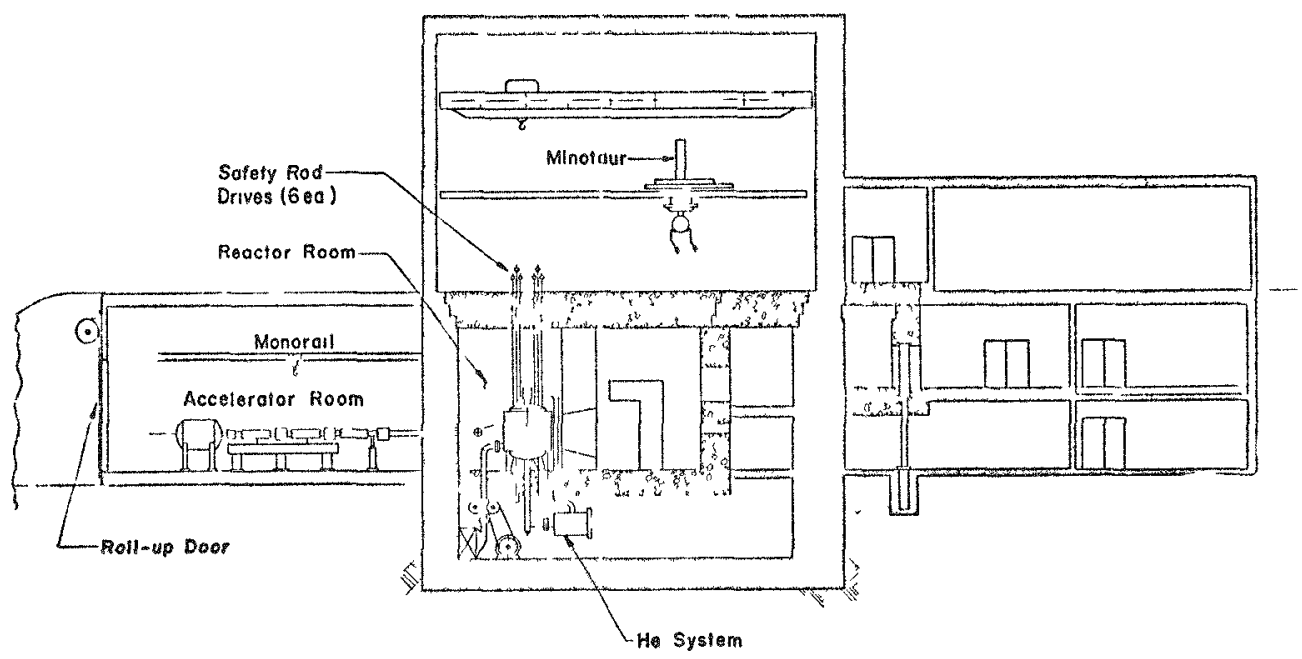

Fig. 9. UHTREX, section, south elevation. 
section of the experimental package. A sealed alpha box w111 be fabricated for these operations and special tooling and fixtures will be designed.

The operations at the top of the cell can be viewed from the operating corridor through the existing lead glass window. There are two master-slave manipulator positions at the window.

Final disassembly will be done in an alpha box bullt for this purpose and 1ocated in Room 217. Two windows currently exist and a third will be added. The existing master-slave positions will be used.

All of this manipulation is not expected to be easy and wlll be one of the time-consuming steps that will limat the number of experiments per year. Considerable shuffling of shield slabs may be necessary if there is need to enter Room 106 during any of this operation.

\section{SCHEDULE AND COSTS}

This section contains a broadly drawn schedule and a compilation of costs of preparing the PHOEBUS/UHTREX for test operation. The schedule (F1g. 10) provides for rehabilitation of, modification to, and an addition to (for the $x$-ray accelerator) the UHTREX bullang: prelıminary and final design; procurement, installation and check-out of all components of the facility. Facility and equipment costs are listed in Table VI-A. The manpower and costs for the staff needed to carry out this work are listed in Table VI-B. An estimate of the staff needed to operate the facility and the associated manpower costs are shown in Table VI-C. However, neither the schedule nor the costs include provision for experiment design and fabrication. A possible large effort in safety and environmental documentation is also omitted.

V. REACTOR STUDIES

A. General

The reactor studies for the PHOEBUS/ UHTREX reference design were based on the general geometry of the nuclear rocket program reactor, Phoebus-2, because of the avallabllity of beryllium reflector segments and associated hardware orıg1nally fabricated to the Phoebus-2 dimensions. Similarly, fuel element external dimensions, that Is, hexagonal rods

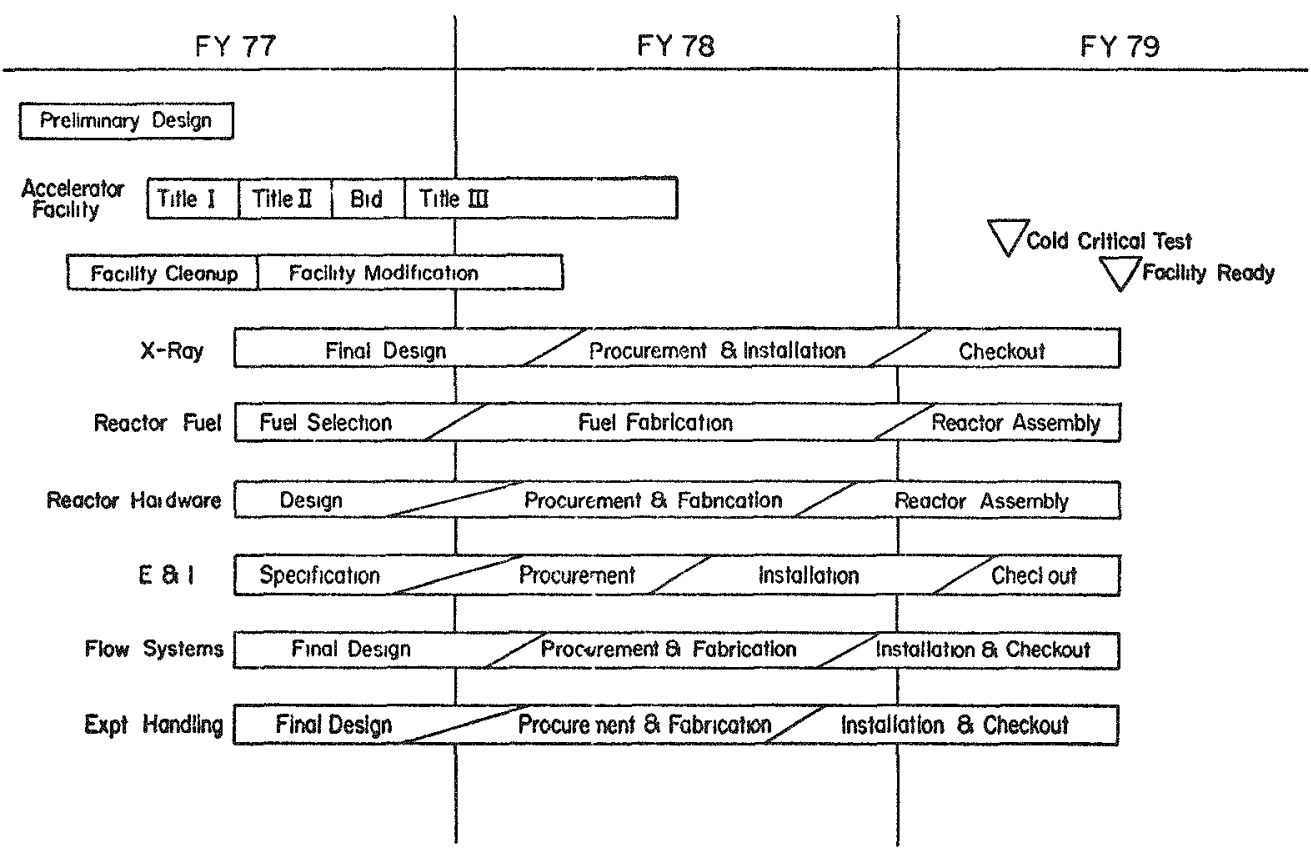

Fig. 10. Tentative PHOEBUS/UHTREX schedule. 
TABLE VI -A

COST ESTIMATE SUMMARY - THOUSANDS

$\left(F Y-76\right.$ Dollars $\left.\times 10^{3}\right)$

\section{Facilities}

UHTREX Facility Cleanup

X-Ray Accelerator Addition

300

Facility Modifications

200

Equipment

Reactor Hardware

Reactor Fuel

Coolant Systems (He, Air)

Sodium Systems

X-Ray Accelerator

Electronics \& Instrumentation

Remote Tooling \& Fixtures

posttest Handling

Hot Cel1 Preparation

Sub Tota1

Contingency $25 \%$

Quality Assurance 5\%

Total

TABLE VI-B

FACILITY PREPARATION MANPOWER REQUIREMENTS AND COSTS

$$
\left(\mathrm{FY}-76 \$ \times 10^{3}\right)
$$

$\begin{array}{ll}\text { Fiscal Year } & \text { Man-years } \\ 1977 \text { (average) } & 14 \text { Scientific } \\ & 8 \text { Additional } \\ 1978 & 20 \text { Scientific } \\ & 20 \text { Additional } \\ 1979 \text { (1st } 6 \text { mo.) } & 10 \text { Scientific } \\ & 10 \text { Additional }\end{array}$

Sub Total
TABLE VI -C

OPERATING STAFF COSTS

$\left(\mathrm{FY}-76 \$ \times 10^{3}\right)$

8 Scientific

15 Additional

1.000

$1.91 \mathrm{~cm}$ across flats and $1.32 \mathrm{~m}$ long, were retained because of the existing fabrication capability for those dimensions. Two types of fuel material, both of which were developed during the nuclear rocket program, were considered. One, the "beadloaded" fuel, consists of tiny spheres of $\mathrm{UC}_{2}$, coated with a layer of pyrocarbon, incorporated in a graphite matrix. The other, the "composite" fuel, consists of a solid solution of UC-ZrC incorporated in a graphite matrix. The nuclear rocket (Rover) program background is discussed in Appendix A.

Reactor neutronic and thermal analysis are discussed in subsequent sections. More parametric calculations have been carried out in the neutronics area because the nuclear design has a more complex interaction with the capability of the reactor to meet various performance goals. These calculations and the design trends established by them are discussed in the section on neutronics. Thermal calculations have been carried out with the general goal of avoiding excessive temperatures during the cooldown in various reactor structures with minimal coolant flows and pressures.

B. Neutronic Calculations The neutronic calculations were performed using the one-dimensional DTF-IV transport theory code ${ }^{3}$ in $\mathrm{S}_{4}$ angular segmentation. The 25 energy group neutron cross sections used in these calculations were the same as those used in the original analysis of the Phoebus-2 reactor and are tabulated in Ref. 4. 
The calculational model maintained the same fueled length, $1.32 \mathrm{~m}$, and diameter, $1.4 \mathrm{~m}$, as existed in the Phoebus -2 reactor. The $0.20-m-t h i c k$ Phoebus -2 beryllium reflector and boron control system were also incorporated into the current calculations. A boron sheath mocked up the control vanes in their outermost position $\left(180^{\circ}\right)$. The interface region between the core and reflector which previously contained a $5.6-\mathrm{cm}$ aluminum cylinder was modified to incorporate the insulating material required for the new application.

The test bundle was assumed to contain highly enriched (93\%) $\mathrm{UO}_{2}$ fuel pins in the FTR geometry. The FTR fuel pellets are contained within a $0.23-i n$. outer diameter by $0.015-i n$. thick stainless steel clad. The fuel pins are packed in a hexagonal lattice with a 1.24 pitch-todiameter ratio. The calculational model assumed a 127-pin bundle with an equivalent diameter of $8.56 \mathrm{~cm}$. The test vehicle model used in the initial calculations was obtained from Ref. 5 and resulted in an inner core diameter of $18.9 \mathrm{~cm}$. The one-dimensional calculational model used in the neutronic parameter study is shown in Table VII. The one-dimensional model does not incorporate any instrument diagnostic slot. Instead, as will be discussed later in this section, the calculated $\mathrm{K}_{\text {eff }}$ is made sufficiently large to account for expected reactivity losses associated with a 12- $\mathrm{cm}-$ wide slot.

Three performance characteristics derived from the neutronic calculations, along with their desired values, are shown in Table VIII. Fissions in the test pins are primarily produced by neutrons entering from the driver region. With a soft spectrum driver the radial fission profile in the test section peaks at the outer surface and monotonically decreases toward the center. A relatively flat fission profile is desirable when simulating
LMFBR transients. Based on experimental requirements, an upper limit of 1.30 has been specified for the radial maximum-tominimum fission ratio in the test section. The Figure of Merit (FOM) is defined as the ratio of the minimum power density in the test fuel to the maximum power density in the driver fuel at a given axial location. The FOM relates the energy deposited in the test fuel to the corresponding maximum temperature rise in the ariver fuel. This relationship is shown in Fig. 11 for $\mathrm{UO}_{2}$ test fuel and $\mathrm{UC}_{2}-\mathrm{C}$ driver fuel. Since the volumetric heat capacity of UC-ZrC-C composite fuel is similar to graphite fuel, Fig. Il can be used for the composite fuel as well. With an FOM of $\sim 13$, an energy deposition of $5000 \mathrm{~J} / \mathrm{g}$ in the test fuel will produce a $1200 \mathrm{~K}$ temperature rise in the driver fuel.

The one-dimensional transport theory calculations do not incorporate any diagnostic instrument slots. The calculated reactivity must therefore allow for losses associated with these slots as well as for control and burst requirements. Monte Carlo calculations performed with the MCNK code ${ }^{3}$ indicated that a 12-cm-wide slot through the core and reflector would reduce reactivity by $13.4 \%$; $11.5 \%$ due to removal of fuel material and $1.9 \%$ due to removal of reflector. Additional calculations indicate that reactivity will decrease $0.5 \%$ due to temperature increases prior to the burst and an additional $2 \%$ will be sufficient to initiate the maximum burst. An excess reactivity of $16 \% \Delta \mathrm{K}$ $\left(\mathrm{K}_{\text {eff }}=1.16\right)$, therefore appears sufficient for the one-dimensional ambient calculations.

Within the framework of the Phoebus-2 model as described above, the neutronic performance characteristics are influenced primarily by the carbon and uranium densities in the driver region. Unfortunately, changes in the driver composition have opposing effects on the performance characteristics in the sense that conditions which 
TABLE VII

Atom Densities $\times 10^{24}$ atoms $/ \mathrm{cm}^{3}$

\begin{tabular}{|c|c|c|c|c|c|c|c|c|c|c|c|c|c|c|c|}
\hline & Zone & $\begin{array}{c}\text { Outer } \\
\text { Radius } \\
\mathrm{cm}\end{array}$ & $235_{U}$ & $238_{u}$ & $\mathrm{C}$ & $\mathrm{Zr}$ & 0 & $\mathrm{Fe}$ & $\mathrm{Cr}$ & $\mathrm{Ni}$ & $\mathrm{Na}$ & Mo & $\mathrm{Be}$ & A1 & B \\
\hline Test Bundle & 1 & 4.28 & $8.65 E-3$ & $6.31 \mathrm{E}-4$ & & & $1.82 \mathrm{E}-2$ & $1.04 \mathrm{E}-2$ & $2.97 \mathrm{E}-3$ & $1.75 E-3$ & $9.23 E-3$ & $2.2 E-4$ & & & \\
\hline Test Vehicle & $\begin{array}{l}2 \\
3\end{array}$ & $\begin{array}{l}9.14 \\
9.47\end{array}$ & & & & & & $\begin{array}{l}3.56 \\
2.90\end{array}$ & $\begin{array}{l}9.29 \\
7.58\end{array}$ & $\begin{array}{l}3.66 \\
2.99\end{array}$ & $6.92 \downarrow$ & & & & * \\
\hline Driver & 4 & 69.45 & * & * & * & $*$ & & & & & & & & & \\
\hline Fillers & 5 & $70.5]$ & & & $8.0 \mathrm{E}-2$ & & & & & & & & & & \\
\hline Interface & $\begin{array}{l}6 \\
7 \\
8\end{array}$ & $\begin{array}{l}70.83 \\
71.96 \\
79.20\end{array}$ & & & $\left.\begin{array}{l}8.0 \\
8.0 \\
1.2\end{array}\right\rfloor$ & & & $2.75 \mathrm{E}-3$ & & $1.47 E-3$ & & & & & \\
\hline Reflector & $\begin{array}{r}9 \\
10\end{array}$ & $\begin{array}{l}89.36 \\
96.60\end{array}$ & & & & & & & & & & & $\begin{array}{l}1.049 \mathrm{E}-1 \\
1.094\end{array}$ & $\begin{array}{l}1.37 \mathrm{E}-3 \\
1.22\end{array}$ & \\
\hline Control Sheath & 11 & 96.85 & & & & & & & & & & & 1.094 & 1.22 & $2.55 \mathrm{E}-2$ \\
\hline Reflector & 12 & 99.52 & & & & & & & & & & & $1.094 \downarrow$ & $1.22 \downarrow$ & \\
\hline Vesse1 & 13 & 102.06 & & & & & & & & & & & & $6.03 E-2$ & \\
\hline
\end{tabular}

*Varied in survey calculations. 
TABLE VIII

NEUTRONIC PERFORMANCE CHARACTERISTICS

1. Reactivity

$K_{\text {eff }}=1.16$

2. Figure of Merif

$$
\text { FOM }=\frac{\text { Minimum } \frac{\text { Fissions }}{\mathrm{cm}^{3}} \text { Test }}{\text { Maximum } \frac{\text { Fissions }}{\mathrm{cm}^{3}} \text { Driver }} \approx 13
$$

\section{Max/Min Fission Ratio}

improve FOM are usually detrimental to both maximum/minimum and reactivity. The objective of the neutronic survey calculations was to maximize the FOM while maintaining the maximum/minimum and reactivity at their acceptable limits of 1.30 and 1.16 , respectively.

The maximum/minimum fission ratio across the test region is determined by the neutron energy spectrum in the driver. The harder the spectrum, the greater the neutron penetration and the lower the resulting maximum/minimum. Figure 12A shows the maximum/minimum across a 127-pin

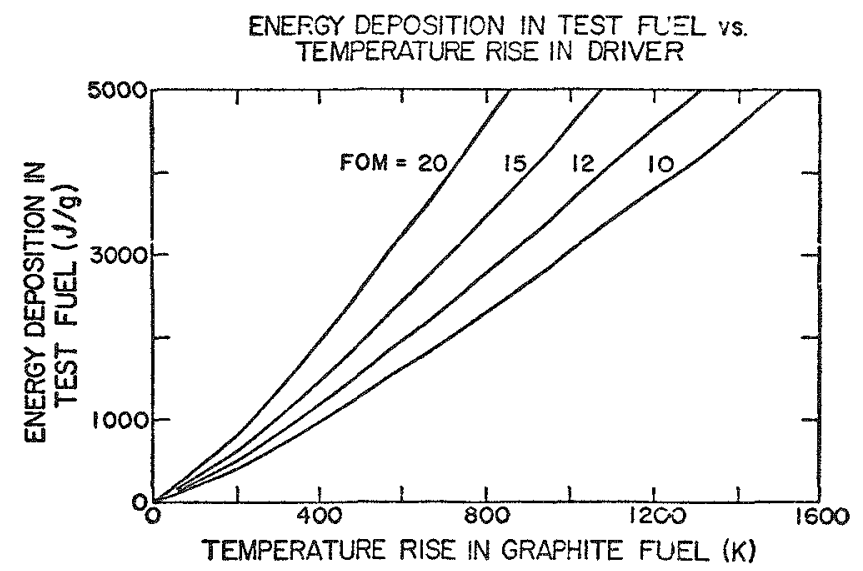

Fig. 11. Energy deposition in test fuel vs temperature rise in ariver.

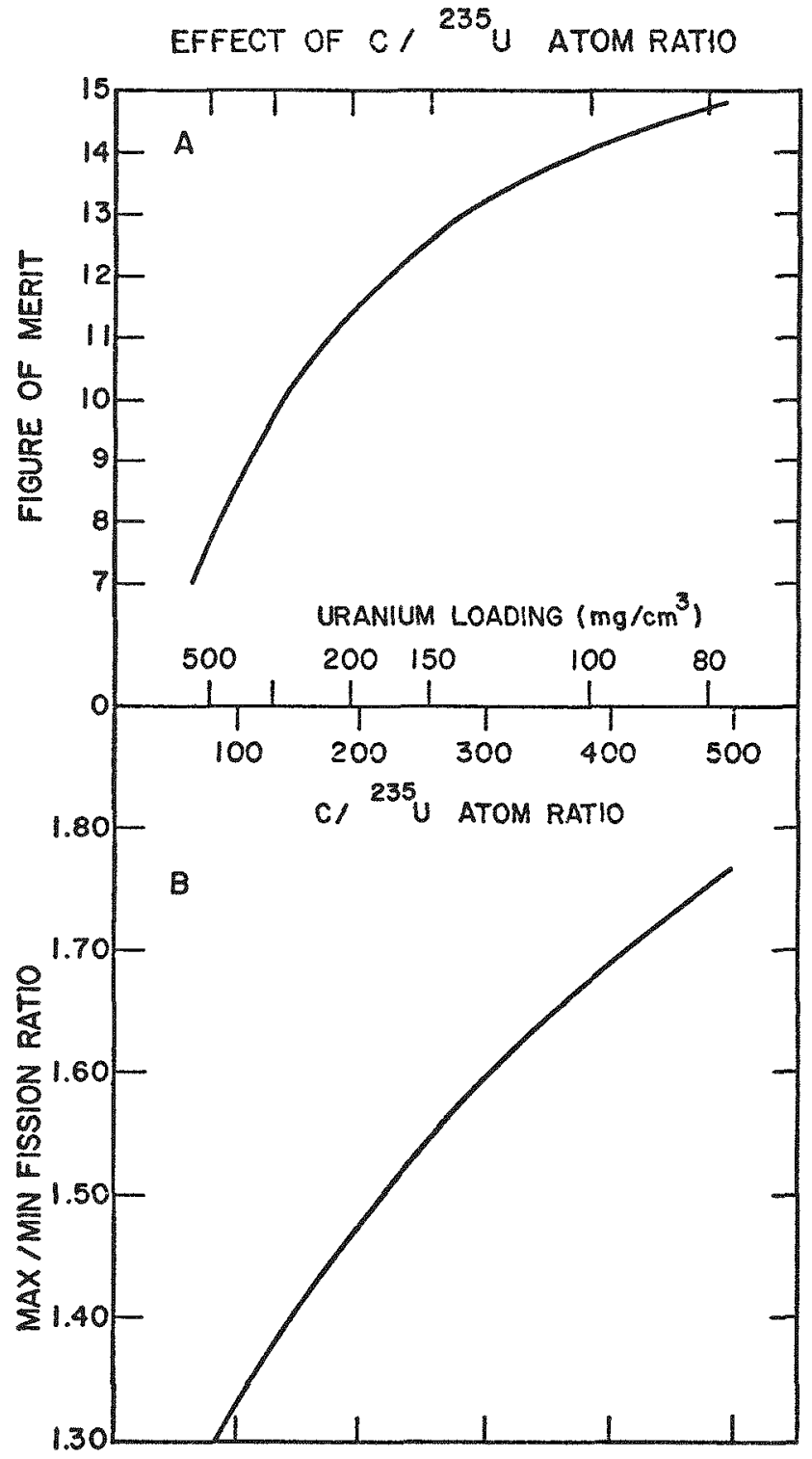

Fig. 12. Effect of $\mathrm{C} /{ }^{235} \mathrm{U}$ atom ratio.

test bundle as a function of the $\mathrm{c} /{ }^{235} \mathrm{U}$ atom ratio in the $\mathrm{UC}_{2}-\mathrm{C}$ fueled driver. Adding uranium (decreasing the $\mathrm{C} / \mathrm{U}$ ratio) hardens the neutron spectrum and lowers the maximum/minimum. A C/ ${ }^{235} \mathrm{U}$ ratio of $\sim 80$, equivalent to a uranium loading of $480 \mathrm{mg} / \mathrm{cm}^{3}$ in graphite fuel is needed to produce a maximum/minimum of 1.30 . Figure $12 \mathrm{~B}$ shows the effect of $\mathrm{C} / \mathrm{U}$ ratio on the FOM. The condition which improves maximum/minimum (adding uranium to harden 
the spectrum) is detrimental to FOM which benefits from a low uranium density in the driver.

It is therefore desirable to reduce the uranium density without degrading the neutron energy spectrum. Since FOM is based upon fission density per $\mathrm{cm}^{3}$ of solid driver fuel material, reducing overall uranium density by increasing void fraction (removing fuel material) does not in itself significantly improve FOM. The effect of void fraction on FOM for $\mathrm{UC}_{2}-\mathrm{C}$ fuel with a $C /{ }^{235} \mathrm{U}$ ratio of 80 is shown in Fig. 13 (curve labeled "GRAPHITE"). The slight increase in FOM with increasing void is primarily due to a hardening of the neutron spectrum in the inner driver region and a redistribution of the radial fission profile. The increased void results in a reactivity 1oss. A significant increase in the FOM can be achieved, however, by filling existing void with a relatively neutral material which does not degrade the neutronic characteristics of the system.

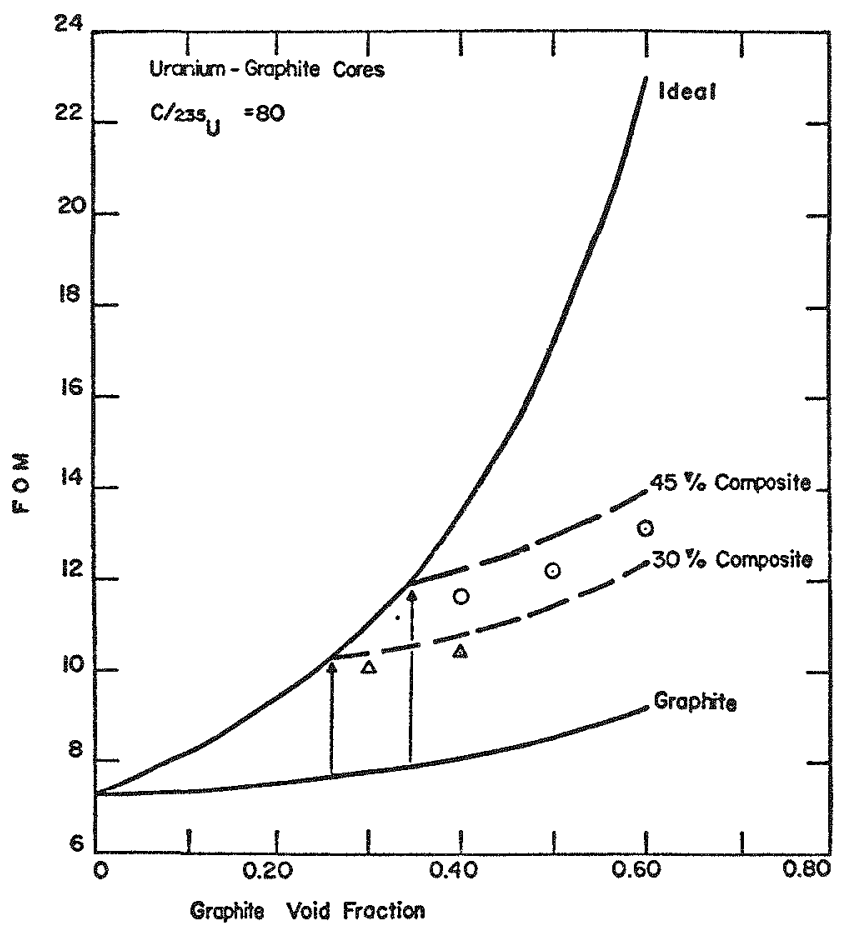

Fig. 13. Effect of void fraction on FOM.
The curve in Fig. 13 labeled "ideal" shows what the FOM would be if the voids were indeed completely filled with such a neutral material. Since zirconium is relatively neutral, the $\mathrm{ZrC}$ in the UC-ZrC-C composite fuel is a prime candidate for an "ideal" material that would essentially add heat capacity by filling the voids with ZrC. Thirty volume percent composite has a carbon density of $1.35 \mathrm{~g} / \mathrm{cm}^{3}$ and would remain on the "ideal" curve at an equivalent $\mathrm{UC}_{2}-\mathrm{C}$ void of $26 \%$

Figure 13 shows the expected FOM for $30 \%$ and $45 \%$ composite material assuming zr would be neutronically neutral, along with results of calculations that incorporated $\mathrm{Zr}$ into the model. Addition of zirconium had only a small effect on FOM and reactivity.

Further increases in FOM can be achieved by decreasing the uranium density in the driver fuel while maintaining the maximum/minimum at its upper limit of 1.30 with a filter or converter region. Figure 14 shows the FOM as a function of

FOM FOR UNFILTERED DRIVERS



Fig. 14. FOM for unfiltered drivers. 
uranium inventory in the driver region for $\mathrm{UC}_{2}-\mathrm{C}$ fuel. The crossing over of the parametric void fraction curves in Fig. 14 indicate that at low uranium inventories adding carbon to the driver actually decreases FOM because fewer neutrons in the softer spectrum produced by the addition of carbon are able to penetrate to the center of the 127-pin test region.

The increase in FOM obtained by removing uranium from the driver region is accompanied by a corresponding increase in the maximum/minimum fission ratio across the test section. A relatively simple way of reducing the maximum/minimum is to insert a filter that is a strong thermal neutron absorber between the driver and test fuel to preferentially absorb the low energy neutrons causing the large fission gradients in the test section. Figure 15 compares the FOM

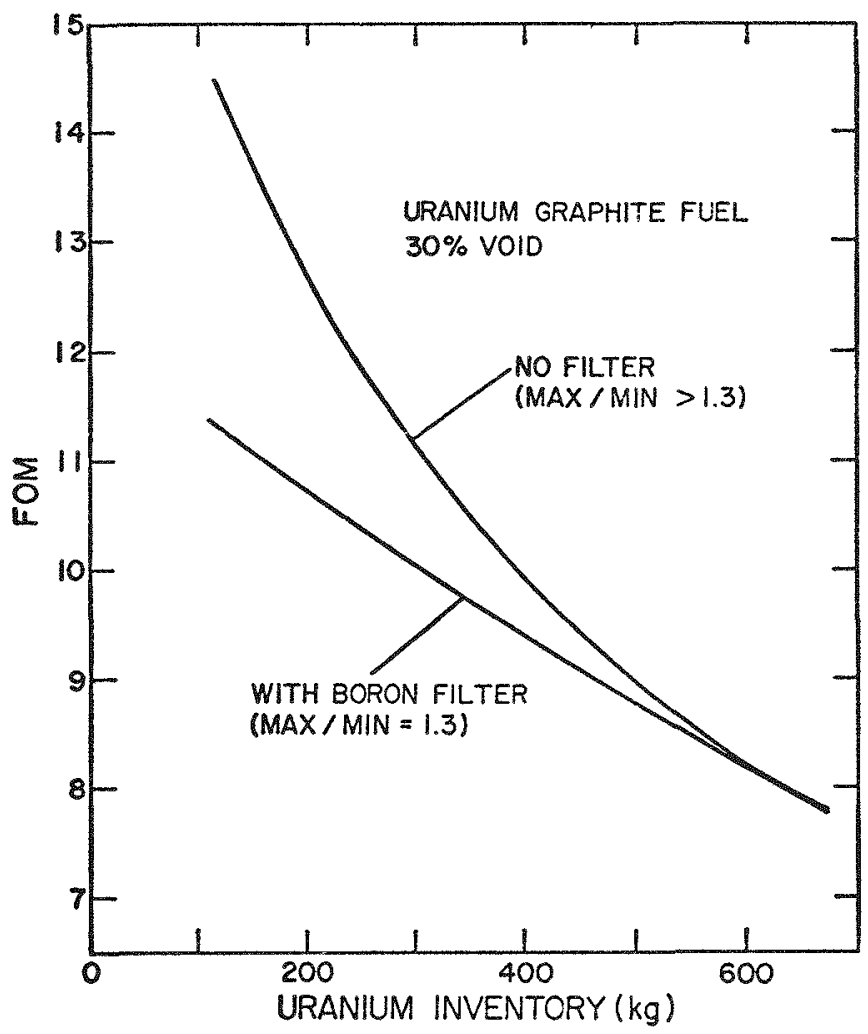

Fig. 15. Effect of boron filter on FOM. obtained without a filter to that obtained using a boron filter to bring the maximum/ minimum down to a value of 1.30. Although the addition of boron reduced the FOM, there is still a significant gain in the filtered FOM with decreasing uranium inventory. Figure 16 plots the filtered FOM for the three parametric void fraction curves shown in Fig. 14. Also shown in Fig. 16 are the calculated values of $\mathrm{K}_{\text {eff. }}$ Conditions which improve FOM, such as reducing the uranium inventory or void fraction are seen to reduce the reactivity. As has previously reen discussed, a $K_{\text {eff }}$ of 1.16 may be required in the one-dimensional calculations to allow sufficient excess reactivity for instrument slots and control requirements. The system containing $352 \mathrm{~kg}$ of uranium, 30\% void and $a k_{\text {eff }}$ of 1.16 was chosen for further study. This configuration was "neutronically converted" to a 35\% UC-ZrC-C system by adding the appropriate $\mathrm{Zr}$ density to the calculational model. The addition of ZrC reduces the void fraction from $30 \%$



Fig. 16. Figure of Merit vs uranium inventory. 
to $7 \%$ and results in an increase in the FOM from 9.7 to 12.1 .

Calculations described thus far incorporated a single, uniform driver core. The radial fission distribution in the driver of the selected configuration is shown in Fig. 17. The sharp spike at the core edge is due to the return of low energy neutrons from the beryliium reflector. The FOMs have been based upon the maximum fission density in the driver excluding the edge peak which will be reduced by lowering the uranium loading at the driver periphery. Further flattening of the fission distribution in the driver core by adjustment of uranium loadings results in a $7 \%$ increase in the FOM to a value of 12.9 .

It is not obvious that a completely flat radial power profile in the driver is desirable. The temperature constraints in the proposed reference design are governed by materials outside the driver and not by the driver fuel material. Thus, a power profile that minimizes the total heat generated might be the desirable objective. The FOM could, therefore, be optimized with respect to the average rather than the maximum driver fission density. The maximum to average radial

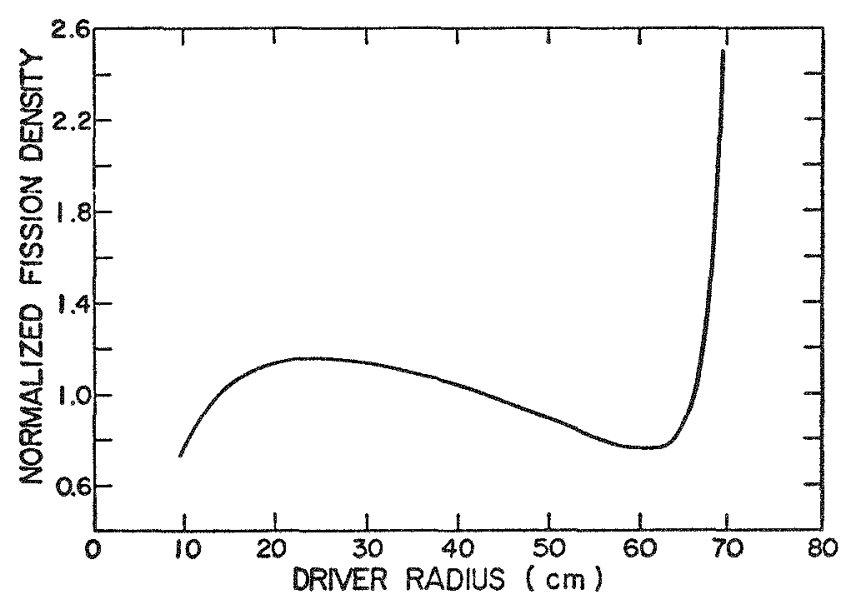

Fig. 17. Radial fission distribution in uniform driver. fission density ratio in the flattened driver is 1.07 compared with 1.20 in the core with only the edge spike removed. For a given energy deposition in the test fuel the total energy produced in the unflattened driver core will be 7 응 less than in the flattened core, while maximum local energy densities will be about $7 \%$ higher in the former.

Further neutronic and thermal calculations are required to determine the optimum driver radial fission profile. The reference design in the current study will incorporate a flattened driver. The neutronic survey calculations were performed with a test vehicle that required a 19-cm-diam hole in the ariver core. During the study it was decided to incorporate a 22.9-cm-diam hole in the driver along with a 0.64 -cm-thick stainless steel experiment containment tube and a 1-cm-thick insulation layer resulting in an inner ariver fuel diameter of $26.2 \mathrm{~cm}$. The changes in test vehicle and driver configuration resulted in an $8 \%$ decrease in the FOM to a value of 11.9 . Use of a zirconium containment tube in place of steel would regain $2 \%$ in the FOM. The use of a converter region in place of a boron filter was briefly investigated. The converter was assumed to be a $\mathrm{UO}_{2}-\mathrm{Cr}$ cermet. The uranium density in the converter must be low enough to make the converter FOM and corresponding temperature rise compatible with its material properties and thick enough to harden the spectrum to yield 2 1. 30 maximum/minimum across the 127 pins. For the system investigated a $11-\mathrm{cm}$-thick converter yielded an FOM 22\% greater than that attainable with a boron filter. Converters offer the greatest potential in relatively large high-density graphite systems. Since it is not certain that a suitable converter material could be developed in the time schedule proposed for 
the PHOEBUS/UHTREX STF, the convertertype systems were not optimized or included in the reference design.

C. Thermal and Fluid Flow studies 1. Introduction The major effort in the thermal and fluid analysis area was directed toward the study of postburst cooldown of the reactor. Forced convection cooling is necessary to maintain acceptable temperatures in the reactor containment vessels. Preliminary scoping calculations were made to size the air blower used to cool the beryllium reflector and aluminum containment vessel. Performance calculations were done for the helium cooling system to check its heat removal capacity.

\section{Thermal Model AYER, ${ }^{6}$ a two-dimensional, time-} dependent, finite element heat conduction code was used to provide a numerical solution to the postburst cooldown. The reactor was modeled as a series of concentric cylinders of the materials shown in Fig. 18. Gross model dimensions are $\mathrm{h}=1.32 \mathrm{~m}, r_{i}=0.101 \mathrm{~m}$, and $r_{0}=0.995 \mathrm{~m}$. Radial dimensions to other points in the reactor are shown in Sec. III. The instrumentation slots for the flash $x$-ray or hodoscope were not modeled.

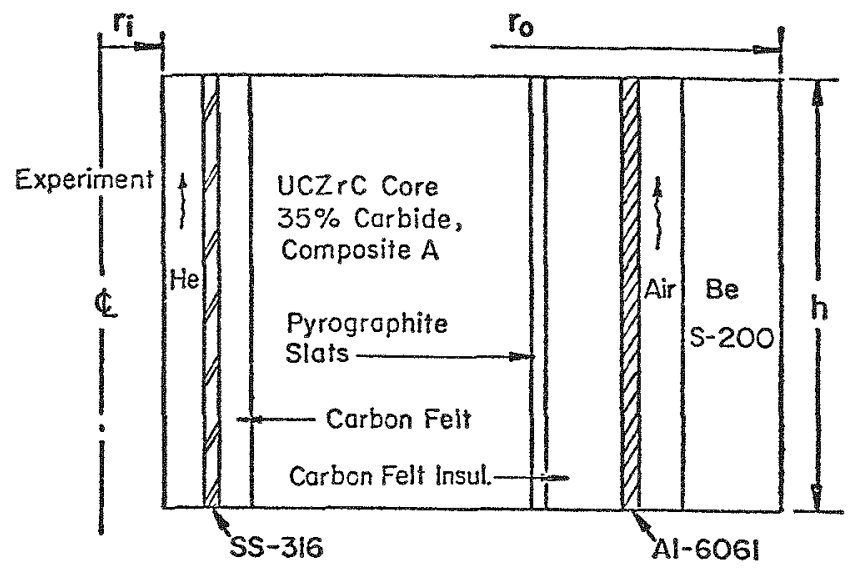

Fig. 18. Reactor thermal model.
The finite element model of the axisymmetric body was constructed of an array of $8 \times 29$ (232) rectangular elements with 270 nodes. The model simulates conditions for 13 boundaries and the $8 \mathrm{ma}-$ terials shown in Fig. 18.

Properties of the fuel and coolant gases used in the numerical analysis are described below.

a. Core material properties were taken from LA-5398 (Ref. 7) for UC-ZrC composite fuel of $35 \%$ carbide volume fraction, $435 \mathrm{~kg} / \mathrm{m}^{3}$ uranium loading, and the composite A heat treatment.

$$
\begin{aligned}
& \rho=3590 \frac{\mathrm{kg}}{\mathrm{m}^{3}} . \\
& \mathrm{C}_{\mathrm{p}}=737.7 \frac{\mathrm{J}}{\mathrm{kg}-\mathrm{K}} . \\
& \mathrm{T}<1200 \mathrm{~K}, \mathrm{~K}=(-2.28 \mathrm{E}-2 * \mathrm{~T}+57.5) \frac{\mathrm{W}}{\mathrm{m}-\mathrm{K}} . \\
& \mathrm{T}>1200 \mathrm{~K}, \mathrm{~K}=30 \frac{\mathrm{W}}{\mathrm{m}-\mathrm{K}} .
\end{aligned}
$$

b. The helium coolant was

modeled as a perfect gas for $T=400 \mathrm{~K}$ and $P=3.45 \times 10^{6} \mathrm{~Pa}$ conditions,

$$
\begin{aligned}
& \rho=\frac{48.78}{\mathrm{~T}} \cdot \frac{\mathrm{kg}}{\mathrm{m}^{3}}, \\
& C_{p}=5188 \frac{\mathrm{J}}{\mathrm{kg}-\mathrm{K}}, \\
& \mathrm{K}=1.76 \mathrm{E}-3 * \mathrm{~T}^{0.771} .
\end{aligned}
$$

c. The air coolant was modeled as a perfect gas operating at room temperature $(300 \mathrm{~K})$ and atmospheric pressure

$$
\begin{aligned}
& \rho=\frac{341.2}{\mathrm{~T}} \frac{\mathrm{kg}}{\mathrm{m}^{3}} \\
& \mathrm{C}_{\mathrm{p}}=1040 \frac{\mathrm{J}}{\mathrm{kg-K}}, \\
& \mathrm{K}=3.21 \mathrm{E}-4 * \mathrm{~T}_{\mathrm{T}} 0.771 .
\end{aligned}
$$

The thermal analysis assumes

that the reactor starts from room temperature, undergoes a burst, and then is 
shut down. This assumption results in an axial sine-shaped temperature distribution of the form

$\mathrm{T}=\mathrm{T}_{0}+\mathrm{DT}^{*} \mathrm{SIN}(I .929 * \mathrm{Y}+0.352)$,

where

$$
\begin{aligned}
\mathrm{T}_{0}= & \text { room temperature, } 300 \mathrm{~K} \\
\mathrm{DT}= & \text { TMAX }-\mathrm{T}_{0} \\
\mathrm{Y}= & \text { axial distance from bottom of } \\
& \text { reactor core, in meters. }
\end{aligned}
$$

This initial temperature distribution is a little too high for the reference case, since not all the heat is produced during the burst, some being produced (and partially removed) during the 15-s preburst heat up and about $8 \%$ being produced due to afterheat during the postburst shutdown. The stainless steel and aluminum containment vessels, the core, and the beryllium reflector are all initialized with the stated axial temperature distribution for various values of DT. The helium coolant inlet temperature is $400 \mathrm{~K}$ and the air coolant inlet temperature is $300 \mathrm{~K}$.

The thermal analysis required the use of 13 boundaries. The boundary conditions used in the numerical model are as follows:

- radiation to room temperature gas from the top and the bottom of the model,

- adiabatic boundaries on the inside and outside radii,

- convection from the stainless steel vessel to the helium coolant,

- convection from the aluminum vessel to the air coolant, and

- radiation across coolant gaps.

Early results showed that radiation across the gas-cooled annular surfaces was negligible due to the small temperature differences.

\section{Results}

Figure 19 illustrates the temperature-time history of the hottest nodes in the core and the aluminum and stainless steel vessels. With the postulated cooling systems, the reactor can be cooled close to room temperature in $72 \mathrm{~h}$ and the containment vessels can be maintained at acceptable temperatures. Figure 20 illustrates the heat removal time-history for the containment vessels. Maximum heat flux across the vessel surfaces is $47 \mathrm{~kW}$ across the aluminum and $60 \mathrm{~kW}$ across the stainless steel.

$$
\frac{\text { 4. Coolant Systems }}{\frac{\text { a. Helium coolant System }}{\text { The helium cooling system }}}
$$

is assumed to operate at the following conditions:

$$
\begin{array}{ll}
\mathrm{T} & =400 \mathrm{~K}, \\
\mathrm{P} & =3.45 \cdot 10^{6} \mathrm{~Pa}, \\
\dot{\mathrm{m}} & =1.29 \mathrm{~kg} / \mathrm{s}, \\
\Delta \mathrm{P}_{\max } & =3.5 \cdot 10^{4} \mathrm{~Pa},
\end{array}
$$

which represent the characteristics of the circulator already available in the present building. Helium is pumped through the annulus between the stainless steel

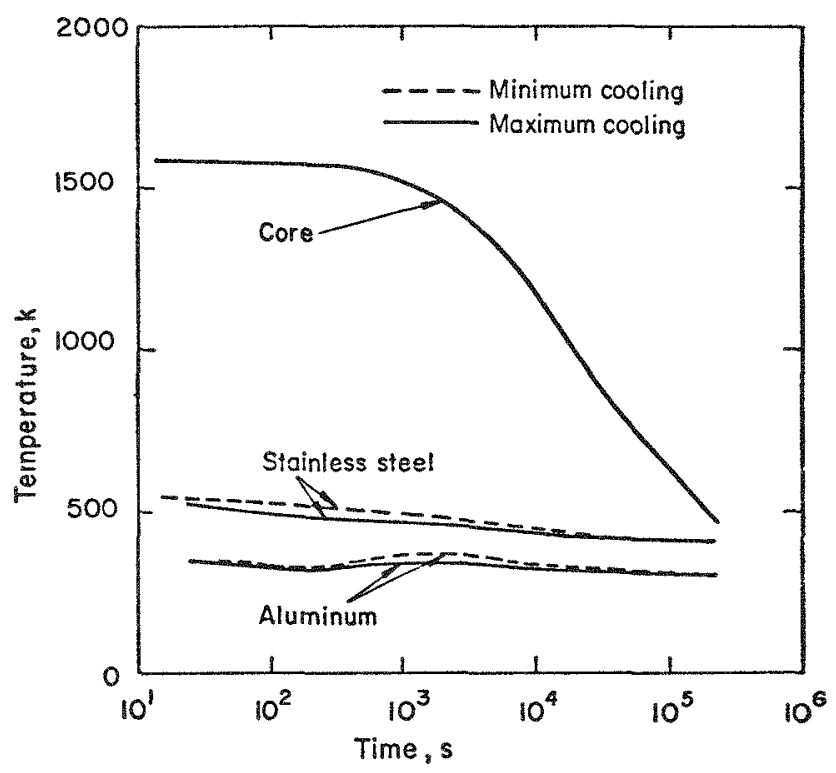

Fig. 19. Temperature vs time-history. 


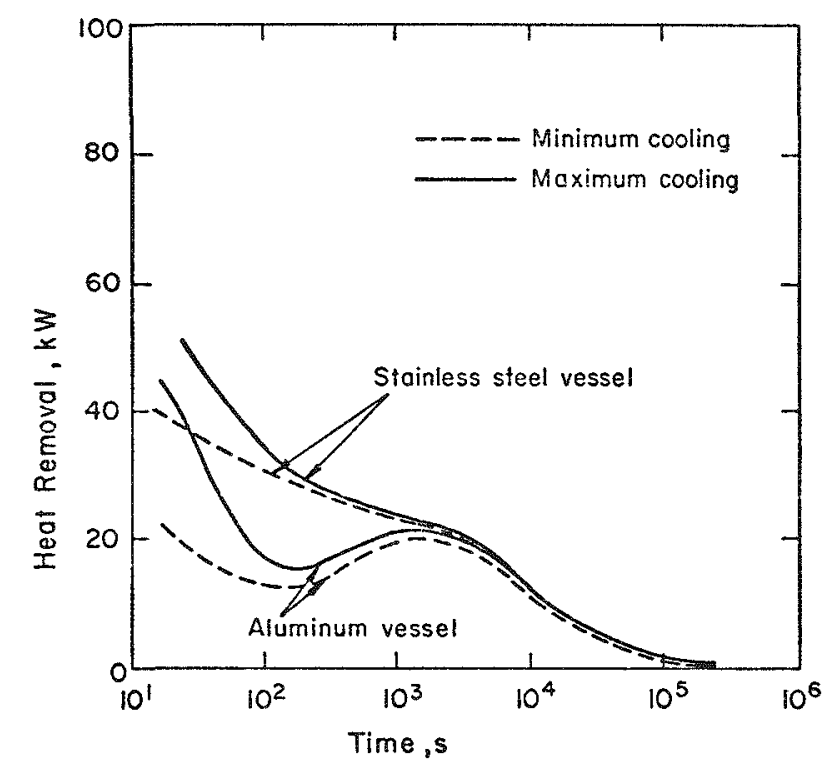

Fig. 20. Heat flux time-history.

reactor vessel and the experimental containment vessel. Pressure losses due to friction are based on the Darcy-Weisbach relation and the inlet and outlet piping losses were assumed to be two velocity heads. A short program was written to evaluate static pressure drop, Reynolds number, and the convection heat transfer coefficient for various circulator flow rates. Flow conditions vary from laminar to turbulent flow above $\dot{\mathrm{m}}=0.57 \mathrm{~kg} / \mathrm{s}$. Since the annulus is short, $L / D E=55$, the manifold piping minimizes the end effects and quickly produces fully established turbulent flow. The heat transfer coefficients were analyzed using the turbulent flow relationship,

$\frac{h}{C_{p} G} \cdot \operatorname{Pr}^{2 / 3}=\frac{0.023}{\operatorname{Re}^{0.2}}$, and varied from 625 to $1200 \frac{W}{\mathrm{~m}^{2}-\mathrm{K}}$. Results are shown in Table IX.

b. Air Cooling system Scoping calculations were done for preliminary sizing of the air blower used to cool the beryllium reflector. The air cooling system is assumed to operate at the following conditions:

$$
\begin{array}{ll}
\mathrm{T} & =300 \mathrm{~K}, \\
\mathrm{P} & =\text { atmospheric }, \\
\dot{\mathrm{m}} & =\text { variable, } \\
\Delta \mathrm{P}_{\max } & =1.38 \text { by } 10^{4} \mathrm{~Pa} .
\end{array}
$$

Air is circulated through the 6.4 by $10^{-3} \mathrm{~m}$ annulus between the beryllium reflector and the aluminum vessel. The pressure loss due to friction is based on the Darcy-Weisbach relation and the inlet and outlet losses are assumed to $1-1 / 2$ velocity heads. A short program was written to evaluate the static pressure drop, mass flow rate, Reynolds number, and the convection heat transfer coefficient. Results show that the heat transfer coefficient varied from 100 to $260 \frac{\mathrm{W}}{\mathrm{m}^{2}-\mathrm{K}}$ for turbulent flow conditions. Results are shown in Table $X$.

VI. DISCUSSION OF EXPERIMENT STUDIES A. Loop Considerations

For reference in this study, a 127fuel pin integral, sodium-cooled loop has been chosen. This type of loop was chosen (1) to provide the greatest demand expected for support facilities inside the UHTREX building and (2) to provide a large test loop at a modest cost within the same time schedule as that required to complete the PHOEBUS/UHTREX facility. One of the ground rules for this study is to use, as far as possible, existing equipment and technology. This precludes the development of large new package loops and the modification of the UHTREX building to accept them.

The reference experiment loop can be operated as a loop with sodium flowing through the test section or as a sodiumcooled autoclave with the sodium cooling the autoclave primary containment and/or melt-through barrier. The test section inside the autoclave could be loaded with or without sodium. Many useful experiments in the past have been performed in autoclaves and such experiments may be useful in the future. Autoclave 
TABLE IX

HELIUM COOLING SYSTEM PARAMETERS

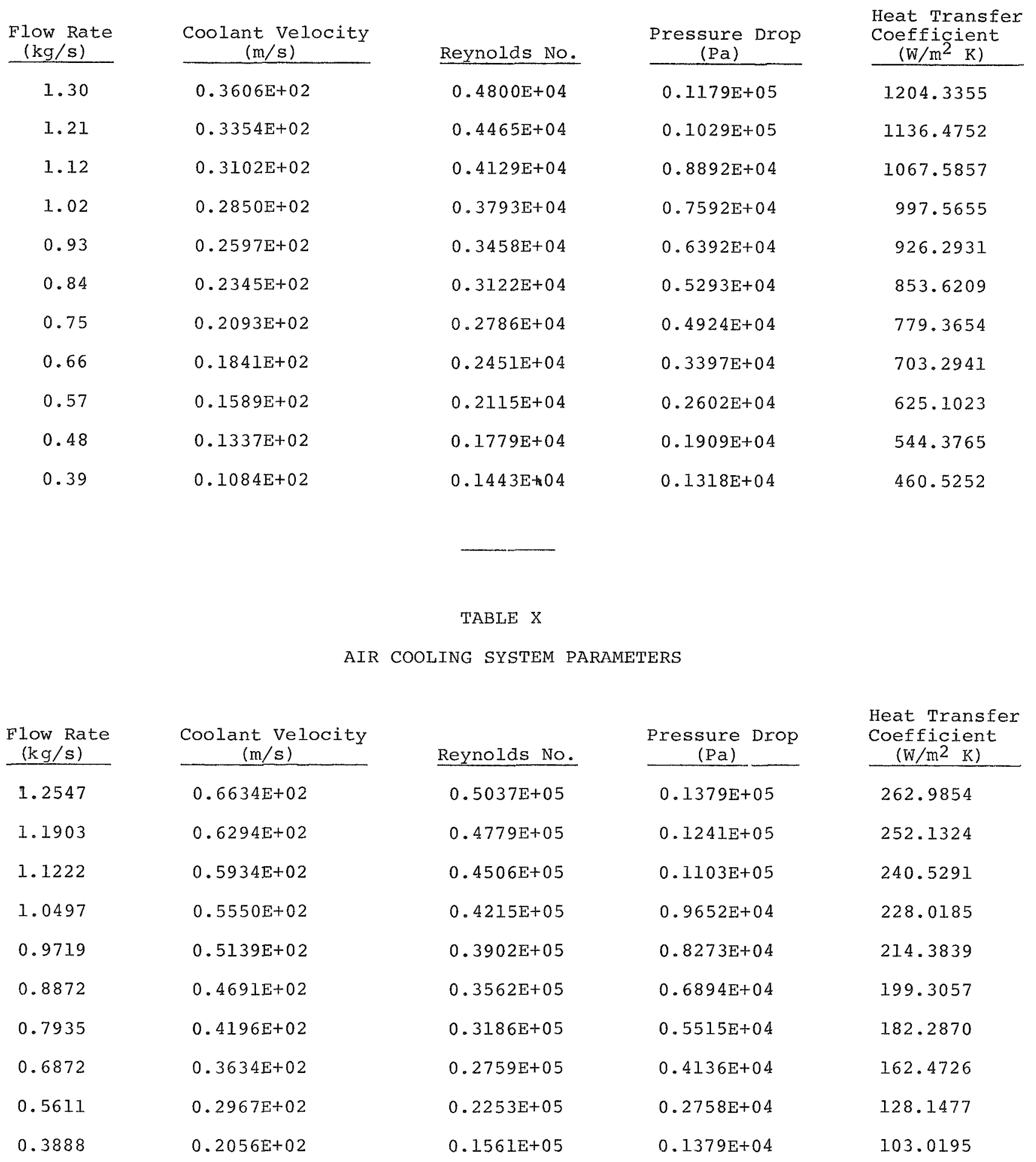


experiments are simpler in design, easier to perform, and more economical than those in a flowing sodium loop.

The 22.86-cm (9-in.)-inside diameter of the test thimble through the center of the Phoebus core can accept the in-core section of currently available and proposed TREAT and ETR autoclaves and loops. These are listed in Table XI. As indicated, some modification of the loops will be necessary. For example, the pumps on the TREAT Mark-II loops should be relocated in order to have less material in the beam of the flash $x$-ray fuel motion detector. Also the heat exchanger of the present SLSF is not necessary if that loop is used in a class I facility. The removal of the heat exchanger will shorten the loop and lower its weight. A large secondary cooling system will not then be required for the SLSF. With these modifications the SISF can be handled within the UHTREX building if a new loop handling machine and portable turntable is built. Disassembly of such a large package loop would not be possible at LASI without the construction of a large new posttest examination facility. Either such a facility would have to be built at LASL or the loop shipped in its loop handling machine on a transporter to such a facility at another site. The disassembly of the reference experimental loop and available posttest examination facilities at LASL will be discussed in Sec. B, Experiment Handling. The use of loops other

TABLE XI

PHOEBUS/UHTREX ADDITIONAL CAPABILITY

Modified TREAT Loops

GE Capsules ${ }^{\mathrm{a}}$

HEDL Autoclave ${ }^{a}$

ANL Piston Autoclave ${ }^{a}$

ANL R-Series Loop, ${ }^{b}$ tanks relocated

ANL Mark-II A, Mark II-C Loops, b pump relocated

ANL Advanced TREAT Loop, ${ }^{C}$ pump relocated

Modified FTR Loops

ANL SLSF, d heat exchanger removed

ANL Advanced SLSF, ${ }^{e}$ heat exchanger reduced in size

\footnotetext{
$\mathrm{a}_{10.16-\mathrm{cm}}(4-\mathrm{in}$.$) -square can.$

$\mathrm{b}_{10.16-\mathrm{cm}}(4-\mathrm{in.})$ by $20.32 \mathrm{~cm}(8-i n.) \mathrm{can}$.

CProposed, probably $10.16-\mathrm{cm}(4-\mathrm{in.})$ by $20.32-\mathrm{cm}(8-\mathrm{in.})$ can.

$\mathrm{d}_{15.24-\mathrm{cm}}(6-\mathrm{in}$.$) -diam test hole,$

$e_{22.86-\mathrm{cm}}(9-\mathrm{in}$.$) -diam test hole.$
} 
than the reference experimental loop for PHOEBUS/UHTREX will not be considered further in this study.

A flowing sodium loop can be either an integral loop as chosen or a package loop as presently commonly used for fewpin fast reactor safety experiments. An integral loop has a removable in-core test region with the rest of the loop system an integral part of the facility. A package loop is a completely self-contained sodium system with in-core test region, pump, sodium plenums, and possibly a heat exchanger in a portable package. The advantages of an integral loop are the disadvantages of a package loop and vice versa. The advantage of a package loop is that it can be used to test preirradiated mixed oxide fuel pins to complete failure with subsequent dispersal of $\mathrm{Pu}$ and fission products throughout the loop. On the other hand, an integral loop can better match actual reactor coolant flow impedances. In addition an integral loop can be much simpler in design, easier and quicker to fabricate, and less expensive. The out-of-pile components of the loop can be reused. The in-pile tube is much smaller and lighter than a package loop and thus is easier to handle and disassemble. In the case of PHOEBUS/UHTREX the advantages of an integral loop are significant.

\section{In-Pile Tube} The in-pile-tube consists of

(1) containment vessel, (2) the flow divider and melt-down cup, (3) the upper plenum simulator, and (4) the top manifold. The in-pile-tube interfaces with the outof-pile systems at the top manifold for coolant, instrument, and heater connections. The test train fits inside the in-pile tube and is inserted prior to the attachment of the top manifold.

An integral loop can have various flow paths in the in-pile-tube. A re-entrant flow through concentric channels was chosen to (1) center the test region in the loop and in the reactor and (2) eliminate the necessity of disconnecting any sodium lines below the test region. A centered test region gives the most symmetric test fuel pin power distribution and provides the smallest amount of material in the beam of the $x$ ray. A U-tube or hairpin loop if oriented perpendicular to the visual viewing slot in the reactor would require either an offcenter slot or, if oriented in the direction of the slot, would have two containment vessels in the beam. In addition the U-tube or hairpin loop has angular power skewing in the test fuel pins. A once-through loop with a disconnect at the bottom has the problem of breaking a sodium connection below a failed fuel region. In a reentrant loop with concentric flow channels, the coolant flow travels down an outer annulus and up through the central test section. Additional flow paths for either downward or upward flow can be created by simply adding extra vessels to make additional annuli. Thus a variety of inlet and bypass flows can be easily accommodated.

The flow divider is an insulated barrier with a neutron filter on the outside. Nichrome heaters are located on both sides of the flow divider. The flow divider separates the coolant downflow from the bypass upflow. The bypass flow cools both the thermal neutron filter and the containment vessel. The containment vessel provides the main pressure containment of the in-pile tube. Some additional containment capability for impulse loads will be provided by the flow divider and melt-through barrier.

Typical dimensions for the inpile-tube and test train are given in Table XII for the in-core experiment region, which was shown in cross section, Fig. 2. The reference experimental loop 
TABLE XII

REFERENCE IN-CORE DIMENSIONS AND SYSTEM PARAMETERS

Experiment Containment Tube

Containment Vessel

Flow Divider

Melt-Through Barrier

127 FTR Type Fuel Pins

Across Flats

Bundle Diameter

In-Pile-Tube

Length

weight

Design Pressure

Design Temperature

Test Train

Length

weight

Out-of-Pile systems

Maximum Flow Rate

Inlet and outlet Reservoir volume

Pump

Heat Exchanger

Design Pressure

Design Temperature
$22.68 \mathrm{~cm} \mathrm{i.d.}$

$20.3 \mathrm{~cm} \mathrm{o.d.}$

$16.5 \mathrm{~cm} \mathrm{i.d.}$

$15.5 \mathrm{~cm} \mathrm{o.d.}$

$15.1 \mathrm{~cm} \mathrm{i.d.}$

$12.7 \mathrm{~cm} \mathrm{o.d.}$

$12.1 \mathrm{~cm} \mathrm{i.d.}$

$9.1 \mathrm{~cm}$

$10.5 \mathrm{~cm}$

$7 \mathrm{~m}$

$1000 \mathrm{~kg}$

$20 \mathrm{MPa}$

$900 \mathrm{~K}$

$4.5 \mathrm{~m}$

$250 \mathrm{~kg}$

$3 \mathrm{~m}^{3} / \mathrm{min}$

$4 \mathrm{~m}^{3}$ each

$0.9 \mathrm{~m}^{3} / \mathrm{min}$

$2.5 \mathrm{~kW}$

$2 \mathrm{MPa}$

$900 \mathrm{~K}$ 
at present is in the conceptual design stage and all numbers are preliminary.

\section{Test Train}

The test train consists of the melt-through barrier, the test fuel pin holder, the test fuel pins, and the test section instrumentation. The melt-through barrier, along with the melt-down cup and upper plenum baffles, protects the in-piletube containment vessel from direct contact with hot or molten fuel. The test fuel pin holder can be designed in many ways. For example it could be a nuclearly heated wall to simulate additional rows of fuel pins, it could be a structural and thermal mock-up of adjoining subassembly walls, or it could be simply an insulated holder. The test instrumentation will measure test section coolant inlet and coolant outlet conditions; that is, the temperature, pressure, and flow at both ends of the test train. Instrumentation within the test train will most likely be thermocouples. Thermocouples in fuel pin spacer wires, along the fuel pin holder, and in the fuel pin structure above and below the active core region of the test will provide a temperature map of the test section during an experiment. Additional instrumentation, external to the in-pile tube and not a part of the test train, will provide the test fuel power history and information on fuel motion.

\section{Out-of-Pile systems}

The out-of-pile part of an

integral loop must provide the proper coolant flow at the desired temperature and pressure during an experiment. The proper inlet flow and pressure can be provided by a pumped system or a blowdown system. The proper inlet temperature can be provided by a heat exchanger or a large enough volume of sodium in the system so that at the maximum flow rate the hot sodium leaving the in-pile-tube does not reenter the in-pile tube during the experimental transient.
For a 127-fuel pin experiment a simple out-of-pile system consisting of a blowdown system with modest-size sodium reservoirs appears to be practical. This selection eliminates the development of a large $\left(1.6 \mathrm{~m}^{3} / \mathrm{min}\right)$ annular linear induction pump (ALIP). It also eliminates the necessity for a large (4.5 MW) heat exchanger and an equally large secondary heat exchanger system. Only a pump and heat exchanger large enough to control preand posttest loop temperatures would be required. Note that in a blowdown system, the coolant flows from a pressurized inlet reservoir through the in-pile tube to an outlet reservoir at a low pressure after the valves are opened during a reactor experimental transient.

The loop cleanup system is used to measure, decrease, and maintain a low oxide content in the loop sodium prior to an experiment. After the experiment, the loop cleanup system will remove fission products, fuel pin plenum gas, and any fuel or steel particles in the sodium so that the in-pile tube can be safely disconnected from the out-of-pile systems.

Heaters will be provided throughout the entire out-of-pile system. The system will be well insulated. Nevertheless, heat losses may be significant enough so that a heat exchanger is not necessary.

B. Experiment Handling

The actual performance of an experi-

ment involves many pre- and posttest

operations. Part of a hypothetical

typical test sequence is outlined in

Table XIII. The following paragraphs discuss various loop support facilities identified from the hypothetical typical test sequence.

\section{Assembly Area}

The assembly area is used to store, inspect, and assemble the components of the in-pile tube and the test train. 
TYPICAL TEST SEQUENCE FOR REFERENCE EXPERIMENTAL LOOP

PRETEST

Design and Fabrication

- Acquire test fuel pins

- Collect instrumentation and other test-train components

- Assemble in-pile tube components

Assemb1y Area

- Check out all components, instruments and fuel pins

- Assemble test train

- Assemble in-pile tube

- Load test train into in-pile tube

UHTREX Building

- Do power calibrations and trial transients

- Check out out-of-pile systems

Sodium Fill Area

- Transport in-pile tube to UHTREX building

- Fill with sodium

PHOEBUS Reactor

- Move in-pile tube to PHOEBUS reactor

- Insert in reactor and connect to out-of-pile systems

- Clear up sodium in system

- Check out total system

- Perform heat balance run

TEST

PHOEBUS/UHTREX

- Check out total system

- Count down for test

- Test

- Analyze on-line data

\section{POSTTEST}

PHOEBUS/UHTREX

- Check out posttest system

- Remove grab samples of sodium and plenum gas and foils

- Clean up sodium in system

- Disconnect in-pile tube from out-of-pile system

Storage Area

- Remove loop from PHOEBUS reactor

- $\gamma$-scan in-pile tube

- Store in-pile tube 
TABLE XIII (cont)

Sodium Fill Area

- Move in-pile tube to sodium fill area

- Remelt and drain sodium

- Possibly remove test train

Sectioning Area

- Move test train or in-pile tube to sectioning area

- Perform visual examination of test train

- Section test train

- Insert sections into $\alpha$-cans

Final Examination Area

- Transport sections to final examination area

- Progressively disassemble sections with macro- and microexamination

- Disposal of analyzed sections

UHTREX Building

- Do final clean up of out-of-pile system

- Disposal of in-pile tube and contaminated sodium

- Analyze data

The area should be near or adjacent to the UHTREX building. A floor area of about 2500 square feet will be needed with a 10-ft-square by 50-ft-high insertion area.

\section{Test-Train Transfer Fixture} The test-train transfer fixture would be used to support the test train as it is moved from a horizontal or vertical position or from a vertical to horizontal position. The fixture would also provide shielded containment if used to move the test train from the sodium fill area to the sectioning area. The fixture would be primarily used to insert and remove a test train from an in-pile tube. As such it would allow test-train rotation in order to provide proper orientation in the in-pile tube.

3. In-Pile-Tube Transfer Fixture The in-pile-tube transfer fixture would be used to transport the in-pile tube from the assembly area to the UHTREX building and to handle the in-pile tube inside the UHTREX building. The fixture would provide containment and some shielding, but would not be a large shielded cask. It would be used to transfer irradiated test fuel only inside the UHTREX building. The fixture probably would be self-contained; that is, a winch would be provided to raise and lower the in-pile tube in and out of the Phoebus core, storage area, and sodium fill area in the UHTREX building. The fixture would be designed to obtain proper radial orientation of the in-pile tube while lowering the in-pile tube into the thimble through the center of the reactor core. The fixture would also provide for motion between horizontal and vertical orientations. 


\section{Storage Area}

The storage area would be used to store irradiated in-pile tubes after an experiment. The radioactivity of the in-pile tubes would be allowed to decay to a reasonably low level of activity before draining the sodium and removing and sectioning the test train. The storage area will be large enough to store several different loops. As the loop is inserted into the storage area it will be gamma-scanned.

\section{Loop Connecting Fixture The loop connecting fixture}

will be used to make and break connections between the in-pile tube and the out-ofpile systems. The fixture will prevent entry of air into the loop while connecting the sodium lines prior to an experiment. The fixture will also prevent the spread of contamination while disconnecting the sodium lines after an experiment. The operations may either be done remotely or be a hands-on procedure using a shielded glove box-type enclosure.

\section{Sodium Fill Area} The sodium fill area is an enclosed vertical pit inside the UHTREX building. The area will have sodium storage tanks and a sodium purifying system. The pit will have heaters for heating and maintaining loop temperatures so that the sodium is molten. The pit will be inerted when sodium is handled. The area will be used for charging the in-pile tube with sodium and for remelting and draining sodium from the in-pile tube. The area may possibly be used for the removal of an irradiated test train from an in-pile tube after an experiment. The area could be used to insert a preirradiated test train into an in-pile tube.

\section{Sectioning Area}

The sectioning area will be used for sectioning and canning pieces of the test train for transportation to the final examination area. This operation is necessary since facilities are not currently available at LASL to disassemble large irradiated and alpha-contaminated loops or test trains. In addition the shipment of large irradiated loops off site is presently impractical. Such shipment would require the building of huge casks and transporters. Sectioning the test train at the UHTREX building is possible due to the shielded nature of the building and presently available shielded windows. Equipment and an inert enclosure (alpha-box) would have to be provided, but new cells would not have to be built. Once the test train is sectioned then the final examination could be performed at LASL.

After draining of the sodium, either the in-pile tube (with the top manifold removed in the sodium fill area) or the test train would be moved in its transfer fixture to the sectioning area. The transfer fixture would be connected to the inert enclosure and the test train rotated into the desired position. The test train would then be pulled, photographed, and sectioned. The sections would be sealed in special containers with inert gas and alpha-seal capabilities. These containers would then be removed from the inert enclosure.

$$
\begin{aligned}
& \text { 8. Transportation and Casks } \\
& \text { Transportation of the in-pile }
\end{aligned}
$$

tubes and casks would be on a standard heavy duty truck. A special loop transporter would not have to be built.

The loop sections would be enclosed in standard alpha-cans. The inside dimensions are $17.78 \mathrm{~cm}$ ( $7 \mathrm{in.)}$ in diameter and $45.72 \mathrm{~cm}$ (19 in.) in length. A shipping cask for section loop components will be provided.

Larger sections could be shipped off site in existing Rover casks. These casks weigh $17700 \mathrm{~kg}$ (39000 lbs) and have a $40.64-\mathrm{cm}(16-\mathrm{in}$.$) square by 157.48-\mathrm{cm}$ (62-in.) long cavity. 


\section{Final Examination Area}

The preferred final examination

area is the LASI Chemistry and Materials Science Division (CMB) wing 9 hot cell facility. In order not to impact existing programs, existing unused hot cells would be outfitted. Presently at CMB Wing 9, single fuel pins irradiated in EBR-II are thoroughly examined. This examination includes visual examination, photography, sectioning, sodium distillation, metallographic examination, and microprobe examination. The sectioned test-train components would be similarly examined. Separate cells are used in wing 9 for the examination of uranium and of plutonium fuel elements.

\section{CONTROI AND OPERATION}

A. Introduction

Presented in this section is a dis-

cussion of the transient parameters of the fuel element test reactor, largely based on its neutronic resemblance to the phoebus-2 reactor tested at the Nuclear Rocket Development station in Nevada.

The Phoebus-2 reactor was operated at the Nevada Test Site for final tests by a rapid approach to design power, a few minutes of steady operation, then fast shutdown by means of a scram. Because the proposed version of that reactor will be operated in a similar manner, but on a shorter time scale under essentially adiabatic conditions, the questions to be answered are: (1) Can reactivity be changed fast enough to fulfill test requirements? (2) Do self-limiting power bursts on this reactor have useful time durations for the test program? (3) Is shutdown reactivity adequate to prevent overheating after a power excursion?

To answer these questions, reactivity control characteristics will be illustrated, and excursion behavior of the reactor predicted within the limitations of possible reactivity control.
B. Control Drum Characteristics

The 16 control drums operated synchronously, provide total reactivity control of $4.38 \%(\Delta K / K)$, or slightly over 6 s. Total and differential worths as functions of drum angular position are shown in Fig. 21. Drums of this type are currently operated in the Parka assembly at LASL where they are driven by electrical stepping motors at angular rates up to $45^{\circ} / \mathrm{s}$ while a scram signal permits springs to drive them toward the least reactive position at $\sim 700^{\circ} / \mathrm{s}$. In Phoebus-2, the drums had hydraulic actuators that developed controlled rates up to $500^{\circ} / \mathrm{s}$. At that rate, the last (slowest) dollar of reactivity can be inserted in less than $0.1 \mathrm{~s}$, while in the region of maximum differential worth the rate is $\sim 26.5 \mathrm{\$} / \mathrm{s}$. The total control of $\sim 6 \$$ can be effected in $0.36 \mathrm{~s}$. C. Prompt Burst Generation

To initiate self-quenching power bursts, it is necessary to increase reactivity to a super-prompt value fast enough to prevent fission heating from effectively preinitiating the excursion. The minimum ramp rates required depend upon the shutdown power level resulting from spontaneous fission, photoneutrons from the beryllium reflector, and any extraneous neutron sources present. The inhour equation, relating equilibrium reactor period and excess reactivity, is useful for estimating the effect of background power level even though the equilibrium periods do not apply precisely to ramp reactivity insertions. The inhour relationship plotted in Fig. 22 is for a delayed neutron fraction of 0.0072 and a prompt neutron lifetime of 40 Hs.

A tolerable fission energy release during the reactivity insertion, for instance, to 0.5 s excess prompt reactivity is that which would reduce reactivity by no more than $0.01 \$$. For the proposed 


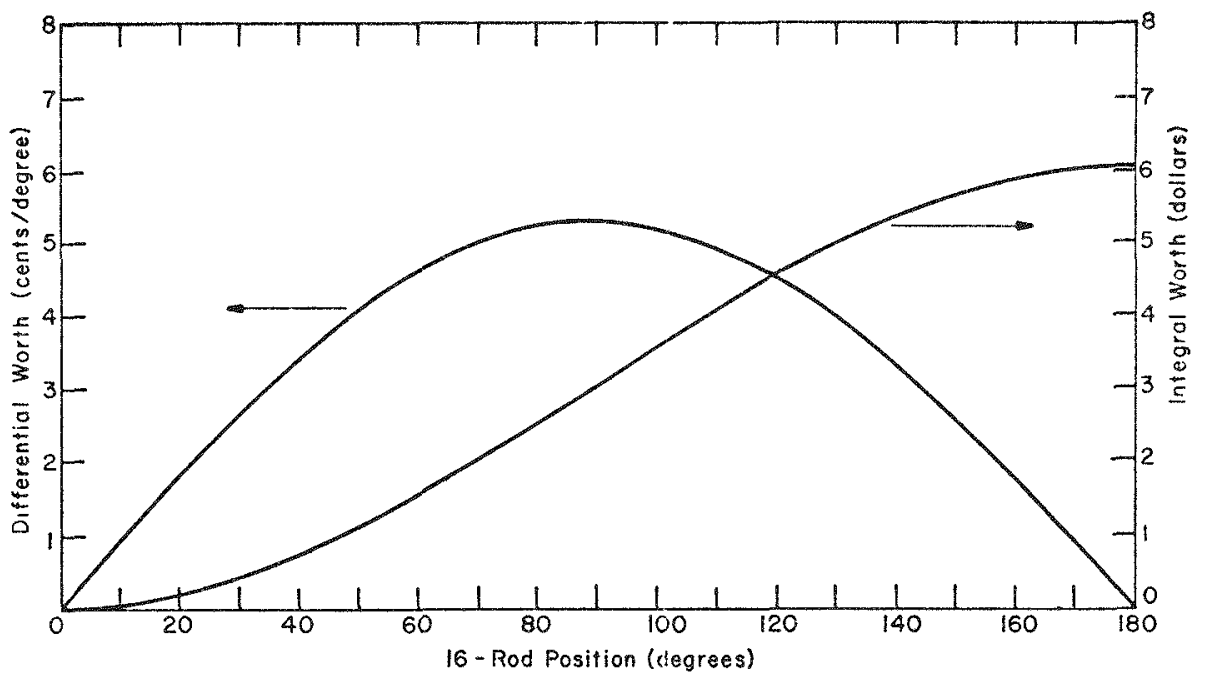

Fig. 21. Total reactivity worth of 16 control drums versus angular position.

reactor, this corresponds to $20 \mathrm{MJ}$. If power had been rising exponentially at the stable period, corresponding to the maximum reactivity attained in the ramp (11 ms from Fig. 22), the instantaneous power at ramp termination would be $20 \mathrm{MJ}$ divided by 0.011 s or 1820 MW.



Fig. 22. Reactor positive period versus excess reactivity in dollars above delayed critical.
In order to estimate the neutron source which would give rise to such a power, we need to estimate the number of power e-foldings that could take place from delayed critical until full reactivity insertion. For this purpose, let us assume reactivity addition at $5 \$ / \mathrm{s}$ from subcriticality to $1.5 \$$ excess. Above prompt criticality, the ramp effectively reduces the stable period of Fig. 22, yielding an average period over this region of order $10 \mathrm{~ms}$. Similarly a period of $0.1 \mathrm{~s}$ is a fair estimate over the region from prompt down to delayed criticality. Dividing insertion times by periods results in a total of 12 power e-foldings from delayed criticality which gives $\sim 11 \mathrm{~kW}$ as the required source power in the neighborhood of delayed criticality. This is many orders of magnitude higher than expected, hence no temperature rise will occur during reactivity insertion. To predict the power profile in a maximum power excursion, a knowledge of reactivity quench parameters is essential. Because the transport calculation of reactivity as a function of temperature is not linear, it is necessary to employ reactivity quench as a function of energy 
release rather than the commonly used temperature coefficient. The predicted function is shown in Fig. 23 where the origin is taken as ambient or $300 \mathrm{~K}$. Using $1200 \mathrm{~K}$ as maximum average core temperature, the excursion must be limited to an energy release of $2.5 \mathrm{~kJ} / \mathrm{cm}^{3}$ which results in a quench of $0.94 \$$. Using a linear approximation for energy quench, features of the maximum burst are

$$
\begin{aligned}
\rho_{\mathrm{O}} & =0.55 \mathrm{\$} \\
\tau & =9.8 \mathrm{~ms} \\
\Delta \mathrm{t}_{\mathrm{h}} & =42.8 \mathrm{~ms} \\
\mathrm{P}_{\mathrm{m}} & =53 \mathrm{~kW} / \mathrm{cm}^{3}
\end{aligned}
$$

Because of the large accumulation of delayed neutron precursors during an excursion, there is a residual (decaying) power of $\sim 0.5 \$ / s$ at $\sim 0.1 \mathrm{~s}$ after burst
Prompt energy release in dollar units*

Initial excess prompt reactivity

Initial positive reactor period

Burst duration at half maximum power

Maximum burst power

$$
\begin{aligned}
& E=0.94 \$ \\
& \rho_{0}=E / 2=0.47 \$ \\
& \tau=11.5 \mathrm{~ms} \text { from Fig. } 23 \\
& \Delta t_{h}=3.52 \tau=40.5 \mathrm{~ms} \\
& P_{m}=E / 4 \tau=17.4 \$ / \mathrm{s}=46.3 \mathrm{~kW} / \mathrm{cm}^{3}
\end{aligned}
$$

* Energy release necessary to change reactivity by one dollar.

Alternatively the quench curve may be approximated by two straight segments to provide a first-order correction. This results in the following slightly improved characteristics for $\mathrm{E}=0.94 \$$ :

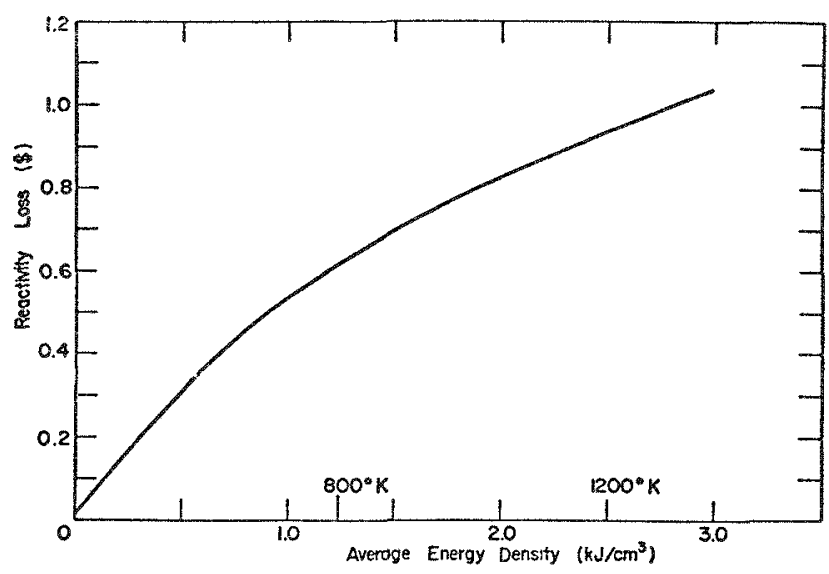

Fig. 23. Reactivity loss as a function of average reactor energy density with no cooling. peak, which in this case corresponds to a heat rate of $\sim 750 \mathrm{k} / \mathrm{s}$. Accordingly, a scram will be programmed to occur soon after the burst peak to prevent afterheat. The effect of this scram is to reduce the prompt multiplication of the delayed neutrons. To estimate this, we assume that prompt criticality occurs with the drums at $\sim 130^{\circ}$ leaving $5 \$$ for shutdown. During the burst, the prompt excess reactivity reduces from $+p_{0}$ to $-p_{0}$, after which the prompt multiplication is $(\rho, \beta)^{-1}$. Following scram, the multiplication becomes $\left[\left(5+2 \rho_{0}\right) \beta\right]^{-1}$ which means that delayed neutron power is reduced by the ratio, $\rho_{0} /\left(5+2 \rho_{0}\right)=0.079$, for the simplified burst approximation and 0.070 for the second evaluation. Scramming therefore will reduce the residual power from $750 \mathrm{~K} / \mathrm{s}$ to about $52.2 \mathrm{~K} / \mathrm{s}$. However, the total delayed neutron energy available is just $\sim 1$ s at the initial multiplication or 0.07 after scram, which translates into a total temperature rise of $107 \mathrm{~K}$ over a time of $1 \mathrm{~min}$. 
D. Constant Preheat Power Operation

Followed by short Burst

Perhaps the most difficult reactor control problem is the reference irradiation experiment involving a preheat stage of $\sim 15 \mathrm{~s}$ followed immediately by a power excursion. This mode will be illustrated by a power profile which deposits about half the maximum available energy at steady state for $15 \mathrm{~s}$ and the remaining half by a burst excursion which is scrammed early to demonstrate a possible scheme to reduce burst duration.

The average temperature will reach $800 \mathrm{~K}$ when $\sim 1.25 \mathrm{~kJ} / \mathrm{cm}^{3}$ are released and reactivity quench should be $\sim 0.62 \$$ from Fig. 23. The steady power necessary is $83.3 \mathrm{~W} / \mathrm{cm}^{3}$ and requires only a slowly varying reactivity up to burst initiation. At that point, the control drums should be adding 0.82 s beyond delayed criticality. This includes the 0.62 from heating with the remainder necessary to account for the nonequilibrium delayedneutron contribution. Since a power burst following this high initial power is not amenable to analytic methods, numerical solutions of the neutron kinetic equations were used to compute power from different reactivity time profiles. For example, Fig. 24 shows a reactivity profile consisting of a positive ramp of $6 \$ / \mathrm{s}$ starting at the end of the preheat cycle and terminating after an increase of 1 , a steady position for $0.03 \mathrm{~s}$, followed by a negative ramp corresponding to a scram rate of $\sim 15 \$ / \mathrm{s}$ with a total scram of 5.3 . Plotted in the same figure is the corresponding power profile as computed.

Total yield in this excursion is $\sim 0.31 \$\left(1.25 \mathrm{~kJ} / \mathrm{cm}^{3}\right)$ at $\sim 10 \mathrm{~s}$ after the burst. As expected, this brings total heating loss up to $0.93 \$$. Peak excursion power is $3.3 \$ / \mathrm{s}$ or $12.9 \mathrm{~kW} / \mathrm{cm}^{3}$ from Fig. 23. Residual power is computed to be $0.0023 \mathrm{\$} / \mathrm{s}$ or $\sim 3 \mathrm{~K} / \mathrm{s}$ after $10 \mathrm{~s}$. A

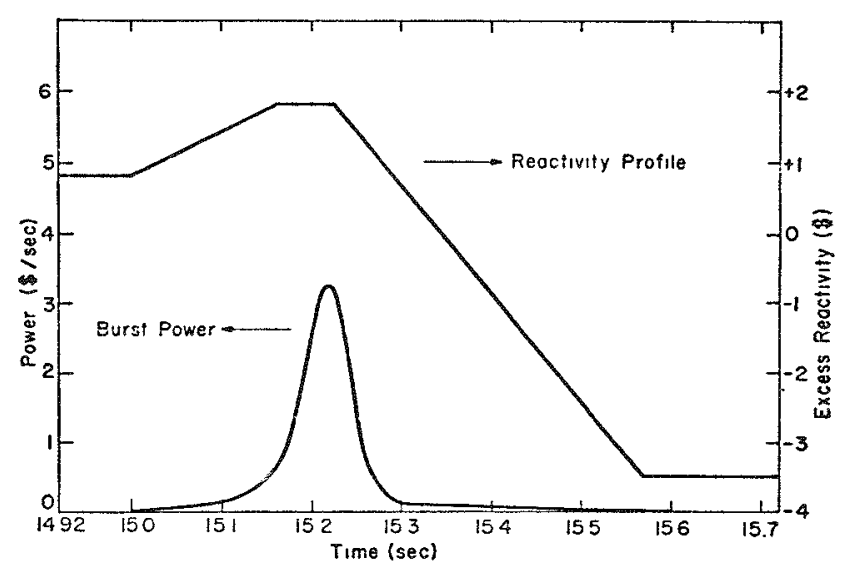

Fig. 24. Reactivity and power profiles.

delay of $5 \mathrm{~ms}$ in the scram ramp initiation was found to increase burst yield by 14\%, or $56 \mathrm{~K}$ temperature increase. (This was the observed time uncertainty in hydraulic drum operation with Phoebus-2.) Residual power is somewhat easier to quench for this profile because many short-lived precursors have decayed during the 15-s power operation.

\section{E. Conclusions}

Bursts can be developed with durations down to $\sim 43 \mathrm{~ms}$ with conservative control drum speeds. The preheat power for $15 \mathrm{~s}$ followed by a burst can be accomplished with control drums at about two-thirds the angular speeds which have been used on the early Phoebus-2. Shutdown reactivity is adequate to limit afterheating to $\sim 100 \mathrm{~K}$ temperature increase which may be of no significance since it is deposited over a period of 1 min.

VIII. FUEL MOTION DIAGNOSTIC INSTRUMENTATION

A. General

This section contains a discussion of the proposed techniques for providing the required monitoring of experimental fuel motion. We will emphasize the needs of the reference experiment in this discussion, but we expect that the resulting 
instrumentation will have general applica-

tion to a wide range of experiments.

One of the major justifications for

the PHOEBUS/UHTREX project is its role in developing and evaluating instrumentation for the next phase in safety Test Facilities (SAREF, Super-TREAT). The time scale for PHOEBUS/UHTREX is such that instrumentation developed in it is available for these longer term facilities. Certainly diagnostic techniques are an important element in establishing any major safety Test Facaility (STF) and it is not conceivable that we can afford to wait until completion of these facilities to test out diagnostic instrumentation effectiveness. On the other hand, monitoring of the behavior of fuel, clad, and sodium in full-scale tests appears so difficult that a development program will require realistic simulation of conditions. There is no assurance that any of the proposed diagnostic instrumentation techniques can furnish acceptable resolution in space and time for extreme transients in multipin arrays larger than subassembly size. For the intermediate class of experiments proposed for the PHOEBUS/UHTREX facility, we believe that flash $x$ ray is an apt diagnostic technique that will provide the information required to carry out meaningful experiments. At the same time these experiments will provide a test bed for developing and evaluating other techniques. Any one instrumentation concept does not appear to be the universal tool for providing the necessary information for the wide range of experiments contemplated for a safety Test Facility. For the extreme transient, when power in test fuel pins may be as high as $10^{6} \mathrm{~W} / \mathrm{g}$ of fuel, gamma and neutron levels from fission provide a source that makes the hodoscope and coded aperture viewing feasible, providing the viewing can penetrate the multipin arrays of interest. At these extreme fission rates, the background may be too large to permit flash $x$-ray measurements. In other tests, which may be even more pertinent to fast reactor safety (such as loss-of-flow), the test fuel fission rates during the times of interest may be down by orders of magnitude. As a result, hodoscope or coded aperture measurements may be impractical, but conditions will be very good for flash $x$-ray imaging.

The various diagnostic instrumentation concepts have been described in some detail in LA-5978-MS ${ }^{1}$ and we will restrict our discussion here to application of these techniques to proposed PHOEBUS/ UHTREX experiments. Recent experiments have shown that a modern linear accelerator used as an x-ray source will provide adequate intensity and that the desired space and time resolution can be attained. We will also provide the capability for inclusion of the hodoscope or coded aperture imaging equipment. In fact, we intend to take advantage of the PHOEBUS/ UHTREX facility to evaluate these methods for multipin diagnostics. An x-ray detection system making use of a collimator to reduce backgrounds by orders of magnitude is discussed as an alternate to an electro-optical imaging system.

Flash $x$ ray requires that a slot extend completely through the driver reactor. The slot size is determined by the fuel pin array size and the distance of the $x$-ray source from the test capsule. The hodoscope and coded aperture methods require a slot extending through only half of the driver. Simple solid angle and fission density considerations show that for the proposed $x$-ray system, the background radiation from fuel pin fissions is large compared with the background from the driver reactor reaching the detector through the slot. Any of the diagnostic techniques will require good shielding of the instrumentation detector area from the driver reactor.

It is proposed to use half of the present UHTREX reactor bay as a shielded instrumentation room by erecting a shield 
wall in the approximate center of the bay. This wall would be penetrated by the slot required for instrumentation. On the other side of the driver reactor the containment will be penetrated to accommodate the $x$-ray source. This is shown in the plan view of Fig. 8 (Sec. III).

The reference experiment has been defined as an array of 127 pins driven at $200 \mathrm{w} / \mathrm{g}$ of fuel for $15 \mathrm{~s}$, followed by a burst of $2000 \mathrm{~J} / \mathrm{g}$ in $0.1 \mathrm{~s}$. Total energy is thus $5000 \mathrm{~J} / \mathrm{g}$ and peak power is about $20000 \mathrm{~W} / \mathrm{g}$ of highly enriched $\mathrm{UO}_{2}$ fuel. For such an experiment, the desired spatial resolution is $5 \mathrm{~mm}$ radially and $25 \mathrm{~mm}$ axially (acceptable resolution distances could be somewhat greater than this). The desired time resolution of $0.01 \mathrm{~s}$ should not be difficult to realize. The desired field of view is the width of the fuel assembly and about $1.2 \mathrm{~m}$ (4 ft) axially. This last requirement appears to be the most difficult one to meet. In addition to the 1.2-m field of view, information is desired at further distances along the test vehicle in regard to fuel motion into these regions. B. Flash X-Ray Cinematography

Flash $x$-ray cinematography is being considered as the prime diagnostic technique for use with the PHOEBUS/UHTREX facility. As currently conceived, the system will consist of an external pulsed $x$-ray source located $3 \mathrm{~m}$ from the reactor center and an electro-optical imaging detector at a corresponding position on the opposite side of the reactor. A $\$ 20-\mathrm{mm}-$ wide diametrical slot through the reactor core will be provided to allow a reasonably clear view of the material in the control test region. Extraneous radiation at the detector will be avoided by careful design of the collimator and shielding associated with the transverse viewing slot. Certain materials such as the containment vessels for the test array and the driver reactor would necessarily be in the $x$-ray path, but other structural components which would attenuate and scatter the $\mathrm{x}$ rays will be minimized.

Flash x-ray cinematography was first proposed in LA-5978-MS ${ }^{1}$ as a diagnostic tool for STF tests. Preliminary assessment of the method was provided for that report by experiments carried out with the 30-MeV PHERMEX pulsed $x$-ray generator. Fast reactor fuel pins were unavailable at the time so $x$-ray pictures were made of arrays of larger PWR fuel pins. Containment vessels were simulated with appropriate thickness of steel. The investigation demonstrated both the capabilities and limitations of flash $x$ ray in this application. Radiographs on film showed that the desired penetration and spatial resolution were obtainable for arrays as large as 217 of the smaller fast reactor fuel pins (subassembly size). It appeared, however, that for larger arrays the background of scattered $x-$ radiation was effectively dominating the transmitted $x$-ray signal. Preliminary experiments ${ }^{8}$ using a fluor-image intensifier-vidicon imaging system indicated that the background neutron and gamma radiation from the fissioning fuel pin array would be tolerable, that detection sensitivities with such an electro-optical viewer were comparable with sensitive $x$-ray film, and that the desired temporal resolution could be obtained.

More recently, experiments have been directed specifically at the PHOEBUS/ UHTREX instrumentation requirements and, in particular, at establishing the parameters for an electron accelerator capable of satisfying these requirements. In this regard, we assembled an array of 127 fast reactor fuel pins in $41 \mathrm{~mm}$ of steel to simulate the PHOEBUS/UHTREX reference experiment. These fuel pins contain enriched $\mathrm{UO}_{2}$ instead of mixed oxide. PHERMEX flash $x$-ray exposures $(0.2 \mu s)$ were then made of this geometry, both on film and with a fluor-image intensifier-vidicon 
system. A reproduction of the film radiograph in Fig. 25 readily shows a 25-mm-long void region in the central fuel pin. In this exposure the $\mathrm{x}$-ray beam penetrated across the flats of the fuel pin hexagon. For the electro-optical imaging experiment, the vidicon signal was stored on magnetic tape and later displayed on a television monitor. A photograph of this TV image in Fig. 26 shows clearly the rows of fuel pins when the $x$-ray beam is incident on an apex of the fuel pin array. However, more effort is needed to optimize the electro-optical imaging capabilities. The radiograph in Fig. 25 includes a superimposed background that has been adjusted to be equivalent to that expected from 127 fuel pins at a power level of $20000 \mathrm{~W} / \mathrm{g}$ of fuel. This background determination is based on comparison of coupled neutron-gamma calculations on Godiva and on a 217-fuel pin array, with

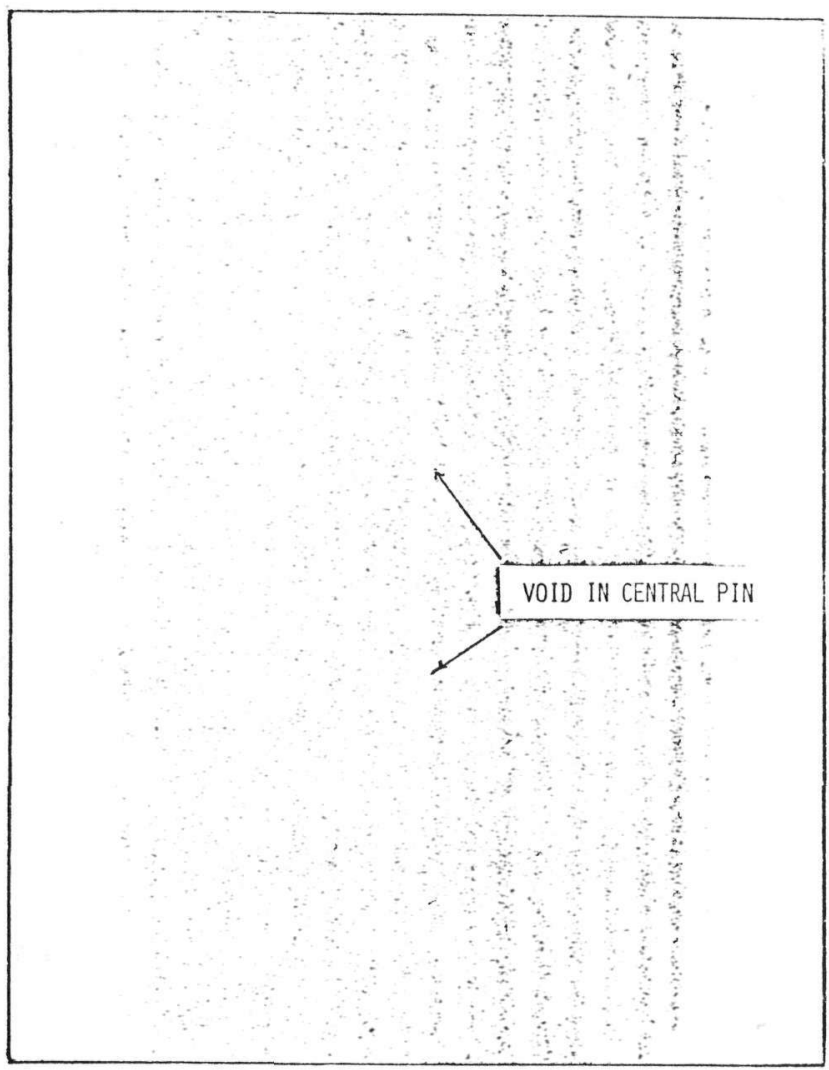

Fig. 25. Radiograph of 127 fuel pins in $41 \mathrm{~mm}$ of steel looking at flats of hexagon.

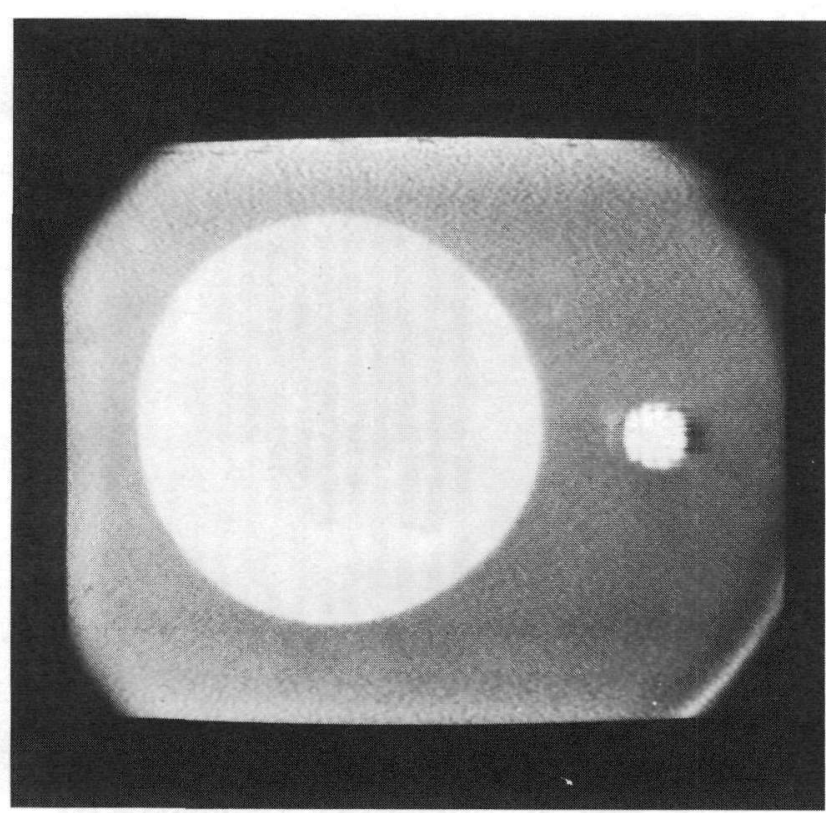

Fig. 26. Photograph of TV image of 127 fuel pins in $29 \mathrm{~mm}$ of steel looking at apex of hexagon (a calibrated light source image appears at the right).

and without $51 \mathrm{~mm}$ of surrounding steel in both cases. Fortuitously, the leakage spectrum from Godiva surrounded by steel is almost identical to that from the fuel pin array surrounded by steel. The major difference is a factor of 3 less leakage from Godiva. For dubbing in the background on the PHERMEX film we have assumed that the computed 217-fuel pin case applies to our 127-pin geometry, and that the background exists during a 2- $\mu$ slong $x$-ray burst. Godiva was operated for $4300 \mathrm{~W}-\mathrm{s}, 3 \mathrm{~m}$ from the undeveloped PHERMEX exposure in order to simulate the effect of the fuel pin background. Data are shown in Table XIV for the calculated gamma leakage from Godiva and the fuel pin array.

The studies discussed above indicate that satisfactory radiographs at the desired repetition rate $(100 \mathrm{~Hz})$ would be obtained with existing electro-optical imaging systems and a pulsed electron accelerator of modern design. Characteristics of the proposed system are given in Table XV. 
TABLE XIV

CALCULATED FUEL PIN ARRAY GAMMA LEAKAGE AND GODIVA SIMULATION

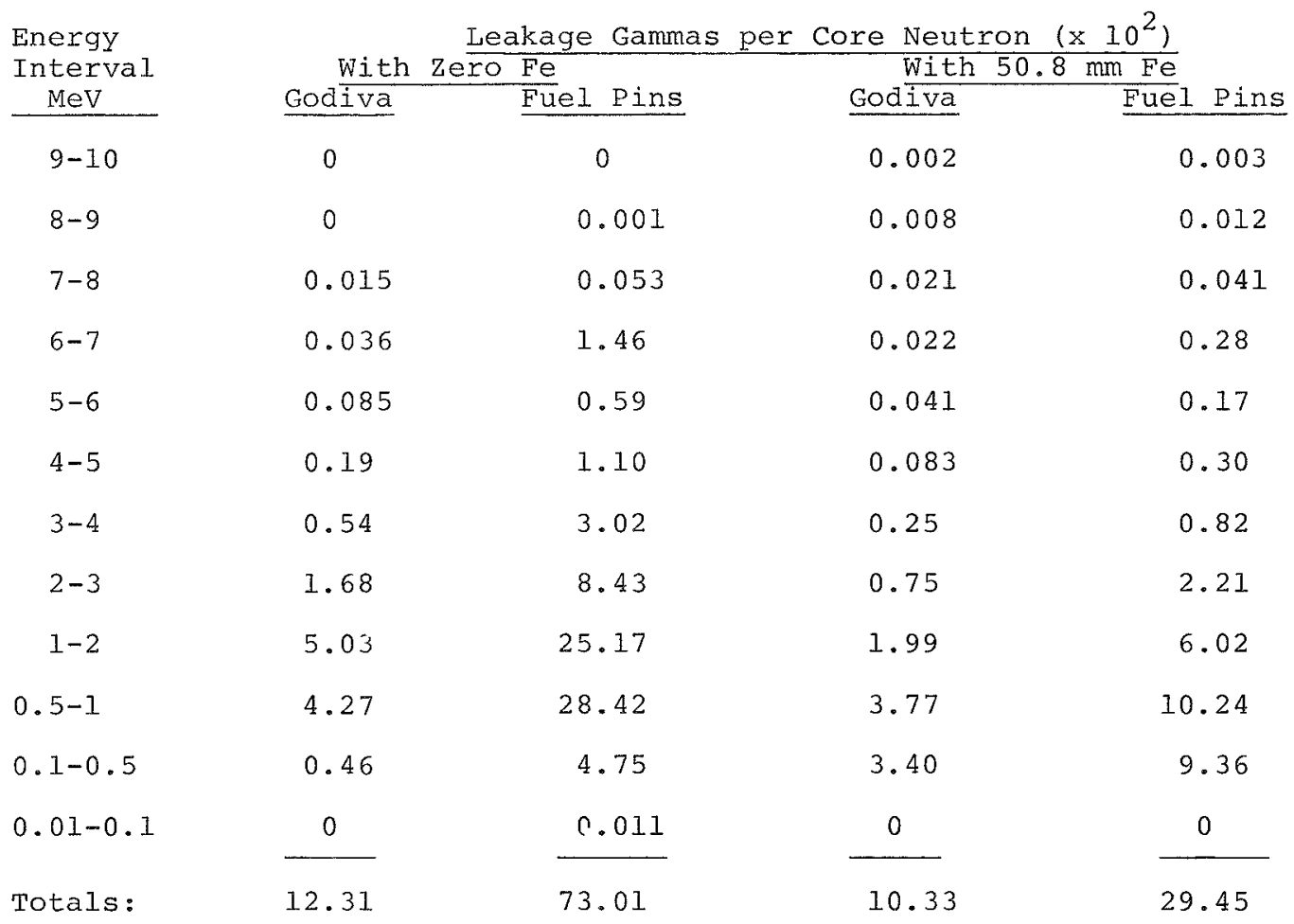

TABLE XV

CHARACTERISTICS OF FLASH X-RAY DIAGNOSTIC SYSTEM

\section{$\underline{X-R a y ~ S o u r c e}$}

Electron energy

$30 \mathrm{MeV}$

Peak current

2 A

Pulse duration

Charge per pulse

Pulse repetition rate

\section{Imaging System}

Gated image intensifier

Silicon tube vidicon

Gain $\leq 10^{4}$

$8 \mathrm{~ms} /$ frame

Video tape recorder

Monitor

Frame grabber
An electron linac developed and built at LASL provides an ideal prototype of the required accelerator. The linac is of a new design based on the side-coupled, standing wave accelerator principles developed for the LAMPF proton accelerator. Performance tests indicate that this type of accelerator will adequately satisfy the requirements of the $x$-ray source. The very high shunt impedance ( $60 \mathrm{M} \Omega / \mathrm{m}$ ) and high beam loading ( $>80 \%$ ) contribute to extremely efficient accelerating structures and therefore a low cost accelerator. To attain the desired $30-\mathrm{MeV}$ electron energy for this STF application, four accelerating tanks, each $1 \mathrm{~m}$ long, and 4 rf sources will be required. Detailed parameters of the accelerator are given in Table XVI. The electro-optical imaging system will consist of a thin scintillator which 
TABLE XVI

DETAILED PARAMETERS OF FLASH X-RAY ACCELERATOR

\begin{tabular}{|c|c|}
\hline Frequency & $1300 \mathrm{MHz}$ \\
\hline Injection energy & $100 \mathrm{keV}$ \\
\hline Buncher & Single cavity \\
\hline Accelerator tanks: & Side-coupled, standing-wave \\
\hline Energy gradient & $7.5 \mathrm{MeV} / \mathrm{m}$ \\
\hline Shunt impedance & $60 \mathrm{M} \Omega / \mathrm{m}$ \\
\hline Length & $1 \mathrm{~m} / \mathrm{tank}$ \\
\hline Number & 4 tanks \\
\hline Beam loading & $85-90 \%$ \\
\hline Number of klystron stations & 4 \\
\hline Peak rf power/klystron & $16 \mathrm{MW}$ (20-MW tube derated to $80 \%)$ \\
\hline Focusing & Quadrupole between tanks \\
\hline Overall accelerator length & $11 \mathrm{~m}$ \\
\hline \multicolumn{2}{|l|}{ Pulse duration: } \\
\hline Klystron cathode & $4 \mu \mathrm{s}$ \\
\hline Radio frequency & $3 \mu \mathrm{s}$ \\
\hline Electron & $2 \mu \mathrm{s}$ \\
\hline Peak beam power/accelerator tank & $15 \mathrm{MW}$ \\
\hline Peak cavity power dissipation & $1 \mathrm{MW}$ \\
\hline Repetition rate & $100 \mathrm{~Hz}$ \\
\hline Average klystron power & $6 \mathrm{~kW}$ \\
\hline \multicolumn{2}{|l|}{ Total beam power: } \\
\hline Peak & $60 \mathrm{MW}$ \\
\hline Average & $12 \mathrm{~kW}$ \\
\hline
\end{tabular}

converts the $\mathrm{x}$-ray radiograph to an optical picture that is viewed by an image intensifler coupled to a silicon vidicon. The image intensifier will be gated to provide a shutter-open time of a few microseconds during the $x$-ray flash. To provide additional coverage along the axial length of the fuel pins under test, more than one imaging system may be required.
Switching the beam alternately to multiple targets has been considered, but would not be planned for the initial operation. It appears feasible to have three targets (one on axis and one each above and below the axis) and to switch the beam between pulses at nearly a 400-pps rate. In this configuration the $\mathrm{x}$-ray pulse sequence would be as follows: the first pulse from the target on axis, the second from the upper target, the third 
pulse from the on-axis target, and the fourth pulse from the below-axis target. This sequence would then be repeated for the desired test duration without exceeding the average power capability of the rf systems. Three imaging systems, each equipped with at least $2: 1$ anamorphic lenses properly synchronized and viewing the $\mathrm{x}$-radiograph from the respective target would cover the entire 1.2-m-long test assembly.

c. Application of a Multiple-slit Collimator for PHOEBUS/UHTREX Diagnostics

1. Introduction

Another possibility being con-

sidered as a diagnostic technique to monitor fuel motion during PHOEBUS/UHTREX experiments is an $\mathrm{x}$-ray collimatordetector. Unlike the type of instrument used on TREAT which detects nuclear radiation from "fluorescing fuel", the $x$-ray collimator would respond to the bremsstrahlung signal from an electron accelerator as shown in Fig. 27. By having each slit of the x-ray collimator aimed at the $x$-ray source, quantitative measurements of areal fuel density in the view of a particular slit would be obtained by monitoring the amount of $x$-ray absorption and scattering at the end of the given slit. This change in emphasis, from monitoring the radiation from fluorescing fuel to measuring the amount of attenuation experience by an externally generated high energy bremsstrahlung spectrum has several significant advantages: (1) the signal level can, in principle, be adjusted to overcome the background and thus provide a good signal-to-background ratio, (2) the signal level at the detector plane is dependent upon the areal density of the fuel and independent of the power density, making image recreation of the areal fuel density possible at all power densities, (3) with fast detectors the relatively small gamma background can be measured in situ and read out during the intervals between $x$-ray pulses, and (4) the transmitted bremsstrahlung signal

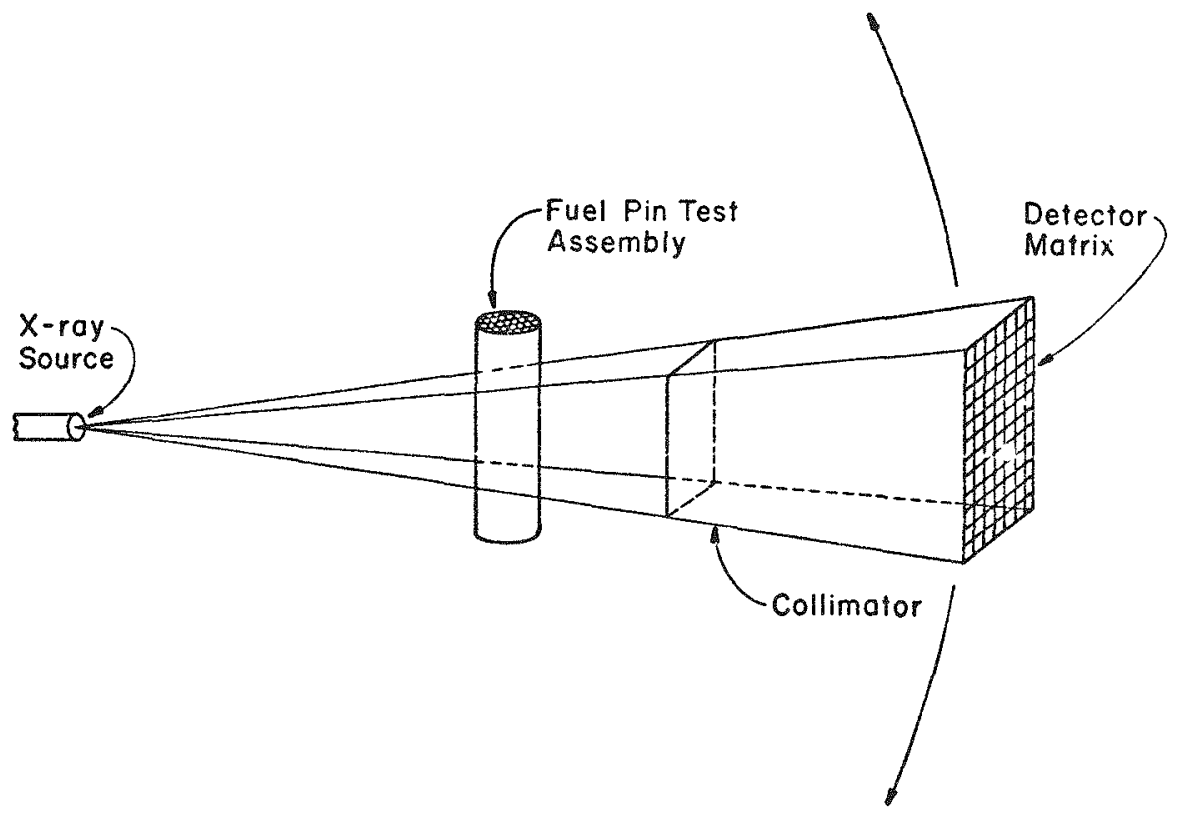

Fig. 27. Flash x-ray collimator-detector. 
need only change by approximately an order of magnitude, eliminating the need for a wide dynamic range detector/data readout system.

In addition to the above advantages, the $x$-ray collimator retains the two best features of the conventional neutron hodoscope, that is, good spatial resolution and detector shielding. In short, the x-ray collimator combines the good features of the conventional neutron hodoscope with the many advantages provided by flash radiography. A summary of the special requirements of the $x$-ray collimator is included in the following section.

\section{Facility Requirements}

The two prime facility requirements of the $x$-ray collimator are the same as those of flash radiography: (a) a slot extending completely through the driver core and environmental shield and (b) an electron accelerator of sufficient energy and intensity to overcome the reactor background. The $x$-ray collimator would probably be 1- to $2-\mathrm{m}$ long and be positioned outside of the driver core to avoid problems in that environment, but within the environmental shield in order to get as close to the viewing region as possible.

A determination of the optimum peak energy and required current of the electron accelerator for an $x$-ray collimator-detector awaits further investigation. However, for good areal mass sensitivity measurements it is advisable that the bremsstrahlung intensity/unit area at the detector plane be at least an order of magnitude larger than the highest possible background from the test fuel pins and driver reactor. It is therefore necessary to estimate the gamma background at the detector plane produced by a 127-pin array at a power density of $2 \times 10^{4} \mathrm{~W} / \mathrm{g}$, and compare this background with the transmitted bremsstrahlung signal produced by a 30-MeV electron accelerator producing $4 \mu \mathrm{C}$ in a pulse length of $2 \mu \mathrm{s}$. In the sections below we present these estimates for a nominal collimator.

3. Gamma Background From Test Fuel The number of core neutrons/s

generated in a $2000 \mathrm{~J} / \mathrm{g}, 0.1-\mathrm{s}$ burst involving 127 pins ( $22 \mathrm{~kg}$ of fuel) is $3.6 \times 10^{19}$ (assuming $3.3 \times 10^{10}$ fissions/J and 2.5 neutrons/fission). The fraction of leakage gammas per core neutron from a fissioning fuel pin array is given in Table XIV. For present considerations, we will assume that the gamma leakage per neutron for 217 fuel pins in $50.8 \mathrm{~mm}$ of iron is similar to that from a 127-pin array in $38 \mathrm{~mm}$ of steel. These leakage values appear in column two of Table XVII and the resulting leakage gammas/s are given in the third column.

As a result of the proposed collimation, a detector point can no longer see the entire fuel pin source, but only that fraction defined by a single channel. For example, if the entire fuel pin array is viewed by a matrix of 500 channels, then each detector sees approximately $1 / 500$ of the total gamma background (on the average). For estimating background,this fraction can be considered to be a point source, with the detector array located at 3-m distance. Gamma backgrounds at the detector plane for a 2-us-long pulse, presented in column four of Table XVII have been estimated on this basis.

4. Bremsstrahlung Signal

The spectral distribution of a bremsstrahlung signal at the detector plane produced by a $4-\mu \mathrm{C}$ pulse machine operating at $30 \mathrm{MeV}$ electron energy can be approximated by transmitting a thintarget bremsstrahlung spectrum (see Fig. 2 from Ref. 9) through a $4 \mathrm{~g} / \mathrm{cm}^{2}$ tungsten target, projecting the radiation into a spatial cone (due to the forward peaking), transmitting this signal through the test array, and finally projecting it onto the detector plane. The resulting 


\begin{tabular}{cl} 
energy, MeV & $\begin{array}{l}\text { gamma leakage } \\
\text { per neutron }\end{array}$ \\
\hline $9-10$ & $3.6 \times 10^{-5}$ \\
$8-9$ & $1.2 \times 10^{-4}$ \\
$7-8$ & $4.0 \times 10^{-4}$ \\
$6-7$ & $2.8 \times 10^{-3}$ \\
$5-6$ & $1.7 \times 10^{-3}$ \\
$4-5$ & $3.0 \times 10^{-3}$ \\
$3-4$ & $8.2 \times 10^{-3}$ \\
$2-3$ & $2.2 \times 10^{-2}$ \\
$1-2$ & $6.0 \times 10^{-2}$ \\
$0.5-1$ & $1.0 \times 10^{-1}$
\end{tabular}

total leakage gammas/second

$1.3 \times 10^{15}$

$4.3 \times 10^{15}$

$1.4 \times 10^{16}$

$1.0 \times 10^{17}$

$6.1 \times 10^{16}$

$1.1 \times 10^{17}$

$3.0 \times 10^{17}$

$7.9 \times 10^{17}$

$2.2 \times 10^{18}$

$3.6 \times 10^{18}$ gammas $/ \mathrm{cm}^{2}$

per $2 \mu s$ at detector

6.9

$2.3 \times 10^{1}$

$7.4 \times 10^{1}$

$5.3 \times 10^{2}$

$3.2 \times 10^{2}$

$5.8 \times 10^{2}$

$1.6 \times 10^{3}$

$4.2 \times 10^{3}$

$1.2 \times 10^{4}$

$1.9 \times 10^{4}$ bremstrahlung intensity spectrum deduced from PHERMEX is shown in Fig. 28. Assuming the spatial distribution within the intensity cone ( $\sim 0.1$ rad half angle at $30 \mathrm{MeV}$ ) to be gaussian for all energies, the number of photons $/ \mathrm{cm}^{2}-s$ incident upon an area corresponding to the base of the cone can be determined as a function of energy. Because the distance between the bremsstrahlung tungsten target and the detector plane is $6 \mathrm{~m}$, a 0.1 -rad intensity half angle would result in an exposed area of $1.1 \times 10^{4} \mathrm{~cm}^{2}$. Taking values obtained by numerical integration of Fig. 28, a sample calculation for the 9 - to $10-\mathrm{MeV}$ energy band indicates an $\mathrm{x}-$ ray intensity of $7 \times 10^{7} \mathrm{x}$-ray photons $/ \mathrm{cm}^{2}$ from the 2- $\mu \mathrm{s} x$-ray pulse. If this signal is now transmitted through $75 \mathrm{~mm}$ of steel container wall and a homogenized mixture of $\mathrm{UO}_{2}$, steel, and sodium corresponding to the 127-pin array, the intensity at the detector plane becomes about $1.4 \times 10^{6}$ $x$-ray photons $/ \mathrm{cm}^{2}$. This result and the

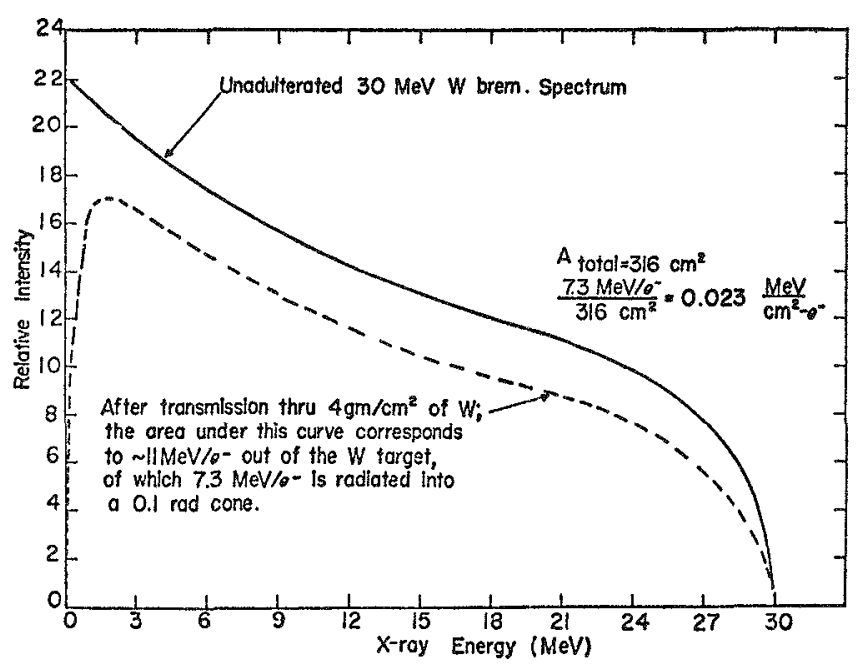

Fig. 28. Effective bremsstrahlung energy spectrum from PHERMEX.

values for the other energy groups are presented in Table XVIII, along with the $x-r a y$ signa1-to-gamma background ratio. Bremsstrahlung energies above $10 \mathrm{MeV}$ have not been considered. 
BREMSSTRAHLUNG SIGNAI AT $6 \mathrm{~m}$ FROM SOURCE TRANSMITTED THROUGH $75 \mathrm{~mm}$ OF STEEL AND A HOMOGENIZED 127-PIN ARRAY

\begin{tabular}{cll}
$\begin{array}{c}\text { Energy } \\
\text { MeV }\end{array}$ & & $\begin{array}{c}\text { Trans. steel } \\
\text { Eraction }\end{array}$ \\
\hline $9-10$ & & $1.41 \times 10^{-1}$ \\
$8-9$ & & $1.38 \times 10^{-1}$ \\
$7-8$ & & $1.38 \times 10^{-1}$ \\
$6-7$ & & $1.29 \times 10^{-1}$ \\
$5-6$ & & $1.25 \times 10^{-1}$ \\
$4-5$ & & $1.13 \times 10^{-1}$ \\
$3-4$ & $9.87 \times 10^{-2}$ \\
$2-3$ & $7.44 \times 10^{-2}$ \\
$1-2$ & $3.73 \times 10^{-2}$ \\
$0.5-1$ & $3.93 \times 10^{-3}$
\end{tabular}
Trans. fuel
hom. array
$1.41 \times 10^{-1}$
$1.49 \times 10^{-1}$
$1.53 \times 10^{-1}$
$1.57 \times 10^{-1}$
$1.59 \times 10^{-1}$
$1.57 \times 10^{-1}$
$1.52 \times 10^{-1}$
$1.34 \times 10^{-1}$
$0.77 \times 10^{-1}$
$1.43 \times 10^{-3}$

\begin{tabular}{|c|c|}
\hline $\begin{array}{l}\mathrm{X} \text {-rays } / \mathrm{cm}^{2} \\
\text { during } 2-\mu \mathrm{s} \\
\quad \text { pulse } \\
\end{array}$ & $\frac{x-r a y \text { signal }}{\text { r-ray background }}$ \\
\hline $1.37 \times 10^{6}$ & $2.0 \times 10^{5}$ \\
\hline $1.68 \times 10^{6}$ & $7.3 \times 10^{4}$ \\
\hline $1.96 \times 10^{6}$ & $2.6 \times 10^{4}$ \\
\hline $2.36 \times 10^{6}$ & $4.5 \times 10^{3}$ \\
\hline $2.83 \times 10^{6}$ & $8.8 \times 10^{3}$ \\
\hline $3.23 \times 10^{6}$ & $5.6 \times 10^{3}$ \\
\hline $3.66 \times 10^{6}$ & $2.3 \times 10^{3}$ \\
\hline $3.51 \times 10^{6}$ & $8.3 \times 10^{2}$ \\
\hline $1.69 \times 10^{6}$ & $1.4 \times 10^{2}$ \\
\hline $2.83 \times 10^{3}$ & $1.5 \times 10^{-1}$ \\
\hline
\end{tabular}

The transmitted signal values presented in Table XVIII assume that a photon which has suffered an interaction with the steel, sodium, or fuel is lost. This assumption is reasonable for the $x$-ray collimator, because of its excellent spatial resolution. Indeed the image obtained would be sharpened over that which could be obtained otherwise, because photons scattered forward by the fuel would be largely eliminated, and hence unable to contribute to the background at the detector plane. However, photons which are scattered by the collimator into the detectors would contribute some background.

It appears that $x-r a y$ viewing across the flats of the hexagonal fuel array is desirable because of the more uniform distribution of mass and less extreme absorption of the $\mathrm{x}$ rays. It is reasonable to assume homogenized fuel for calculations of $x$-ray attenuation since it is expected that some shifting and oscillation in position will occur during an energetic test.

\section{5. x-ray Collimator Detector Signal Levels \\ It is apparent from Table XVIII}

that excellent $x$-ray signal-to-gamma background ratios can be obtained using an $x$-ray collimator in conjunction with an electron accelerator of 2- $\mu$ s pulse length producing $4-\mu \mathrm{C}$ pulses. Indeed these excellent signal-to-background ratios suggest that the $\mathrm{x}$-ray collimator-detector is capable of viewing large axial lengths of fuel pins at off-axis positions where the forward peaked $x$-ray intensity may be at least an order of magnitude lower. For such an off-axis position the signal/background would be 210 , with a photon intensity in the region of interest (2-4 Mev) of $210^{5} \mathrm{x}$-ray photons/ $\mathrm{cm}^{2}$-pulse. The analog signal that can be obtained from this relatively low off-axis intensity can be estimated. As an example, assume 1-MeV $\mathrm{x}$-rays are incident on a 1 -cm-thick 
NaI(T1) scintillator. The efficiency of converting the energy incident on the crystal to blue light incident on the photocathode of a photomultiplier (PM) tube is $2.5 \times 10^{-3}$ (see Ref. 10). The efficiency of then converting this blue light into photoelectrons is $\sim 4 \times 10^{-2}$ for a typical PM tube. Thus for $10^{5} 1-\mathrm{MeV}$ $x$-ray photons/pulse incident on the scintillator, we have $210^{7}$ photoelectrons/ pulse from the anode during the 2-us time. This corresponds to a pulse current of $8 \mathrm{~mA}$ and a statistical accuracy of $0.03 \%$. In short, a modest detector system used in conjunction with the $x$-ray collimator is adequate to image fuel in off-axis positions where the forward peaked $x$-ray signal is reduced by an order of magnitude. Further, the high sensitivity and the discrimination against background of this collimatordetector system would appear to make diagnostic measurements feasible for subassembly-size arrays of fuel pins. In addition, it should be possible to measure the gamma background between $x$-ray bursts. This measured gamma background, which could be integrated over times long compared to $2 \mu \mathrm{s}$, would then provide gamma hodoscope type of information and may be useful diagnostically in itself.

Although we have not addressed data acquisition techniques for the $x-r a y$ collimator in this report, processing or storing 500 channels of data in $10 \mathrm{~ms}$ is relatively straightforward can be accomplished in a number of ways.

\section{Sensitivity for Detecting Fuel Density Changes \\ The mass sensitivity of the}

$x$-ray collimator for maximum burst conditions in which a 127-pin array is being observed can be estimated by considering the increase in signal intensity at the detector plane which would result from a given amount of fuel being removed from in front of a particular slit. From
Table XVIII the fraction of $x$-ray signal transmitted (at $3 \mathrm{MeV}$ ) through the homogenized array is $21.5 \times 10^{-1}$. A $1 \%$ change in the $\mathrm{UO}_{2}$ areal fuel density would produce about a $1 \%$ change in the transmitted signal provided the scattered background is relatively small. Thus a $1 \%$ change in areal fuel density appears to be within the monitoring capability of the collimator-detector system.

\section{Summary}

Estimates have been made which indicate that an $x$-ray collimator driven


pulse, $30-\mathrm{MeV}$ electron accelerator has sufficient sensitivity to detect areal mass density changes as small as $1 \mathrm{~g} / \mathrm{cm}^{2}$ with a signal-to-background ratio of 100 under the maximum burst conditions obtainable from test fuel in the PHOEBUS/ UHTREX reactor. This excellent signalto-background with a relatively modest detector system suggests that higher test fuel power densities, larger arrays, and off-axis viewing would also be within reach of the system with little or no modification. In addition, the technique can be used either alone or simultaneously with other detector methods. The lower background and high spatial resolution afforded by the collimator, and the fact that in situ background measurements can be made between $x$-ray pulses are some of the most important features of this technique.

The principal disadvantages of the $x$-ray collimator are that many data channels are needed, image recreation is more involved, and the alignment of the collimator slits with respect to the test fuel and beam spot is critical. In addition, slit-edge scattering may contribute to the $x$-ray background.

D. Backup Fuel Motion-Monitoring Systems The neutron hodoscope and coded aperture imaging systems have been discussed in previous reports. $1,11,12,13$ 
We intend to preserve the capability of adapting either of these detection systems in establishing the PHOEBUS/UHTREX facility and in developing the instrumentation. The neutron hodoscope has been used successfully by the Argonne National Laboratory (ANL) to follow fuel motion for a single fuel pin and for a 7-pin array. In principle the amount of information available from neutrons or gammas associated with fission in fuel pins depends only upon the total energy imparted. For short transients, the higher instantaneous powers permit data to be taken in narrow time channels; while, for the same energy imparted over a longer time interval, longer time channels are required for equivalent statistical accuracy. Thus, to some extent, methods based on viewing the neutron or gamma illumination of the fuel may have time resolution limitations for certain experiments. In this regard, flash $\mathrm{x}$ ray is superior since it is independent of test power. On the other hand, flash $x$ ray monitors only transmission variations and does not readily distinguish between material.

We will be conducting hodoscope evaluation experiments with our PARKA critical assembly and we would plan to continue these in the PHOEBUS/UHTREX facility if they show promise. The flash $x$-ray collimator could have some capability of being converted to the neutron hodoscope application.

Coded aperture imaging is of interest to our diagnostic problem because of its unique potential for three-dimensional viewing with relatively simple equipment. We feel that this class of imaging should be developed to the extent necessary to evaluate its potential. We do not view the coded aperture as an alternative to flash $x$ ray for early PHOEBUS/UHTREX experiments because of uncertainties in sensitivity and questions regarding the ability to penetrate inside a multipin array.
Nonredundant pinhole arrays and Fresnel zone plate apertures were discussed in LA-5978-MS ${ }^{1}$ relative to their application to diagnostics for STF tests. of the two, we consider the pinhole array to be the more favorable because of its inherent superior signal-to-background characteristics for extended sources. A practical consideration is that fabrication of thick pinhole arrays with the necessary tolerances is easier and less expensive than fabrication of thick Fresnel zone plates having comparable resolution.

E. Fuel Motion Detection Outside the Driver Core

The 0.9-m-long active length of fuel pins in a test assembly is normally bounded by $0.45 \mathrm{~m}$ of blanket material at each end. Fuel motion is unlikely to extend past these regions except for possibly the most extreme transients. Posttest examination with $x$ rays from the diagnostic linac immediately following a test and before the test chamber is moved will indicate the condition of the fuel pin active region and will show qualitatively how much fuel has moved to other regions of the test vehicle. Later examination will show the final distribution of the fuel throughout the test vesse1. However, detailed tracking of the fuel to its final configuration as a function of time is important in order to better understand the test sequence. We propose to monitor fuel motion past a few points along the test vessel by detecting delayed neutrons with directional detectors. Simple, wide-channel collimators would be used to provide the required directional properties.

Delayed neutron emission per gram of fuel for times following the reference transient is shown in Fig. 29. The indicated neutron source strengths for short times (up to $10 \mathrm{~s}$ ) are intense enough to give high counting rates for a variety of neutron detectors located within $0.5 \mathrm{~m}$ or so of the source. The delayed neutron 


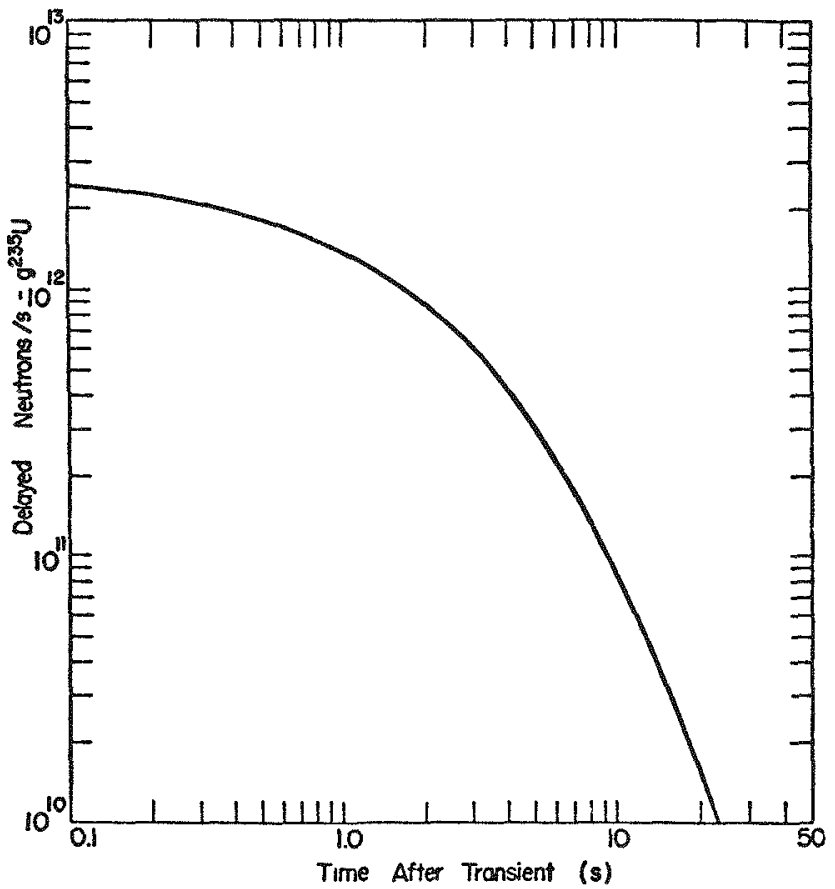

Fig. 29. Delayed neutron emission following reference experiment.

spectrum averages about $500 \mathrm{keV}$, so that appropriate detectors should have high sensitivity in this region, but with a low energy cutoff to discriminate against driver neutrons. Proton recoil counters, helium recoil scintillation counters, Hornyak button scintillation counters, or neptunium fission chambers would be candidates for this application.

\section{DESCRIPTION OF THE UHTREX FACILITY}

The Ultra High Temperature Reactor Experiment (UHTREX) facility, IASL designation RD-I, is located approximately 2-1/2 miles southeast of the townsite of Los Alamos. Figure 30 is an aerial view, looking southeast, of the site taken in 1973, showing the principal reactor building $\mathrm{RD}-1$ and a general support building RD-11. A complete description of the facility is given in the UHTREX Safety Analysis Report (LA-3556 Revised). The UHTREX was a 3-MW (thermal), helium-cooled graphite-moderated reactor operating at $3448 \mathrm{kPa}(500$ psia) at a coolant outlet temperature of $1590 \mathrm{~K}$ $\left(2400^{\circ} \mathrm{F}\right)$. The reactor was operated for a relatively short period of time during which the main experimental objective of demonstrating the $1590 \mathrm{~K}$ coolant outlet temperature capability was achieved. Integrated operation was about 135 MWd with the last reactor operation in December of 1969. After the project was terminated in February 1970, all fuel was unloaded and removed from the site, the facility was cleaned and secured, and the reactor and equipment were put into a standby status. A. Building Description The floor plans of the building for the three main levels are shown in Figs. 31, 32, and 33. The ground floor plan (Fig. 31) shows the location of building services relative to the reactor secondary containment structure, Room 106, on the plan. In the photo, Fig. 30, the secondary containment is the concrete structure comprising the upper right-hand, southeast portion of the facility. The containment structure is a reinforced concrete structure

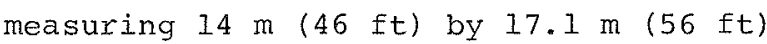

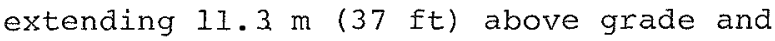

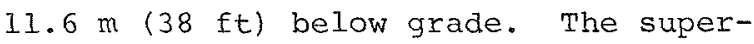
structure is designed to withstand an internal pressure of $3.45 \times 10^{4} \mathrm{~Pa}$. To ensure gas tightness of the superstructure, a liner made of welded steel plate covers the inside walls and roof. Below grade this steel membrane extends within the walls to the base of the building on the two sides adjacent to habitable portions


low grade on the two outside walls. The roof is $0.61-m$ (2-ft)-thick concrete, three walls are $0.46 \mathrm{~m}$ (1.5 ft) thick. The fourth wall, in the direction of the control room and approach road, is $0.91-\mathrm{m}$ (3-ft)-thick concrete.

The measured leak rate from the facility was $3 \% /$ day at $3.45 \times 10^{4} \mathrm{~Pa}$. At $6.9 \mathrm{x}$ $10^{3} \mathrm{~Pa}$ the rate was extrapolated to be 


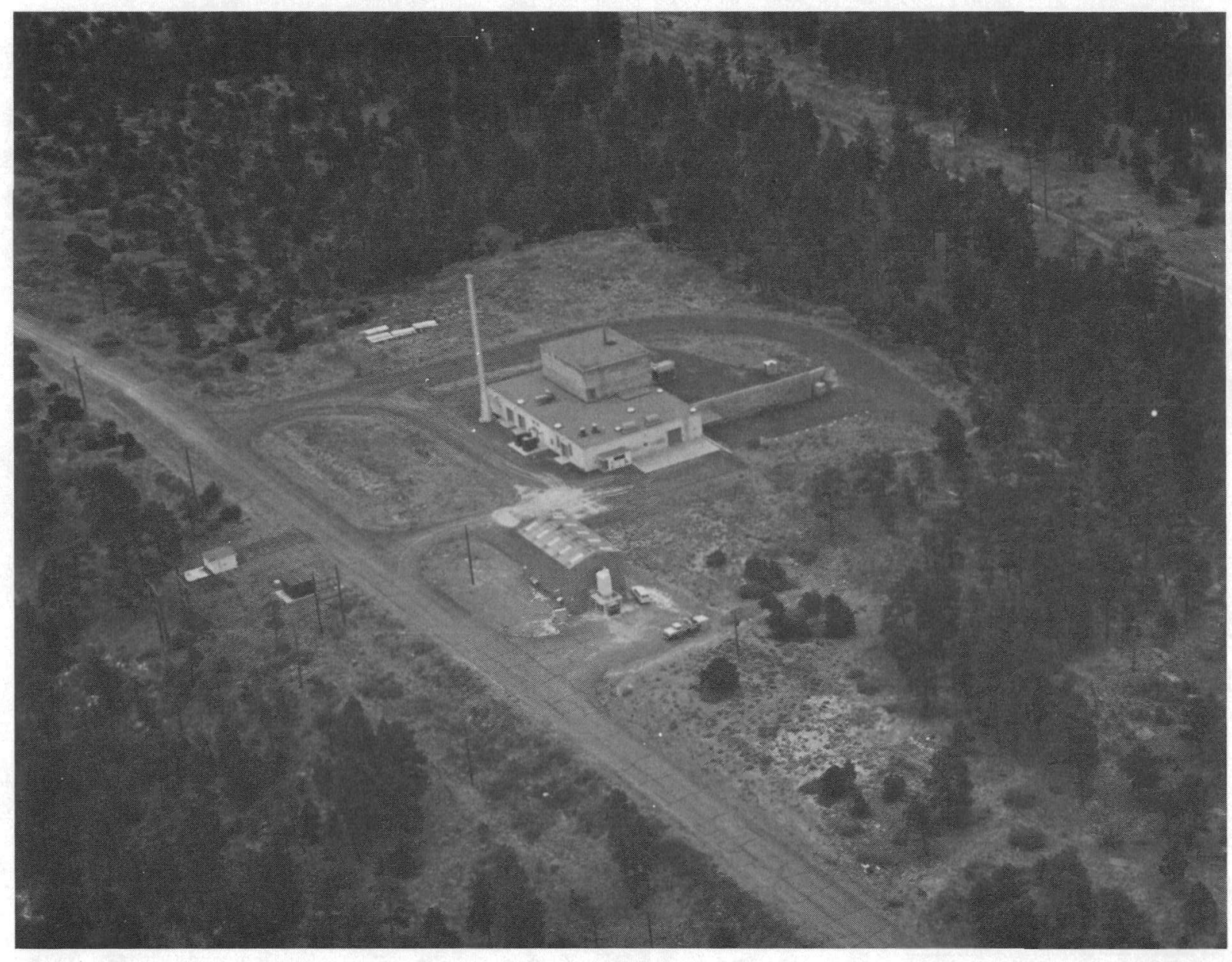

Fig. 30. UHTREX site.

- 




Fig. 31. Building floor plan, ground level. 


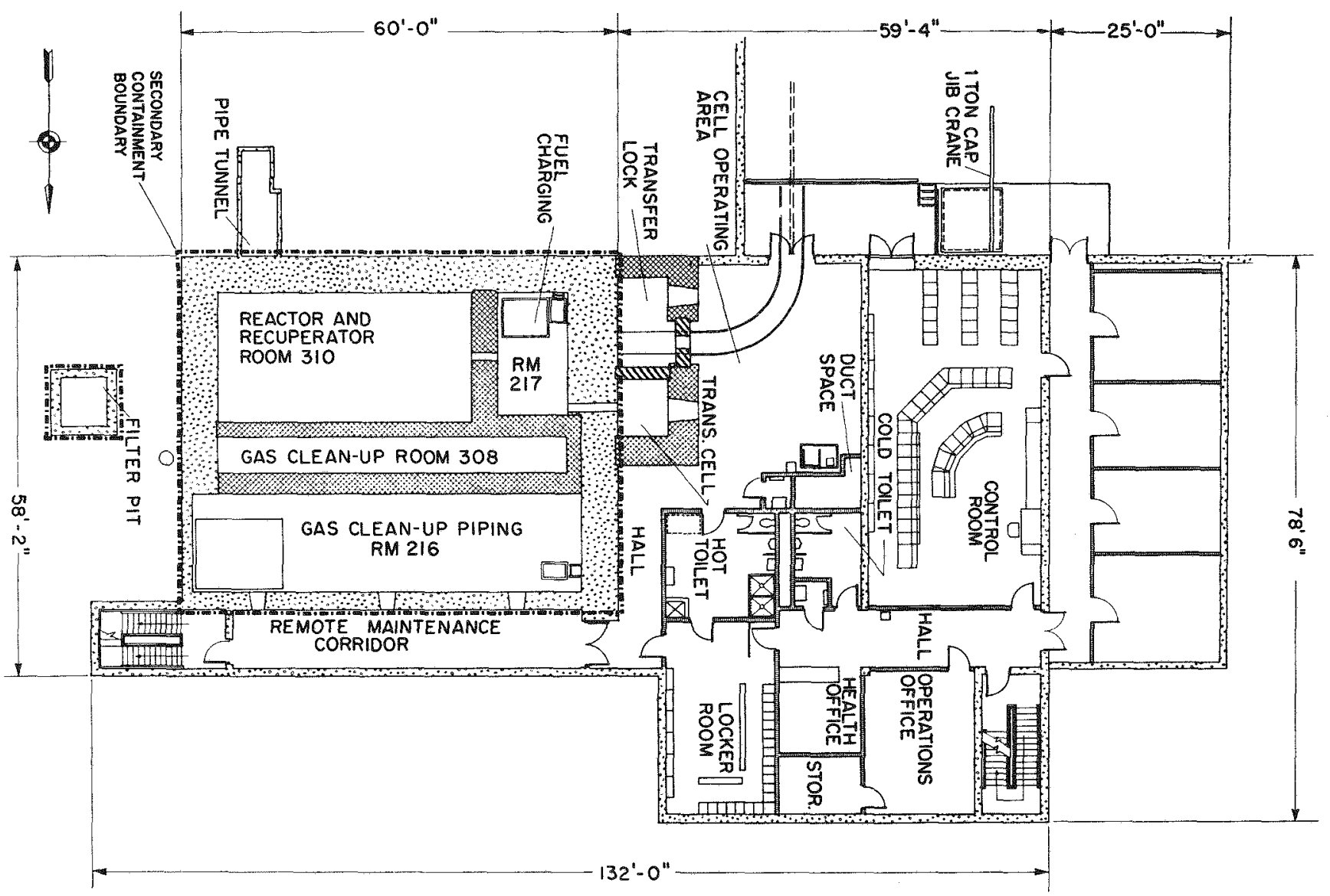




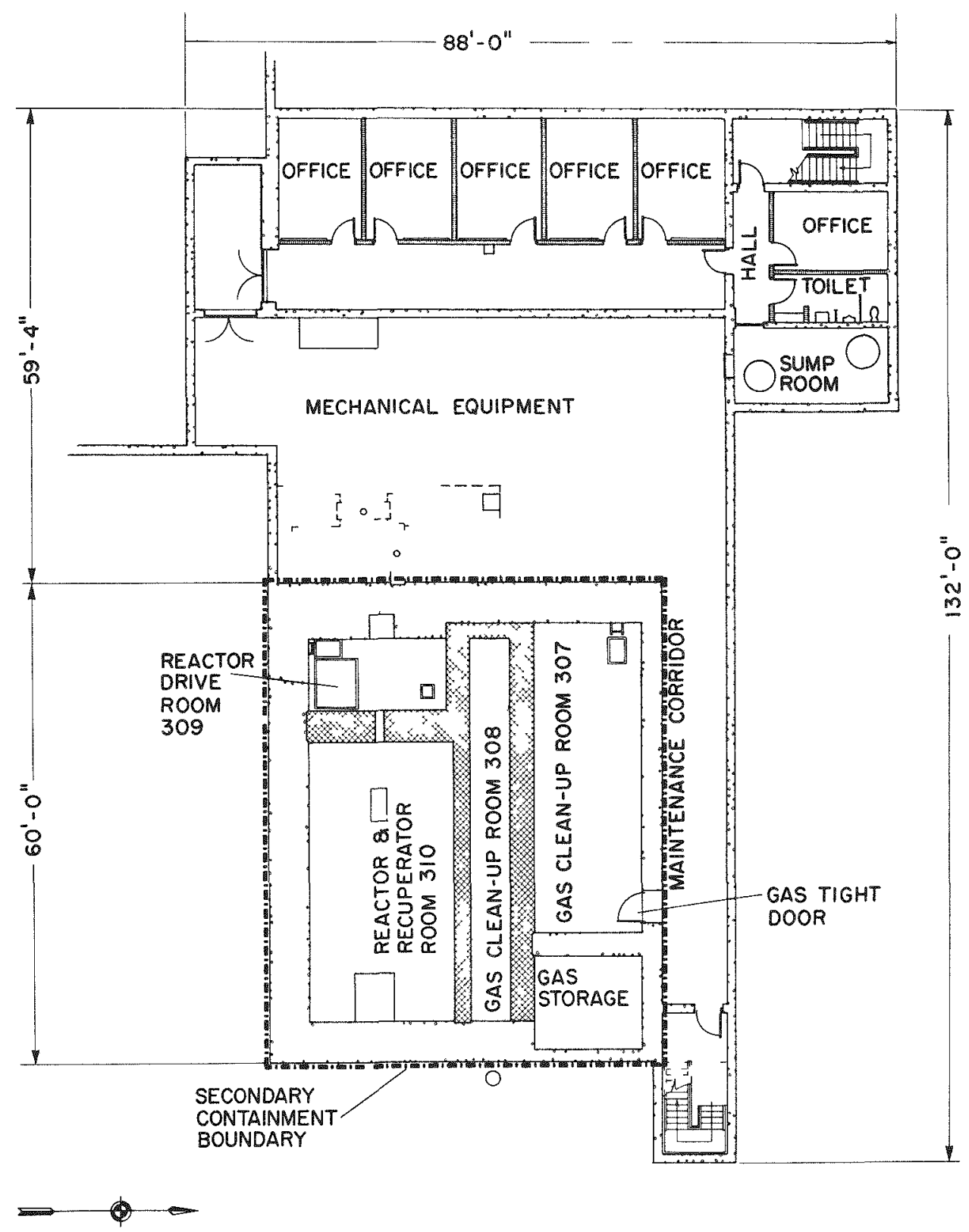

Fig. 33. Bullding floor plan, basement level. 
$0.7 \% /$ day. However, a test on the facility done during January 1970 indicated that the leak rate had increased significantly, possibly to as high as $10 \% /$ day at $3.45 \mathrm{x}$ $10^{4} \mathrm{~Pa}$.

The first level below grade (Fig. 32) includes the control room, the maintenance labs, some office space, and is the level on which the UHTREX gas-cleanup-system blower, compressors, gas chromatograph, infrared analyzer, and valves and pipe manifolds were located. The second level below grade (Fig. 33) is the lowest level normally entered and contains office space, some mechanical equipment primarily for the gas cleanup system, and water pumps for reactor cell cooling. Many of the instrumentation cable trays are located at this level.

Figures 34 and 35 are cross sections of the building. Figure 34 shows how the gas cleanup vessels in Room 308 were isolated from the primary loop in Room 310. The gas cleanup vessels were arranged for easy installation and removal from Room 308. Figure 35 shows that the primary loop installation within Room 310 below grade is isolated from Room 106 by removable concrete floor slabs. This cross section shows the primary-loop blower, the control-rod arives, the bypass-valve actuator, and elevator drive mechanism located in Room 106 above the floor level.

The UHTREX reactor system is to be removed to provide a clean facility for installation of the safety test experiment. All equipment will be removed from Rooms $307,308,309,310,216$, and 217. Room 106 will have all contaminated equipment removed leaving a small demineralized water system, the overhead crane, MINOTAUR, some cabinets, and other small items.

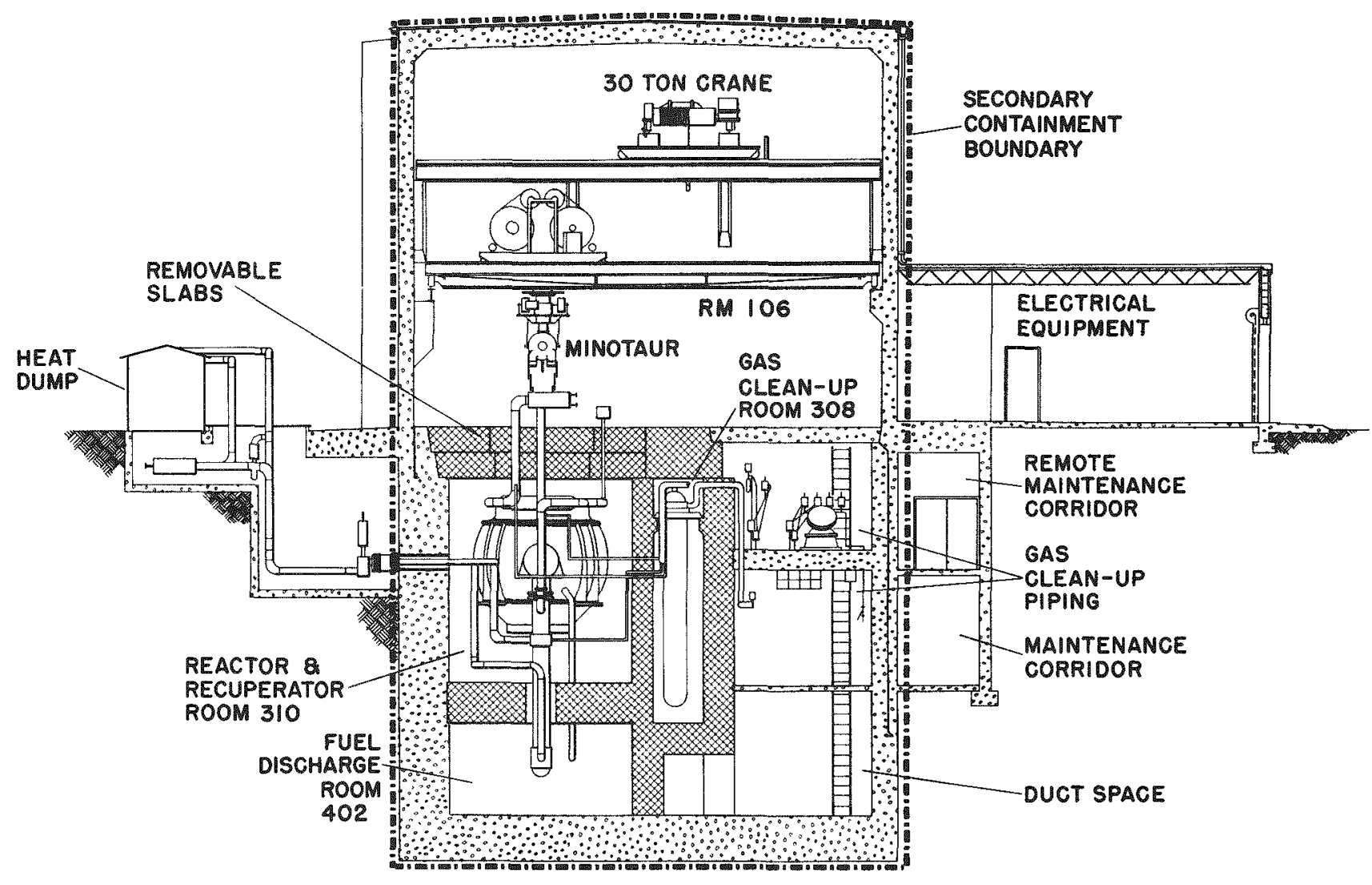

Fig. 34. Building section through reactor room (Room 310 ). 


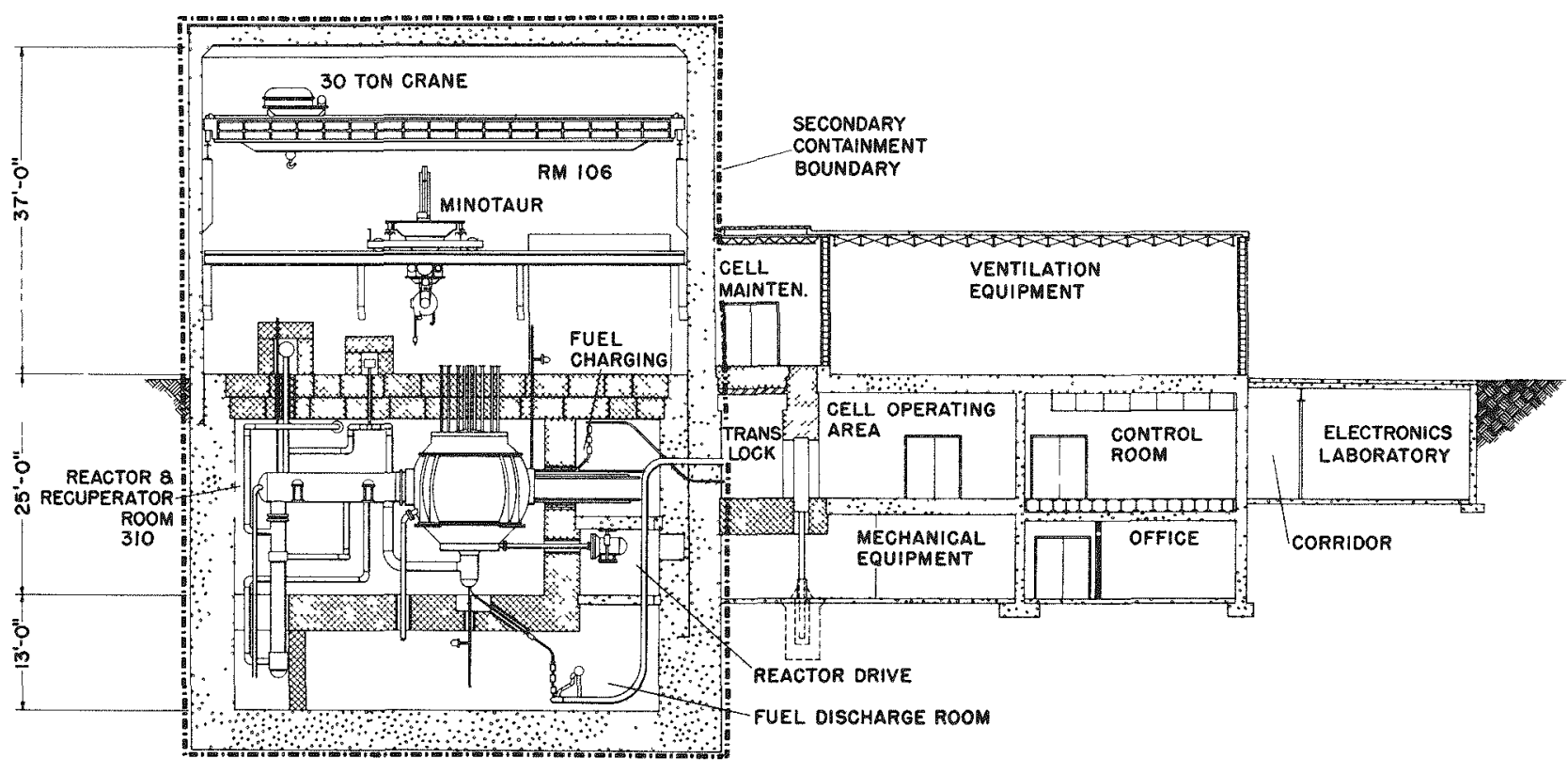

Fig. 35. Building section through control room.

\section{B. Ventilation Systems}

Figure 36 is a schematic air flow diagram for the building. There are four independent ventilation systems, one for each of the following regions: the secondary containment structure, the fuel handling and gas sampling cells and their adjacent operating areas, the change rooms and other "warm areas" that might become contaminated during normal operations, and the control room and other clean areas.

Ventilation air is not recirculated, except to the air-conditioned electronics racks in the control room. All intake air passes through preheat coils, roughing filters, and aerosol filters designed to remove particles as small as $20 \mu$ in diameter. Exhaust air from areas that might be contaminated is passed through absolute and activated carbon filters and vented through a $30.5-\mathrm{m}$ (100-ft) stack. Air from clean areas exhausts through rooftop vents. Throughout the facility, air moves from areas that are clean toward those that might become contaminated.

For ventilation of the secondary containment during reactor operation, one of two parallel, in-line blowers moved the air in a closed cycle. The full air flow, $4.56 \mathrm{~m}^{3} / \mathrm{s}$, circulates through absolute and activated carbon filters and heating and cooling coils. Pressure inside the containment structure is maintained at $1.27-\mathrm{cm}(0.5-i n.) \mathrm{w} . \mathrm{g}$. below atmospheric by a $0.71 \mathrm{~m}^{3} / \mathrm{min}\left(25 \mathrm{ft}^{3} / \mathrm{min}\right)$ continuous bleed of filtered air to the stack through one of two parallel bleed fans. The flow rate is sufficient to provide 15 air changes per hour in the regions where equipment contains fission products. When personnel are inside the secondary containment structure, the ventilation system brings in fresh air, draws it through roughing and Aerosolve filters, passes the filtered air once through the rooms, and exhausts it through the absolute and carbon filters to the stack. 


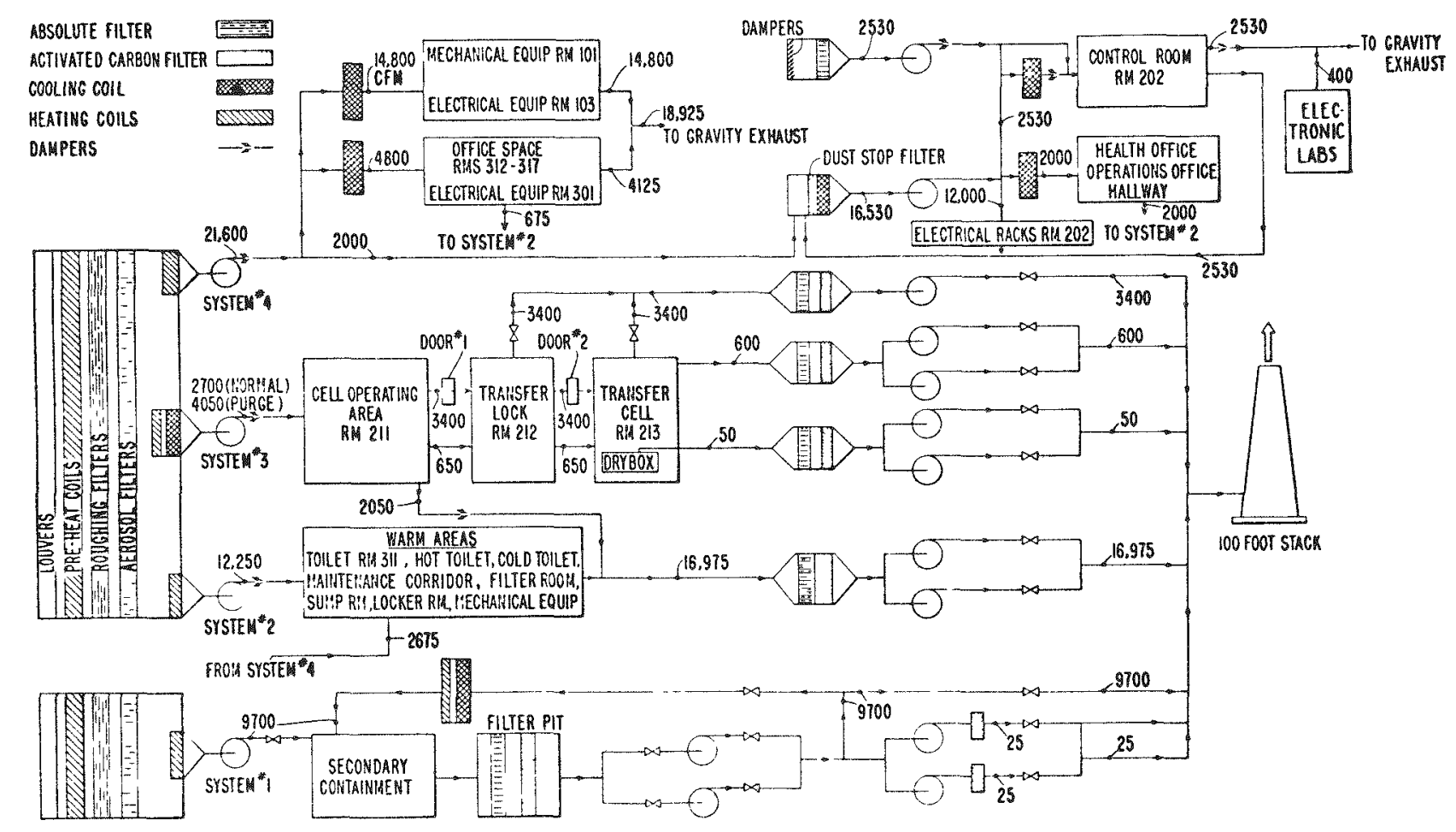

Fig. 36. Building ventilation flow diagram.

The exhaust filters in this system are located in a shielded pit outside the building.

System No. 2, which ventilates the potentially contaminated areas, takes in outside air from a Eilter bank shared with Systems No. 3 and No. 4, heats the air, moves it through the warm areas, and exhausts it through absolute and charcoal filters to the stack. System No. 2 changes the air 10 times per hour in the warm areas.

System No. 3 serves the cell operating area and the two hot cells the fuel transfer lock and the fuel handling cell.

System No. 4 serves the clean areas: the office, the laboratory areas, the ground level equipment rooms, and the control room. The majority of the air passes through offices and equipment rooms to rooftop vents. However, air that ventilates the operations and health offices and the adjacent hallway passes into System No. 2 through the locker room and hot toilet. Some of the exhaust air from the lower level offices also enters System No. 2, through the sump pump room and the adjacent toilet.

In the control room, 85\% of the air flow enters the electronic racks, via a plenum formed by the suspended floor, and is recirculated through an independent system, which filters dust from the air and recools it with a coil served by a refrigerated, chilled water system. A second independent system makes the control room habitable if an accident should result in the release of fission products inside or from the facility. In this emergency system, a blower driven by the emergency power supply takes in outside air through an absolute filter, and discharges into the control room, from which the air exhausts to the atmosphere. 
The electronics laboratories have an independent, conventional, ventilation system. Its only tie to the other facility systems is a connection through which $11.32 \mathrm{~m}^{3} / \mathrm{min}\left(400 \mathrm{ft}^{3} / \mathrm{min}\right)$ of air discharge into the system No. 4 gravity exhaust duct.

All absolute filters in the ventilation systems are designed for minimum efficiency of $99.5 \%$, that is, dioctyl phthalate penetration of $0.05 \%$ for 0.3-u-diam homogeneous particles.

Operation of the ventilation systems is monitored with the aid of the usual instrumentation: pressure and differential pressure transducers, temperature sensors, flow switches, and valve position indicators. Conventional control systems regulate temperatures and maintain pressure differentials.

Meters, recorders, and indicators

for the ventilation systems' instrumentation and controls are located on a panel in the ground level electrical equipment room, together with the control switches for system components. A Scanalarm system on the panel indicates irregular performance, sensed by flow switches, of the intake and exhaust fans in each ventilation system. An alarm on the equipment room panel is indicated also on the control room annunciator panel, but the source of the alarm is not identified there.

\section{Cooling water systems}

The UHTREX site is served by a $0.23-\mathrm{m}$ (9-in.) water main which feeds directly two fire hydrants and the facility water system. Cooling water consists of a closed loop system rated at 1850 liters/ min (490 gal/min) against a heat of $16 \mathrm{~m}$ (54 ft). There are two evaporative coolers each rated at $0.32 \mathrm{MW}$. In the UHTREX operation cooled water $300 \mathrm{~K}\left(78^{\circ} \mathrm{F}\right)$ from the coolers was pumped to: (1) cooling coils in the ventilation systems; condensers and compressors in the refrigeration systems; (3) an aftercooler on the cleanup system process air blower: and (4) the isolation heat exchanger that cools the water in the demineralized system.

Demineralized water was circulated in a closed loop cooling water system referred to as the demineralized system. The demineralized system coolant flowed through the shell side of the isolation heat exchanger which was rated at 0.44 MW thermal. From the isolation heat exchanger the cooled demineralized water flowed to a manifold that fed five pumps; two that served the gas cleanup system and three that served the reactor cooling panels and coolant blower cooling systems. One of the cleanup system pumps was on-line, the other was on standby, and both were driven by line power. Either could circulate 645 liters/min (170 gal/min) against a $25-\mathrm{m}(80-\mathrm{ft})$ heat. Of the three other pumps, one was on-line, one was on standby, and the third was for emergency use. Either of the first two could circulate 1140 liters/min (300 gal/min) against a 27-m (90-ft) head and were driven by line power. The third, rated for 570 Iiters/min (150 gal/min) against a $15-\mathrm{m}(50-\mathrm{ft})$ head and driven by power from the 20-kw emergency supply, was started only if both power lines were lost.

This water system is intact and would be modified as required for blower cooling, cooling loop heat exchangers, etc. Standard pressure, temperature, and

flow instruments monitored the performance of the water systems and transmitted signals to the utilities panel in the electrical equipment room. Each of the reactor coolant panels and blower cooling water circuits had an independent control system on the utilities panel. At the panel, the inlet, and outlet, and vent valves for each circuit could be operated, and the position of each circuit's highlow switch was indicated. 


\section{Electrical system}

Electrical power for the UHTREX facility comes from the Los Alamos power distribution center over two separately routed, 13.2-kV power 1ines. Normally, each of the $13.2-\mathrm{kV}$ lines carried about half of the facility load, but either line with its associated 750-kVA transformer was capable of carrying the full load. If power from one of the lines was interrupted, the main breaker for that line opened, and a normally open tie breaker closed, connecting the two sides of the load center. Upon restoration of the main-line power, the breakers returned to their normal positions.

Loads that were critical for safe shutdown of the reactor were supplied continuously from two generators located near the facility load center. These generators have been removed and would need to be replaced if needed. One generator which supplied $20 \mathrm{~kW}$ to instrumentation and critical motor loads was driven, normally, by a load-center-supplied ac motor or, on line failure, by a diesel engine. The second generator, which fed $10 \mathrm{~kW}$ to critical instrumentation was driven, normally, by an ac motor or, on line failure, by a battery-supplied dc motor. If either generator failed, its load was automatically switched to the line power systems.

\section{E. Control Room}

The central room, shown during construction in Fig. 37 , is at the operating level outside the secondary containment defined essentially by Room 106. All areas within Room 106 are connected to the control room by cables running from terminal cabinets inside the secondary containment to terminal cabinets inside the control room. The control room has a false floor to facilitate cable routing between racks.

\section{F. Contaminated Liquid Waste}

The floor drains in the secondary containment structure and in the hot cells are connected to a contaminated waste system that discharges to the LASL low level waste treatment plant. Iiquid waste flows in $7.62-\mathrm{cm}$ (3-in.) steel pipe from the floor drains to a 8700-liter (2300-gal) tank located under the floor of the basement-level sump room. Waste also flows to the tank from the vacuum cleaning system's cyclone separator, which has water spray nozzles in its hopper. From the tank, duplex centrifugal pumps, operating by an electrode level control, move the waste to a ground-level treatment station in a building about $35 \mathrm{~m}$ (120 ft) north of the facility. The waste is neutralized there with sodium hydroxide to $7.0 \mathrm{pH}$ and can be stored in two 1300liter (5000-gal) tanks. Eventually the waste is pumped through the contaminated sewer to the TA-50 waste treatment plant. G. Vacuum cleaning system

For picking up potentially contaminated dust in the exhaust ventilation filter room and the secondary containment, there is a 13-outlet vacuum cleaning system. Air moves through $5.08-\mathrm{cm}$ (2-in.) stainless steel ducts from the outlet hose connections to a cyclone separator, absolute filter, and multistage centrifugal blower, all located in the sump room. Dust removed in the separator is washed to the contaminated waste tank through a rotary vane valve. Any dust remaining in the air is collected on the absolute filter before the air enters the blower, which discharges to the outlet filter plenum of ventilation system No. 2 .

H. Helium Blowers

There are two identical blowers as shown in Fig. 38, one each in the primary and secondary loops. Most parts exist for a third blower. These blowers were built under a special research and development contract and were designed to provide highly reliable operation with the machinery being totally enclosed in a heliumleakfree container. Each has a 29.53-cm 


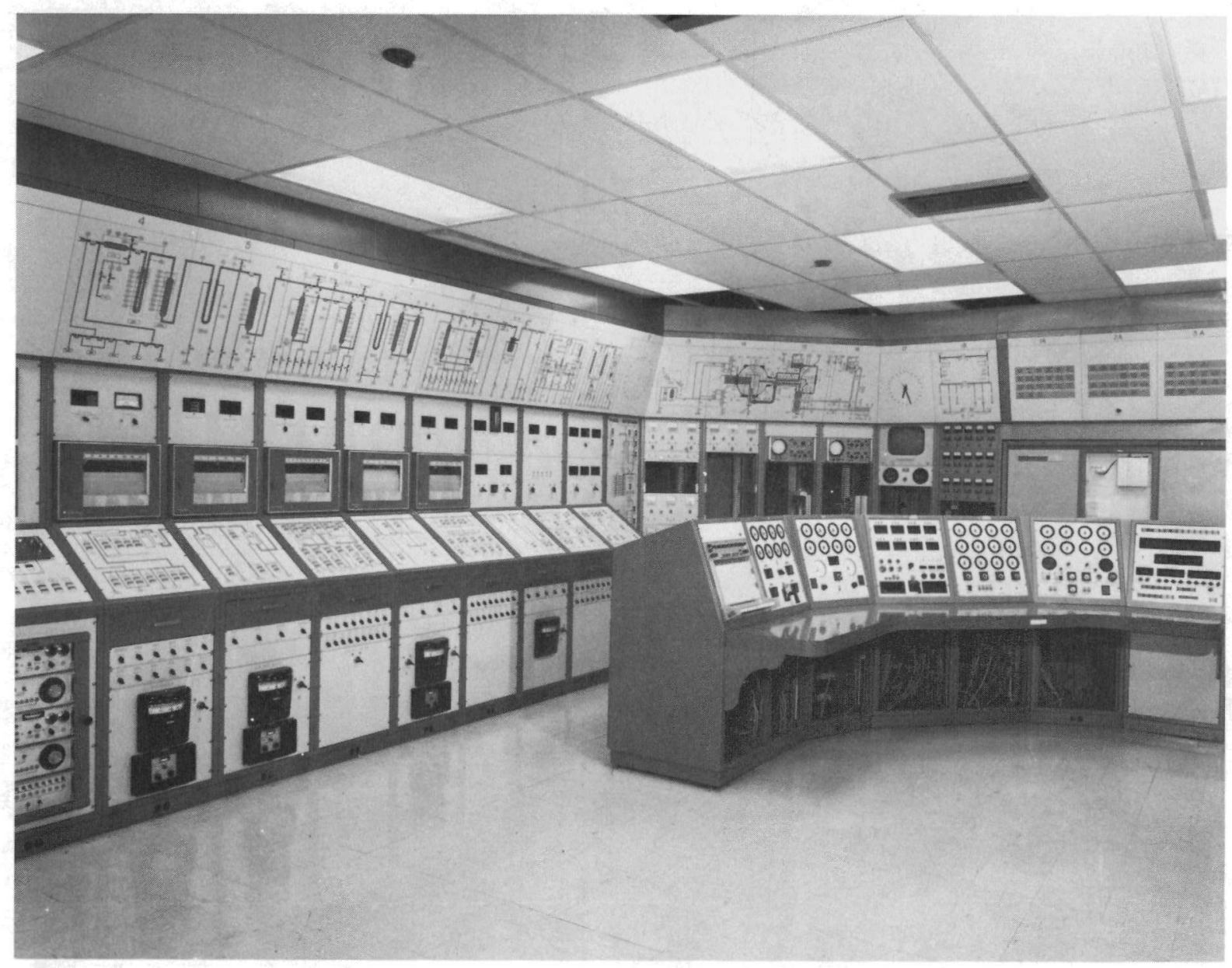




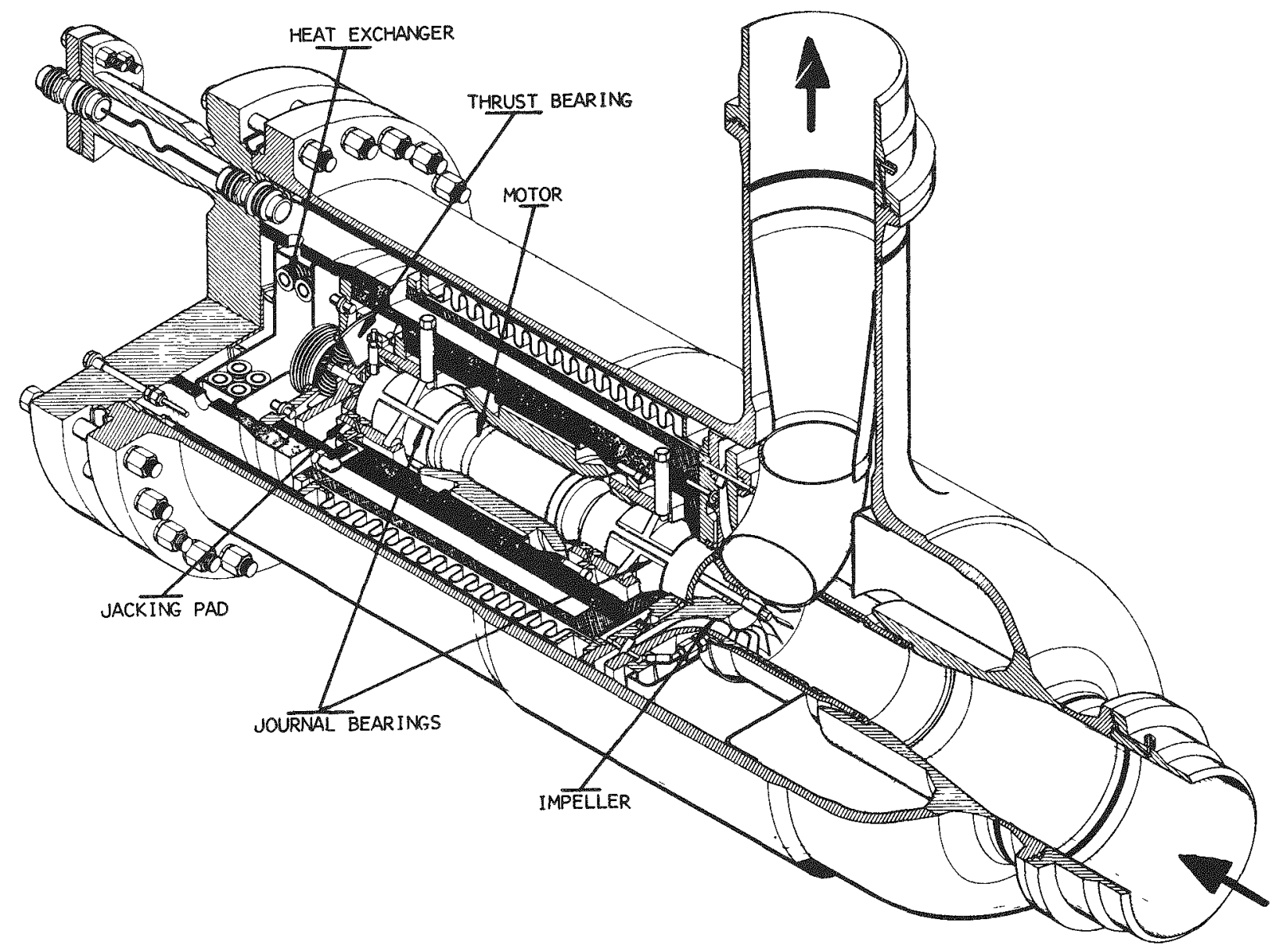

Fig. 38. Sixty hp helium blower.

(11.625-in.)-diam, unshrouded, 19-vane impeller which rotates at a maximum speed of $12000 \mathrm{rpm}$. The impeller is driven by a 60-hp, 2-pole, 60- to 200-cycle, 3-phase, 133- to 400-V c sntinuous-duty squirrel-cage motor whose rotor is an integral part of the blower shaft. Motor speed can be controlled between 4000 and $12000 \mathrm{rpm}$ by changing the frequency of the input power, produced by a 75-hp, 2000-cycle, ac generator. The output frequency of the generator is a direct function of the speed at which it is driven by two ac motors on the common shaft. These motors operate at constant speed, but are coupled to the generator by an eddy-current clutch.
Two self-acting, hydrodynamic journal bearings and a hydrodynamic thrust bearing support the blower rotating assembly, which includes the main impeller bearing journals, motor rotor, and thrust runner, all on one shaft. There are no rotating or stationary shaft seals. Each journal bearing has four segmented, pivot-mounted pads. Jacking gas (helium at $>3.79 \times 10^{6} \mathrm{~Pa}$ ) is injected through hydrostatic jacking pads to lift the rotating assembly off the two journal bearings when the blower is started, stopped, or running at speeds less than $4000 \mathrm{rpm}$.

The entire blower assembly slides into the case through a flanged opening that is bolted tight and sealed with a 
C-section ring joint. All instrumentation and power leads, the water lines, and the jacking gas line enter the case through the closure. Double Conoseal joints connect the case into the primary loop.

Under nominal conditions, the mass flow rate to each blower was $4.65 \times 10^{3} \mathrm{~kg} / \mathrm{h}$ of helium at $590 \mathrm{~K}\left(600^{\circ} \mathrm{F}\right)$ and $3.45 \times 10^{6}$ $\mathrm{Pa}$. The pressure rise was $5.5 \times 10^{4} \mathrm{~Pa}$. A finned tube heat exchanger was located at the rear of the blower case to cool the motor compartment via cooling water from an isolated water system.

I. MINOTAUR

For remote maintenance inside the secondary containment, a machine named
MINOTAUR was installed. This machine, shown in Fig. 39, is suspended from an overhead bridge crane on a telescoping vertical column. It includes two electromechanical manipulators, a small hoist on an extensible boom, closed-circuit television cameras, lights, and a microphone. The machine can be operated from either the reactor room or the remote maintenance corridor, which is shielded from, but has viewing windows into, the gas cleanup area. The machine is operable except for the television camera system which has been removed. The camera system, and possibly some control circuits, will need replacement.

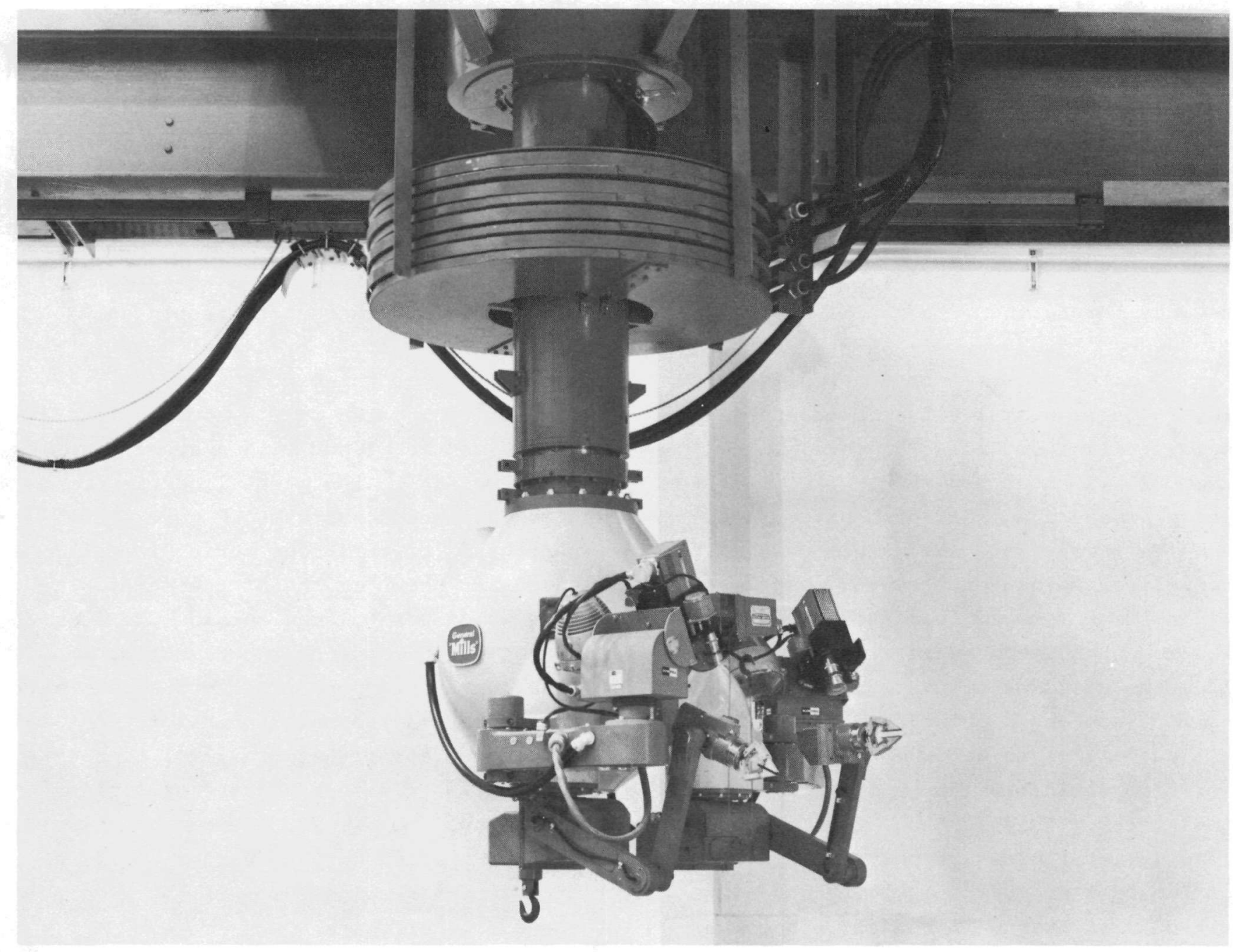

Fig. 39. MINOTAUR. 
X. REMOVAL OF CONTAMINATED EQUIPMENT FROM UHTREX

It is proposed that the contaminated equipment from the UHTREX facility, including the reactor, will be removed. Also, unneeded noncontaminated equipment such as cooling water systems, instrumentation, controls, conduits, etc. will be removed.

All fuel has been removed from the reactor and all areas of the facility are free of contamination. Radiation levels are low. What contamination exists is internally deposited on the various vessels, pipes, and equipment in the primary coolant loop and helium purification and handling systems. Some induced activity remains in the reactor vessel, and iron structures near the vessel.

The internally contaminated equipment is located in Rooms 106, 216, 217, 307,308 , and 309. The hot cells used for fuel loading also contain contamination. There are no plans for using these cells at present and, unless it is decided to use them, they will not be cleaned.

Radiation levels are generally quite low. The highest levels are in the reactor cell, Room 310. The level in Room 310 is about $100 \mathrm{mr} / \mathrm{h}$. The reactor vessel reads about $500 \mathrm{mr} / \mathrm{h}$ on contact.

To investigate the nature of the internal contamination, several samples of piping were removed from the system. One section of $2.54-\mathrm{cm}(1-\mathrm{in}$.$) pipe removed$ from the gas cleanup system that had primary coolant flowing through it during all operations is believed typical of the worst contamination to be dealt with in the system. This section of pipe had no reading externally and only read $15 \mathrm{mr} / \mathrm{h}$ on the open end. The activity was almost all beta and was well bonded. There was no evidence of any airborne activity while the pipe was being removed. If correctly typical, breaking flanges to remove equipment does not appear to be a problem.

A. Burial

Removed items, including the complete reactor vessel, will be buried at the LASI burial site, TA-54, which is approximately 4 miles from the UHTREX site. Burial will be in accordance with LASL standard operating procedures and in compliance with current regulations. All items removed will be sealed to prevent leaching of the internal activity. Due to the size of the reactor vessel $4.25-\mathrm{m}$ (14-ft)-diam a special pit will be prepared.

It is assumed that al1 removed items will be buried, except the primary loop blower which is planned for use in a potentially contaminated 1oop. However, equipment will be surveyed on removal and some additional items may be found sufficiently low in contamination that they also are worth being salvaged.

B. Facility Preparation

Prior to removal of contaminated equipment it is proposed to reopen a $4.9-\mathrm{m}$ by $4.9-\mathrm{m}$ (16-ft by $16-\mathrm{ft})$ door into the secondary containment for access. This door is located on the south wall of Room 106 and is closed with a steel panel that is welded to the steel liner inside the containment structure. Figure 40 is a photograph of this door during installa. tion. Also shown is one of the shield blocks which were placed outside the door. It is proposed to close the resulting opening with a temporary structure with a garage-type door to permit small truck access for transport of equipment to the burial pit. This door closure will have to be removed to remove the reactor vessel, and then replaced during further modification and construction. It will be used for a couple of years.

The 30-ton overhead crane will be returned to service. The operating areas, 


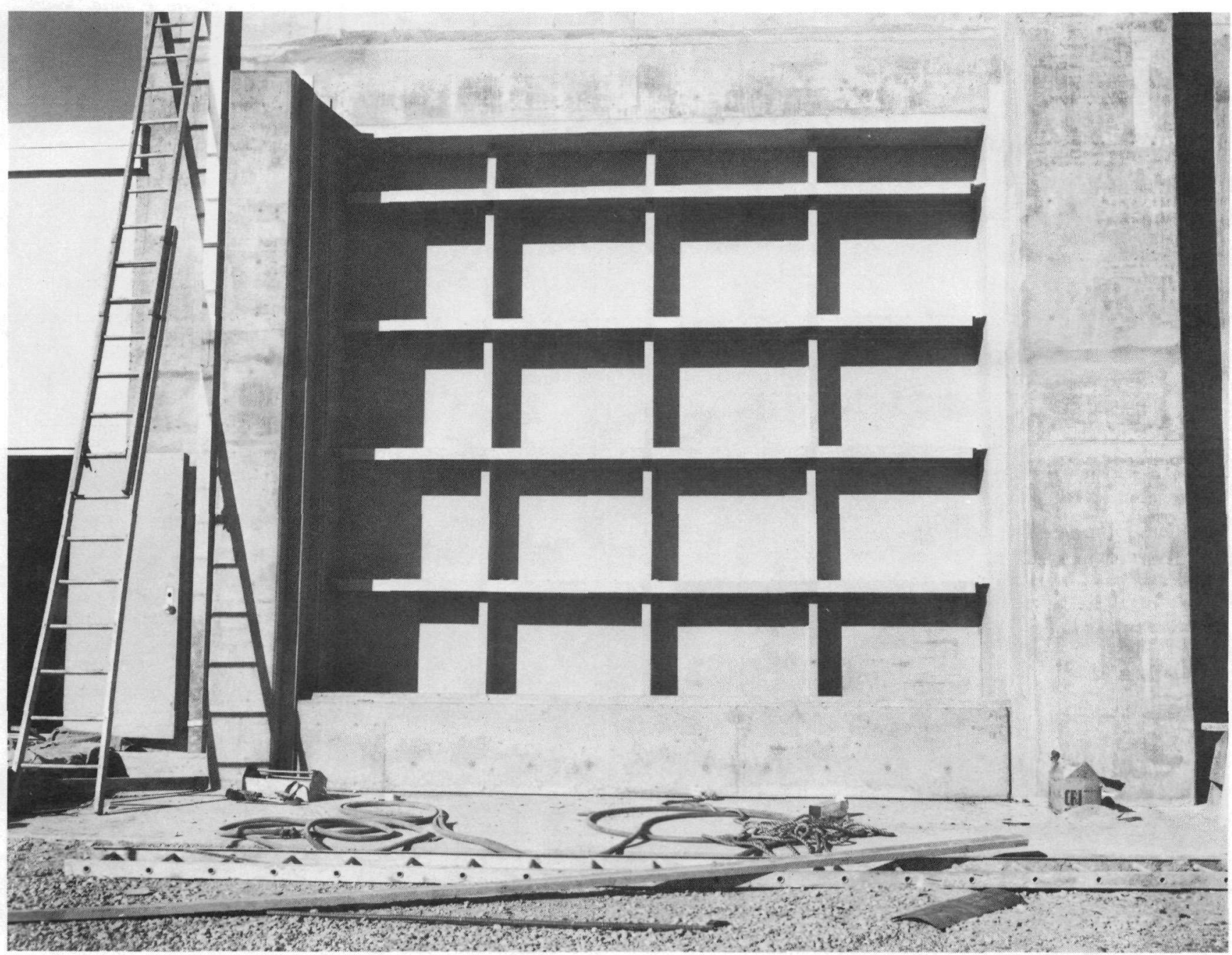

Fig. 40. UHTREX containment door.

offices, and laboratories are used by other LASL project personnel and it may be necessary to start decontamination operations before these areas are cleared. If so, a temporary change area, health monitoring station, and other requirements for personnel protection will be set up. The sequence in which the facility is cleared of unneeded equipment is not significant. Obviously many operations may be carried out in parallel. Removal of uncontaminated equipment may be done any time. Likewise, it may be possible for two crews to work simultaneously on removal of contaminated equipment. The following discusses the removal of gas cleanup equipment and primary loop equipment separately.

This work should start as soon as possible in the project. A small, wellorganized and well-trained crew working methodically will be most successful.

There will be no substitute for doing the job correctly the first time. If contamination is allowed to spread or become airborne the total operation will skyrocket in cost.

\section{Gas Cleanup system}

The UHTREX helium handling and purification system is located in Rooms 216 and 308 except for three large storage tanks which are located below Room 216 and 
Room 403. Figure 41 is a photograph of Room 216 during construction showing two Corblin compressors and piping along the south (left) wall. The principal equipment to be removed from this area are the pipe and valve manifolds, electrical, instrument, and pneumatic lines, and the two compressors. All manifolds are connected with Conoseal flanges and, because they were designed for remote removal, will be readily removed. The most contaminated pipe section is the one piece of pipe which has already been removed. Following the cleanup of Room 216 and removal of manifolds, the gas cleanup vessels in Room 308 may be removed.

Room 308 contains the gas cleanup vessels arranged as shown in Fig. 42. Figure 42 is a photograph of a model of the gas cleanup system. This figure shows how

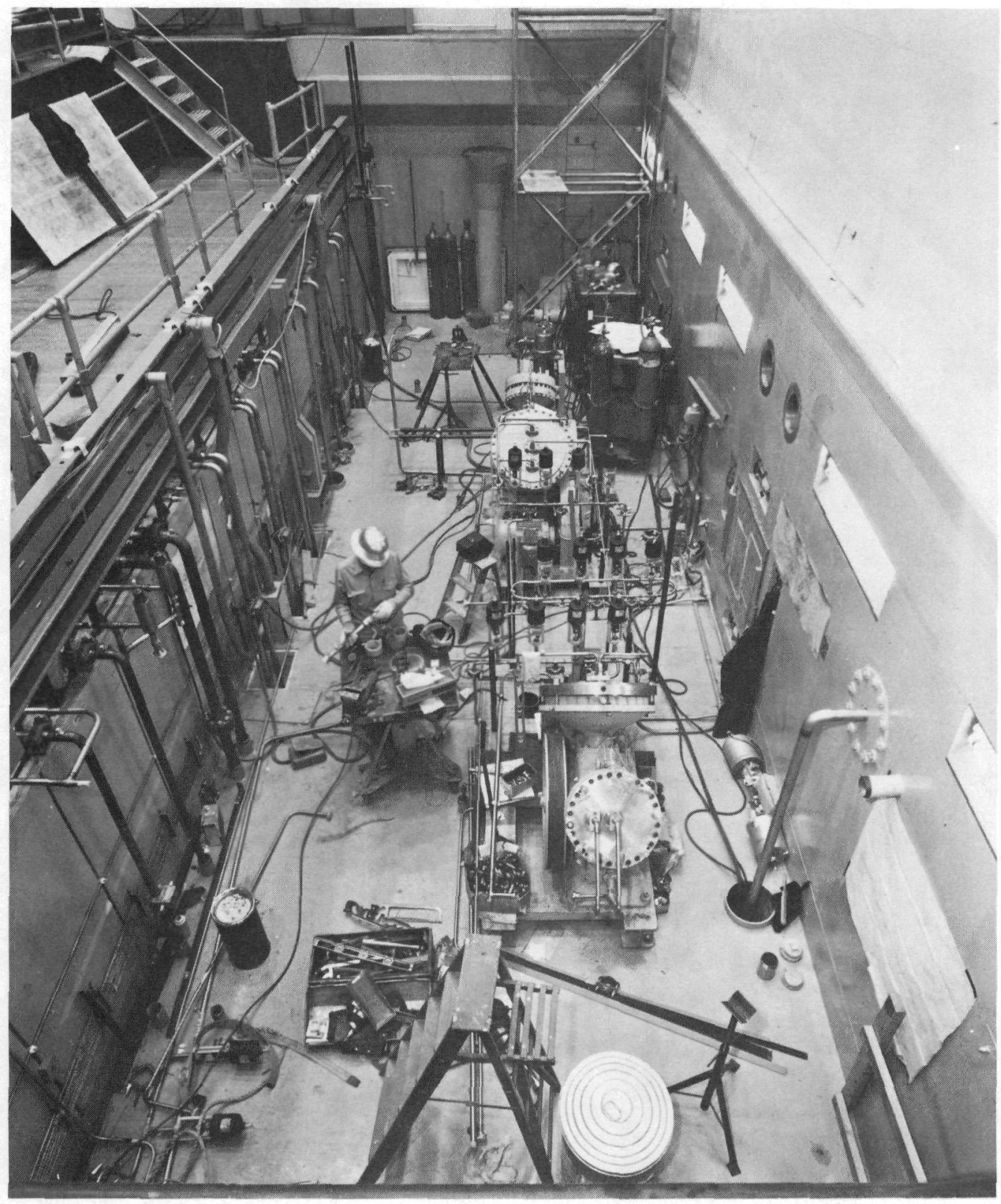

Fig. 41. UHTREX equipment (Room 216). 

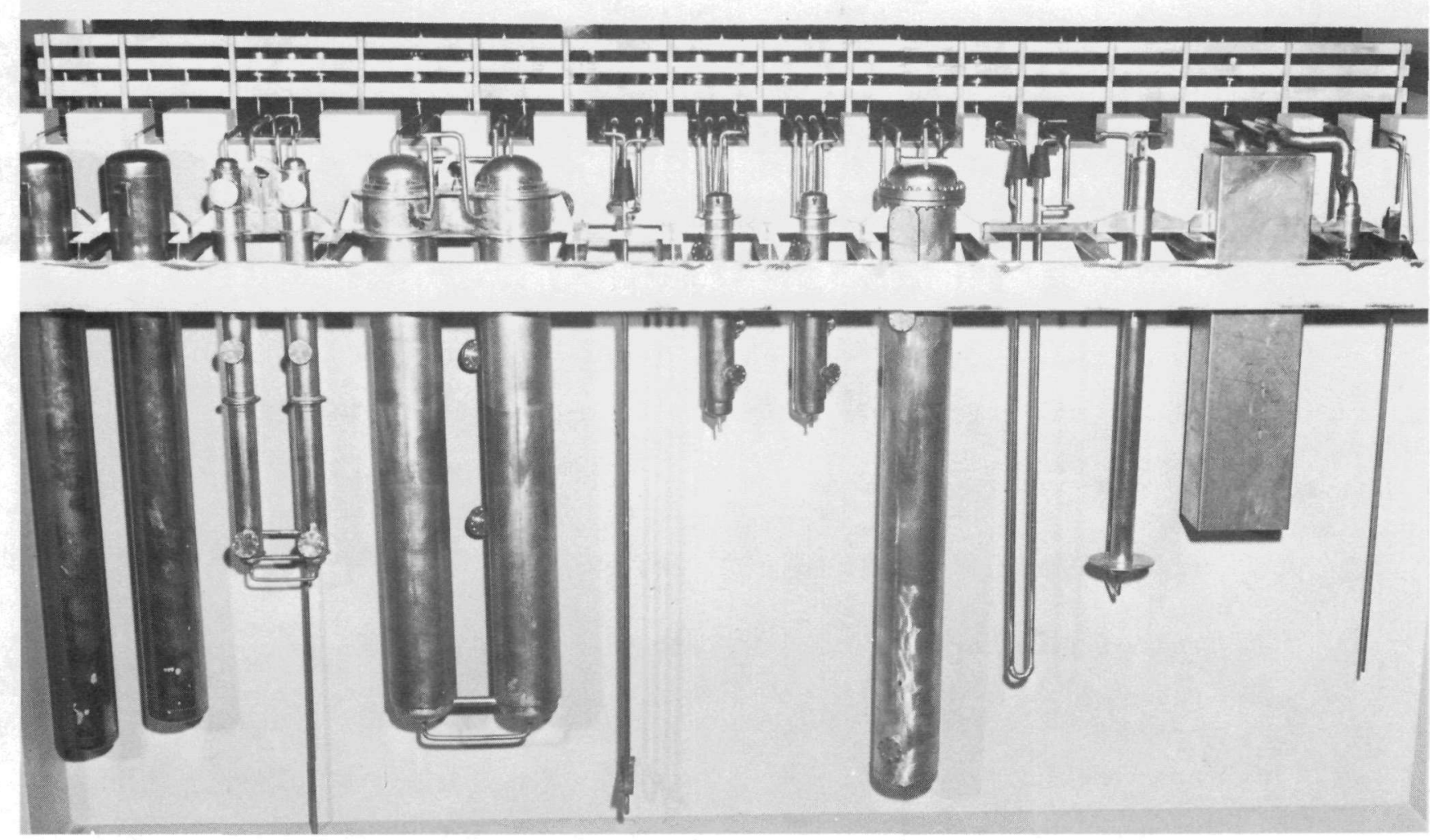

Fig. 42. UHTREX gas cleanup vessels.

all piping goes up over the shield wall separating Rooms 216 and 308 so the vessels can be lifted easily. These items were installed with the intent that they be easily removed. Once disconnected from the manifolds all vessels can be lifted vertically and placed on a truck by the crane and transported directly to the burial area.

Three large storage vessels are 1ocated in a Gas storage pit, Room 403, which is shown in Fig. 33. These vessels have not been surveyed, but are expected to be very low in contamination. They can be removed by the overhead crane. Table XIX lists the gas cleanup equipment to be removed and buried.

\section{Reactor and Primary Loop}

The reactor and primary loop are located in Room 310 as shown in Fig. 43
(Fig. 5.1.1.1 in SAR). The reactor vessel is a $1.22-\mathrm{m}$ (4-ft)-diam vessel and, including the recuperator, weighs 115 tons. coolant flowed from the reactor, through one pass of the recuperator, into the bayonet tube main heat exchanger, to the flowmeter, filter, blower, back to the recuperator and into the reactor. One side of the recuperator could be bypassed through a control valve. Fuel elements measuring $2.54-\mathrm{cm}$ o.d. by $14 \mathrm{~cm}$ (1-in. o.d. by 5.5 in.) long were loaded from the fuel system dry box (hot cell). The fuel conveyor moved one element at a time to the inlet primary gas lock valves (three in series), the fuel preloader moved the element into the fuel elevator, the fuel elevator positioned the element vertically, one of thirteen fuel loaders pushed the element into the reactor core displacing 
TABLE XIX

GAS CLEANUP EQUIPMENT

\author{
Component \\ Size \\ Filter \\ Preheater (contaminated piping) \\ 15.24-cm o.d. by $0.61-m$ long \\ $5.08-\mathrm{cm} 0 . \mathrm{d}$. by $3.05-\mathrm{m}$ long \\ CuO Bed \\ $20.32-\mathrm{cm} 0 . d$. by $3.96-\mathrm{m}$ long \\ Water Heat Exchanger \\ $5.08-\mathrm{cm} 0 . \mathrm{d}$. by $6.1-\mathrm{m}$ long \\ Decay Heat Exchanger \\ $71.12-\mathrm{cm} 0 . \mathrm{d}$. by $6.71-\mathrm{m}$ long \\ Molecular Sieve Beds (2 ea.) \\ $25.4-\mathrm{cm} 0 . \mathrm{d}$. by $3.05-\mathrm{m}$ long \\ Glycol Heat Exchanger \\ $6.35-\mathrm{cm}$ o.d. by $3.05-\mathrm{m}$ long \\ Delay Bed (2 ea.) \\ $60.96-\mathrm{cm} 0 . \mathrm{d}$. by $5.49-\mathrm{m}$ long \\ Sidestream Adsorption Bed (2 ea.) \\ $20.32-\mathrm{cm}$ o.d. by $3.96-\mathrm{m}$ long \\ Low Pressure Receiver \\ $60.96-\mathrm{cm} 0 . d$. by $6.1-\mathrm{m}$ long \\ High Pressure Receiver \\ $60.96-\mathrm{cm} 0 . d$. by $5.49-\mathrm{m}$ long \\ High Pressure Storage \\ 1.47-m i.d. by $5.49-\mathrm{m}$ long \\ Low Pressure Storage (2 ea.) \\ 1.83-m i.d. by $4.88-\mathrm{m}$ long \\ Manifolds \\ Valves \\ Corblin Compressors (may not be contaminated) \\ Gas Bearing Blower \\ Miscellaneous
}

an element in the core. The displaced element aropped out into the outlet gas lock valves, and was transferred back to the dry box in the hot cell.

All of the primary loop is contaminated. The reactor reads approximately $500 \mathrm{mr} / \mathrm{h}$ on contact and in Room 310 the general background is about $100 \mathrm{mr} / \mathrm{h}$.

The main problem will be to remove the reactor. Of the possible schemes for removal, the one which seems most likely to be successful involves contracting with a commercial rigging firm to lift the reactor, recuperator, and connecting $1144 \mathrm{~K}$ helium pipe as a unit. One firm has been contacted and has concluded that such a rigging job is feasible. LASL will be responsible for preparation of the facility and reactor for the riggers. Room 106 will be cleared of the primary loop blower which is to be disassembled and decontaminated, the control rod drives, bypass valve actuator, fuel elevator drive, and some other equipment which is not shown in Fig. 43. This includes the startup detector drive, some 


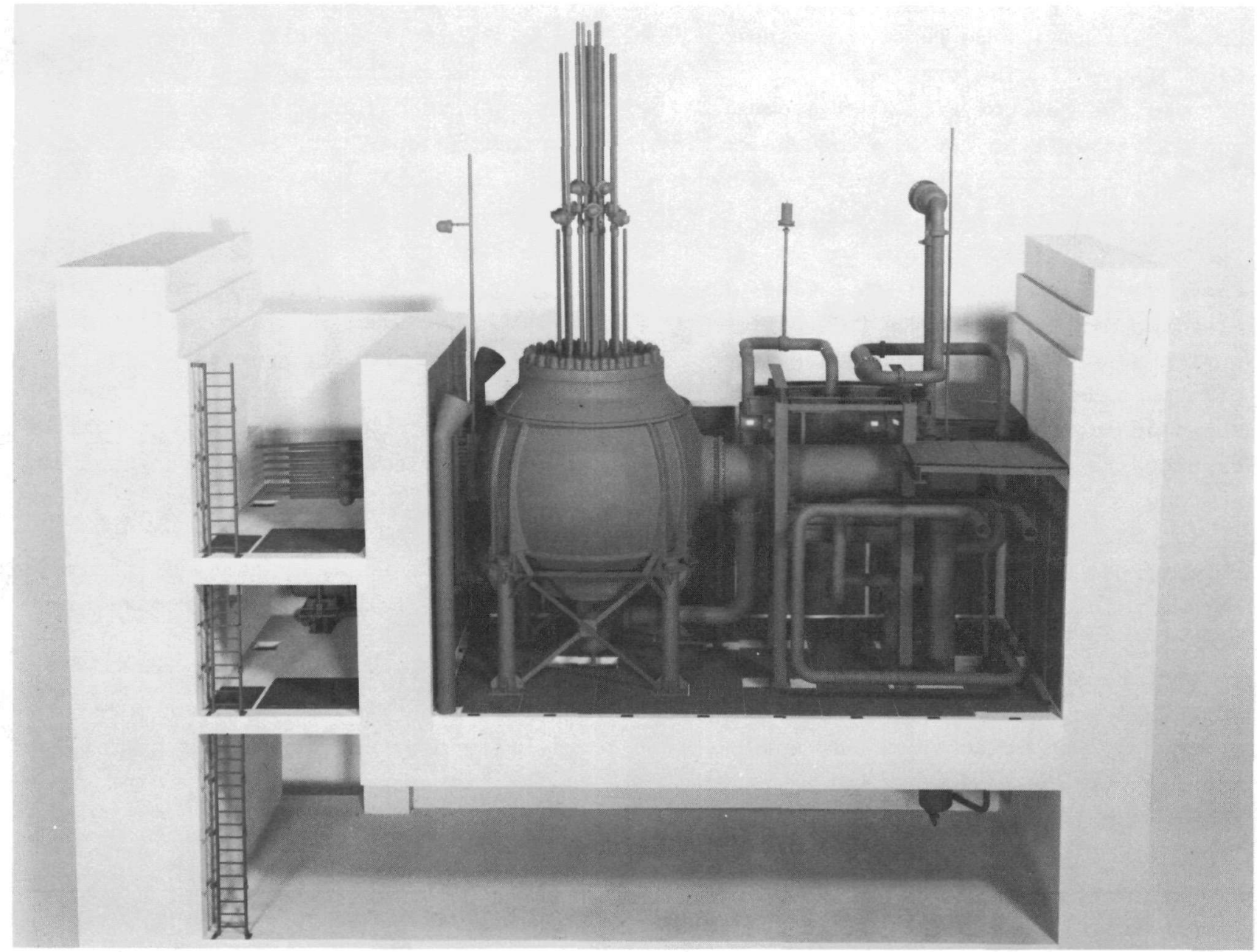

Fig. 43. Reactor and primary loop (photograph of model).

bypass helium piping, control and instrument cabling, and experimental equipment installed to sample the primary loop coolant.

With the overhead shielding for Room 310 removed to permit access, the rest of the loop and equipment is to be removed. The recuperator bypass line from blower to recuperator will be removed. This requires breaking two bolted, seal-welded flanges. The filter, which was replaced just prior to cancellation of the UHTREX project, and pipe to blower will be removed. The pipe from the filter to heat exchanger will be removed only if it will interfere with the removal of the reactor. If removal is necessary, the $20.32-\mathrm{cm}(8-i n$.$) stainless pipe will have$ to be cut, since it is welded to the heat exchanger nozzle.

The heat exchanger will be separated from the recuperator, requiring that a 55.9-cm (22-in.) i.d. bolted, seal-welded flange be separated. The heat exchanger will be lowered some to clear the recuperator.

Uncontaminated, secondary loop piping will be cut and removed to free the heat exchangers for subsequent removal and to reduce congestion in Room 310. Supporting 
beams, etc., will be removed at the option of the rigging crew.

On the reactor, the twelve control rod drives will be cut at the level of the top of the reactor vessel. A survey is planned of one drive and control rod to see if it is acceptable for use in the proposed experiment. Likewise, the elevator drive, preloader and thirteen fuel loader tubes, and fuel discharge pipe must be cut. Considerable care and planning will be required for the operations to protect the operating personnel and to prevent spread of contamination. It is essential that the reactor be free of external contamination before a commercial rigger starts his efforts.

A modest development program to develop techniques will be required before these cuts of contaminated piping are done. Suggestions include heating and pinching to seal the pipe as it is severed. Alternates are various cutters, saws, etc. All such operations must be done in a manner that prevents the spread of contamination from the inside of the pipe. The technique employed must also reduce exposure to radiation. Either the cut is done quickly, and the workmen are protected by temporary shielding, or they are able to work from some distance.

The core indexing drive, inlet and outlet gas lock valves, and conveyors will be removed. The reactor instrument pipe will be disconnected.

All this contaminated or activated equipment that has been removed will be transported to the burial site. Remaining equipment will be sealed, surveyed, and tagged in preparation for allowing the rigging crew to set up. Cables, conduits, etc., will be removed as far back as the wall panels to permit as much free room as possible for the main lift. Shielding over Rooms 216, 308, and 310 will be replaced at the convenience of the rigging crew.
The proposed contract for rigging includes installation of a gantry or whatever is needed for lifting, raising the reactor, recuperator, and connecting $1144 \mathrm{k}$ pipe, taking reactor out of the $4.9-m$ by $4.9-m$ door, transporting it to the burial site, TA-54, and off-loading it into the burial pit. A special pit will be dug, with good access for the large vessel and transporter. This job has been reviewed with one firm. The 115-ton lift and maneuvering through the door was reviewed. It is apparent that some enlargement of the doorway will be necessary. The wall will be cut and broken out to permit passage of the vessel. This will be permitted with restriction on method. Replacement will be a LASL responsibility.

With the reactor vessel removed, the temporary door structure will be replaced, the heat exchanger and any remaining contaminated equipment removed. Table XX is a summary list of items to be removed.

XI. DISCUSSION OF RADIOLOGICAL SAFETY Special characteristics of the Phoebus-2 reactor ard of expected operations lead to unusual radiological-safety conclusions, The controlling reactor features are a refractory core, nearambient pressure, and postburst temperatures as high as $1600 \mathrm{~K}$. The significant features of operation are infrequent (possibly weekly) short-duration runs that may approach $4000 \mathrm{MJ}$ each.

A. Fission-P roduct Inventory It may be noted that a $4000-\mathrm{MJ}$ operation each week averages the same as that of a $7-\mathrm{kW}$ reactor operating continuously. Thus in the UHTREX housing, designed for a 3-MW reactor, long-1ife fission products are of minor radiological-safety significance. Short-life fission products, however, are different. Although they present no problem in the control room and outside the exclusion area, they restrict 
TABLE XX

PRIMARY LOOP EQUIPMENT

Component

Reactor vessel (115 tons)

Recuperator ${ }^{a}$

Heat exchanger

Filter

Bypass pipe

Filter to blower pipe

Filter to heat exchanger pipe

Control rods (12 ea.)

Fuel loader tuber (13 ea.)

Preloader tube

Elevator drive

Instrument pipe

Index motor drive

Gas-lock valves

Fuel conveyor tubes

Water panels

Supports and structures

Platforms

Miscellaneous small items



$\underline{\text { Size }}$

4.27-m-diam sphere

107-cm o.d. by $4.88-\mathrm{m}$ long

$55.9-\mathrm{cm} 0 . d$. by $5.49-\mathrm{m}$ long

$45.7-\mathrm{cm} 0 . \mathrm{d}$. by $3.35-\mathrm{m}$ long

20.32-cm pipe by $9.75-\mathrm{m}$ long

$20.32-\mathrm{cm}$ pipe by $5.49-\mathrm{m}$ long

20.32-cm pipe by $9.15-m$ long activities with instrumentation and irradiated specimens during the first day after operation.

B. Radiation Fields Shortly After Operation Requirements for special shielding or for remote handling during recovery of instrument records or irradiated specimens are suggested by the following estimates.
In the absence of shielding, the gamma-ray field near the reactor may be approximated by scaling values measured outside the similar phoebus-2A reactor. The resulting dose rates at given times after a $4000-\mathrm{MJ}$ run are those of Table XXI. Depending upon assumptions concerning scattered radiation, values at $2 \mathrm{~m}$ from the surface would be one-quarter to one-third of those at $0.6 \mathrm{~m}$. 
TABLE XXI

DOSE RATES NEAR REACTOR FOLLOWING A 4000 MJ RUN

\begin{tabular}{|c|c|c|c|}
\hline \multirow[b]{2}{*}{ Elapsed Time } & \multicolumn{3}{|c|}{ Dose Rate $(\mathrm{r} / \mathrm{h})$} \\
\hline & $0.6 \mathrm{~m}$ & from Surface & In Contact \\
\hline $1 \mathrm{~h}$ & & 3700 & 7900 \\
\hline 1 day & & 83 & 180 \\
\hline 5 days & & 12 & 26 \\
\hline 30 days & & 1.4 & 2.9 \\
\hline
\end{tabular}

Capsules for irradiation are expected to contain FFTF-type fuel pins, each pin having $141 \mathrm{~g}^{235_{\mathrm{U}}}$ as $\mathrm{U}(93)$. The average energy deposition, $5000 \mathrm{~J} / \mathrm{g} \mathrm{UO} \mathrm{UO}_{2}$, translates to time-dependent values of curies and unshielded dose rates by using phoebus$2 \mathrm{~A}$ experimental information. Table XXII gives the resulting dose rates per test pin at $1 \mathrm{~m}$ for various times after irradiation.

C. Fission-Product Leakage From Core Experimental data on release of $\mathrm{fis-}$ sion products from heated graphiteuranium fuel appear to depend strongly upon the fuel-preparation technique. Thus they provide only a crude estimate of PHOEBUS/UHTREX release after a 4000-MJ run. Assuming, for our purpose, a core-cooling history equivalent to $1400 \mathrm{~K}$ for $3 \mathrm{~h}$, the most nearly appropriate data can be extrapolated. The result is $I$ and $X e$ release

TABLE XXII

DOSE RATE PER PIN AT ONE METER

\begin{tabular}{cc} 
Elapsed Time & Dose Rate Per Pin $(r / h)$ \\
\hline 1 h & 48 \\
1 day & 1.1 \\
5 days & 0.16 \\
30 days & 0.018
\end{tabular}

that decays to $80 \mathrm{Ci}$ one day after the operation. Most of this activity is expected to be from $I$, in which case it should drop to about one curie after five days.

D. Safety Instrumentation The safety circuit will be designed to produce a scram if the neutron power should exceed a preset value, if electric power should fail, and probably if some critical voltage in the automatic power conroller should go out of bounds, or if the core temperature should become too high. Because of short self-quenching pulses, a period scram would be ineffective, and a floating scram may be substituted. Proper functioning of the safety instrumentation will be confirmed before each reactor operation (within the same day), which will ease the requirement for long-term reliability. Furthermore, check-list items will confirm adequate response of start-up instrumentation before the power controller is turned on. Interlocks in the scram chain will prevent operation unless doors into the containment are secured, the cooling system is operating, and there is power to diagnostic instrumentation. Scramchain logic is illustrated by Fig. 44; core temperature, floating, and powercontroller scrams may be added.

The above requirements are bolstered by the following criteria that the safety circuit must satisfy.

- To provide redundance, a scram will result if only one of two or three flux monitors is tripped.

- To prevent sneak circuits in the scram chain, all actuating relays will be in series, and parallel circuits will be avoided.

- To give a scram on power loss, each relay in the safety system will be connected so that normally open contacts must be closed for operation. 


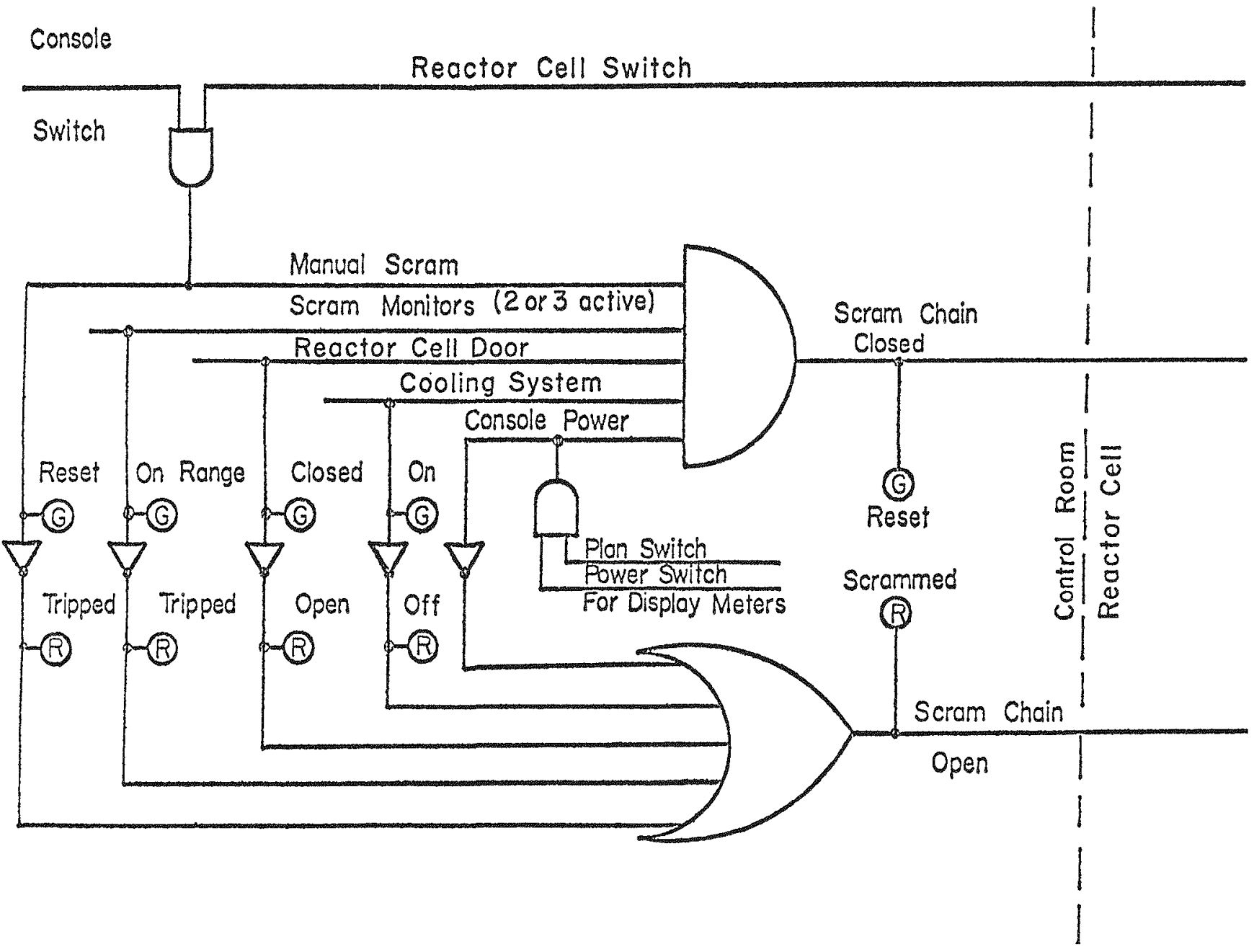

Fig. 44. Representative scram-chain logic.

- To prevent welding of relay contacts, lightning-induced surges will be bypassed to ground by special arresters.

E. Reactor Characteristics of Safety Significance

From Rover experience it is estimated that the refractory core of the reactor will withstand a temperature of $2800 \mathrm{~K}$ without damage. The margin of $1200 \mathrm{~K}$ above operating temperature is generous in that $500 \mathrm{~K}$ should be adequate for overshoot of reactivity and scram response. It may be noted that the more temperature-sensitive reflector will be gas cooled. There will be the capability of adjusting excess reactivity to limit the peak power of the excursion.
Phoebus-2 characteristics suggest that the 16 control drums will be worth about 6.5 . The greater part of this will be available for shutdown. The drums are independently sprung to seek the position of minimum reactivity when a scram signal is received or electric power is lost. If the reliability of this scram system should be judged inadequate, there can be a backup safety device that enters the instrumentation channel of the reactor.

It is apparent that the operating experience with the similar Phoebus reactors provides valuable safety guidance.

F. The Reference Accident

At this time, it appears that the worst accident which need be considered 
is a pulse of $6000 \mathrm{MJ}$ followed by release to the containment of all inert-gas fission products and halogens. This pulse energy corresponds to a core temperature of about $2100 \mathrm{~K}$, which we have judged to be a generous 1imit. We assume that test capsules will be inspected and pretested according to standards that guard against failure. This relieves concern about the $\mathrm{Na}$ that may be contained and about the occasional $\mathrm{PuO}_{2}$-loaded test pin. It is expected that the site gate, $300 \mathrm{~m}$ from the reactor, will be closed during operation; thus it represents the closest approach of uncontrolled persons. There, the direct gamma-ray dose after the reference accident may be estimated from data used for UHTREX dose evaluation and calculated ratios of pulsed to prolonged effects. The significant result is a dose of 5.1 rads at $300 \mathrm{~m}$ during the first two hours after the accident, assuming no source decay. For cloud doses after the reference accident, we must assume a containment leakage rate, and 1\%/day seems reasonable in view of values measured for UHTREX. In this case, doses calculated for a pulse from the kinglet reactor may be scaled directly to our reference accident. Again, no overall decay is assumed, which would be approximated by continuing release (from a hot core) of I growing in as a result of chain decay. The estimated exposures to a person remaining at the gate $(300 \mathrm{~m})$ for $2 \mathrm{~h}$ following the reference accident are 2.7 rads to the thyroid and 0.7 rads whole body.

G. Interaction with Design

Provided that the refractory features of the reactor core and the estimated control-safety worths are retained, safety requirements on design are expected to be satisfied by normal engineering practice. The most serious problem could be overheating of the control elements. Otherwise, there must be provision for adjustment of excess reactivity between runs, and for handling volatile fission products that are normally released from the core. Instrumentation must be designed so that records can be recovered without overexposing personnel. Fortunately, refueling will not be an essential requirement. Because of radiation fields, core changes would be awkward if required by a modification of operational plans.

\section{REFERENCES}

1. G. I. Bell, J. E. Boudreau, T. Mclaughlin, R. G. Palmer, V. Starkovich, W. E. Stein, M. G. Stevenson, and J. L. Yarnel1, "Study of Fast Reactor Safety Test Facilities," Los Alamos Scientific Laboratory report LA-5978-MS (May 1975).

2. Ed Cashwel1, Los Alamos Scientific Laboratory, unpublished report.

3. K. D. Lathrop, "DTFIV, A Fortran-IV Program for Solving the Multigroup Transport Equation with Anisotropic Scattering," Los Alamos Scientific Laboratory report LA-3373 (November 1965).

4. J. Sapir, "Twenty-Five Group Cross Sections Used in the Los Alamos Rover Program," Los Alamos Scientific Laboratory report LA-4484-MS (August 1970).

5. R. Avery, "LMFBR Safety Testing Needs and Acquisitions of New In Pile Testing Facilities," Argonne National Laboratory report ANL/RAS 74-23 Vol. III (March 1975).

6. R. G. Lawton, "The AYER Heat Conduction Computer Program," Los Alamos scientific Laboratory report LA-5613MS (May 1974).

7. Luther $L$. Lyon, "Performance of (U, Zr)C-Graphite (Composite) and of (U, $\mathrm{Zr}$ ) C (Carbide) Fuel Elements in the Nuclear Furnace 1 Test Reactor," Los Alamos Scientific Laboratory report LA-5398-MS (September 1973).

8. W. E. Stein, Los Alamos Scientific Laboratory, personal communications, November 1975.

9. D. Venable, D. O. Dickman, J. N. Hardwick, E. D. Bush, Jr., R. W. Taylor, T. J. Boyd, J. R. Ruhe, E. J. Schneider, B. T. Rogers, and H. G. Worstell, "PHERMEX: A Pulsed High-Energy Radiographic Machine Emitting X-Rays," Los Alamos Scientific Laboratory report LA-3241 (May 1967). 
10. W. J. Price, Nuclear Radiation Detection (McGraw Hill, New York, 1958) p. 161

11. A. De Volpi, R. R. Stewart, J. P. Regis, G. S. Stanford, and E. A. Rhodes, "Fast-Neutron Hodoscope at TREAT: Data Processing, Analysis and Results," Argonne National Laboratory report ANL/RAS 75-15 (June 1975).
12. A. De Volpi, "Fast-Neutron Hodoscope at TREAT: Development \& Operation," Argonne National Laboratory Report, to be published.

13. G. J. Berzins and K. S. Han, Lo's Alamos Scientific Laboratory, personal communication, November 1975.

APPENDIX A

ROVER BACKGROUND

The Los Alamos Scientific Laboratory was an active participant in the nuclear rocket propulsion (Rover) program from 1955 through 1972. LASL's principal program activity was research and development pertaining to the nuclear reactor which is the central part of a nuclear rocket engine. From 1961 to 1971, Aerojet General Corporation and Westinghouse Astronuclear Laboratory were the engine contractor and reactor subcontractor, respectively, for development of a nuclear rocket engine. In 1973, the nuclear rocket program was terminated because of the lack of a suitable mission for it in the planned national space program. During the Rover program, LASL designed, built and tested thirteen reactors, gradually developing reactor fuel elements toward higher temperature and longer life capability. These were the two most important reactor performance parameters; however, high core power density (related to high engine thrust/weight ratio) was also an important goal. In response to changes in potential missions and internal program objectives, reactors varying widely in size and power were tested. Design power, for example, varied from 50 to $5000 \mathrm{MW}$. Phoebus-2, the largest reactor, with a design power of $5000 \mathrm{MW}$, was tested during the summer of 1968;
Nuclear Furnace-1 was tested in 1971 at a maximum power of $50 \mathrm{MW}$.

The general design features of the Rover reactors included: (1) cylindrical cores of various diameters approximately $1.3 \mathrm{~m}$ long, (2) radial beryllium reflectors from $0.1 \mathrm{~m}$ to $0.2 \mathrm{~m}$ thick, (3) cooling by high-pressure hydrogen generally entering the reactor at near-cryogenic temperatures and leaving the reactor core at temperatures near $2500 \mathrm{~K}$, (4) slender hexagonal fuel elements $1.9 \mathrm{~cm}$ across flats and $1.3 \mathrm{~m}$ long containing 19 axial coolant passages $0.25 \mathrm{~cm}$ in diameter, (5) graphitebased fuel elements containing either pyrocarbon-coated $\mathrm{UC}_{2}$ beads or UC-ZrC solid solution, (6) $\mathrm{NbC}$ or (later) ZrC coating of all fuel element surfaces to help protect against corrosion by the hot hydrogen coolant (7) rotating control rods or drums in the reflector covered on $120^{\circ}$ of their surface with boron-containing poison plates.

During the Rover program, substantial and sophisticated techniques were built up in many areas including fuel fabrication, property determinations, and testing. In addition, components from the several different reactor designs were accumulated; some were parts from reactors built, but not tested, others were spares from 
reactors that were tested, and others were parts usable after nuclear testing when their induced radioactivity had decayed sufficiently to permit the necessary personnel access.

The earliest Rover reactor cores were made by extruding a graphite mix containing the proper amount of enriched $\mathrm{UO}_{2}$. The $\mathrm{UO}_{2}$ was converted to $\mathrm{UC}_{2}$ during the high-temperature graphitization operation. Although the fuel elements were coated with $\mathrm{NbC}$, problems related to the hydrolysis of $\mathrm{UC}_{2}$ during storage led to its replacement by $\sim 150 \mathrm{\mu m}$ pyrocarboncoated $\mathrm{UC}_{2}$ spheres "beads". By $1969 \mathrm{six}$ reactor cores had been fabricated with the bead-loaded fuel elements.

The graphite matrix was still subject to considerable carbon loss due to leaching by the hydrogen propellant through cracks in the $\mathrm{NbC}$ during reactor operation. The reactor support system was also subject to these carbon losses and a program of improvement of the support system was pursued. It was found that when a hot pressed 46 vol\% ( $\mathrm{NbC}+$ TaC)-graphite part was coated with NbC or TaC, an extremely strong bond was formed between the matrix of the coating, which was adherent even after prolonged testing at high temperatures. High temperature hydrogen leaching tests on the uncoated part showed that the integrity of the machined part was not lost even after all of the free carbon had been removed.

A program was started about 1966 to develop a procedure to fabricate (U, $\mathrm{Zr}$ ) C-graphite fuel elements which would incorporate the advantages of the support system carbide-graphite composite into the fuel elements. Extrusions of 30 and 35 vol: $(U, Z x) C$ in graphite were found to consist of a connected network of carbide in a connected network of graphite Either network was self-supporting when the other was removed.

Reactor cores were fabricated for Pewee II, NF-I and NF-2 of 30 and 35 vol\% carbides. The Rover program was cancelled before Pewee II or NF-2 could be tested, however, NF-1 was tested and postmortem examinations performed.

All of the fabricating equipmentextrusion press, ovens, and high temperature heat treating furnaces - are in operation in the reactor fuel fabrication facility of the Materials Technology Group at IASL. Most of the tooling, extrusion fixtures, and heat treating fixtures are still available. of great importance is that the expertise gained in the Rover program by two staff members and three technicians is available. Their experience ranges from 6 to 17 years of Rover fuel element development. These people have continued to improve their capabilities over the past three years by developing coated particle fuels for the HTGR and extruding fuel for Argonne for the TREAT converter program. Over the past year and a half, carbide-graphite composites have been produced and supplied to Sandia as a candidate for the ACPR upgrading.

Briefly the capabilities are available and operating to produce, evaluate and qualify (QA) Rover-type carbide-graphite composite fuel elements for reactor use. 
The Ultra High Temperature Reactor Experiment (UHTREX) was conducted by the Los Alamos Scientific Laboratory (LASI) to advance the state of technology applicable to gas-cooled reactors. The experiment was designed to demonstrate the high-temperature capability of a graphite-moderated, helium-cooled reactor using coated particle, graphite matrix fuel elements.

The UHTREX reactor was designed to operate at $3 \mathrm{MW}$ thermal power, $3.45 \times 10^{6}$ Pa coolant pressure, and to produce a $1590 \mathrm{~K}$ outlet.

Construction of the reactor facility at LASI was started in July 1962 and was completed in February 1964. The reactor pressure vessel was delivered and installed in August 1965 and the reactor core installed in June 1966. Low power criticality runs were conducted in late 1967 and design power operation began in June 1969. Full power and temperature was approached in a series of runs to investigate operations, effectiveness of internal insulation, outgassing of the internals, and fuel behavior. The design temperature and power were achieved in June 1969.

The UHTREX project was terminated in February 1970. The total integrated operation of the reactor was equivalent to $135 \mathrm{MW}$-days.

The UHTREX remains the highest temperature, closed cycle, reactor system successfully operated. Significant advances were made in design and in demonstration of the capability of such reactor systems. A large portion of the physicists, engineers, and metallurgists involved with UHTREX remain in the employ of LASI. They are available for consultation, if not active participation, in the design and operation of the experimental systems being proposed.

The reactor was put in stand-by status when the project was terminated. All fuel was removed and the facility and equipment were thoroughly cleaned to insure that there was no exterior contamination. Recently the equipment was declared excess and some items have been removed. However, the facility, including mechanical, electrical, and ventilation equipment is mostly intact.

The UHTREX reactor had a vertical cylindrical core, surrounded by carbon and graphite reflector and insulation contained in a 4.27-m diam carbon steel vessel. The core is a hollow vertical graphite cylinder approximately $1.83-\mathrm{m}$ o.d., 0.61-m i.d., and $0.91 \mathrm{~m}$ high. Fuel channels are $2.79-\mathrm{cm}$ diam radial holes bored through the cylinder wall at $15^{\circ}$ intervals in 13 horizontal planes. The vertical separation of adjacent fuel channels is $7.62 \mathrm{~cm}$ center-to-center. Surrounding the core are graphite and dense carbon reflectors, low density carbon insulation, and the pressure vessel.

The fuel elements were hollow graphite cylinders, 2.54-m o.d., 1.27-m i.d., and $13.97 \mathrm{~cm}$ long. The elements were made by extrusion and curing of a graphitebased matrix loaded with fully enriched, coated particle fuel. Four elements rested end-to-end in each fuel channel.

Fuel loading/unloading was accomplished at power under the control of an on-line computer system. The loading sequence started with placement of an element in a "boat" at the fuel transfer cel1. The element was conveyed, and positioned at the first of a series of three gas-lock valves, sequenced through the valves, positioned vertically at one of 
the 13 fuel channel levels, and then pushed into a core channel. A new element being pushed into the core would displace the inner element of the four which dropped down the central plug of the core and was conveyed back to the fuel transfer cell through gas-lock valves and a conveyor. The core could be indexed (rotated) to any of 24 positions to select the radial channel to be loaded.

There were 12 boron poison control rods - 8 in the central plug and 4 in the core. The central plug control rods had the boron carbide poison supported by a niobium rod and encased in niobium sheath. The core rods were made of articulated stainless steel sections and were designed for use at low temperature to provide shutdown margin.

The helium coolant entered the bottom of the reactor at $1144 \mathrm{~K}$ and flowed up the center of the core, radially outward through the core fuel channels that contained the fuel elements, was collected in an outer annulus, and flowed from the reactor at $1590 \mathrm{~K}$. From the reactor, the coolant flowed in sequence through the hot pass of the all-graphite recuperator (1033 k exit), the primary side of a bayonet tube stainless steel heat exchanger, flowmeter, filter, circulator, through the cold pass of the recuperator, and back to the reactor. For temperature control, a control valve permitted a portion of the coolant to bypass the recuperator.
A secondary loop of helium, at the same flow rate and pressure as the primary loop, and including an identical circulator to the primary circulator, was used to remove heat from the primary loop. The secondary 100 p was cooled by an aircooled heat exchanger outside the facility.

A significant portion of the facility space and controls was devoted to the helium purification and handling system. Approximately $100 \mathrm{lb} / \mathrm{h}$ of the primary loop helium was bypassed through the cleanup system to remove chemical impurities and radioactive contaminants. The chemical impurities were primarily water, hydrocarbons, carbon dioxide, and reaction products of these with carbon. Radioactive impurities of principal interest were iodine, xenon, and krypton. Less volatile contaminants such as strontium and cesium were expected to (and obviously did) plate out on cold surfaces.

Chemical cleanup was achieved by oxidation of carbon monoxide, hydrocarbons, and hydrogen by $\mathrm{CuO}_{2}$ to produce $\mathrm{CO}_{2}$ and $\mathrm{H}_{2} \mathrm{O}$ which were removed by molecular sieves. The radioactive species were adsorbed on activated charcoal. The cleanup equipment is also discussed in sec. IX as part of the discussion of decontamination since this equipment will be removed.

Al1 parts of the gas cleanup were designed for either remote maintenance or for easy removal and replacement. 